\title{
Test Program to Demonstrate the Stability of Hydrazine in Propellant Tanks
}

\section{Final Report}

Clifford M. Moran

Roy A. Bjorklund

April 1983

Prepared for

United Kingdom Treasury and

Supply Delegation

Washıngton, D C

through an agreement with

National Aeronautics and Space Administration

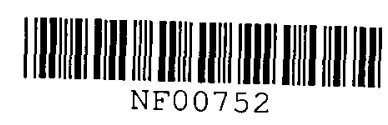

by

Jet Propulsion Laboratory

California Institute of Technology

Pasadena, Calıfornıa

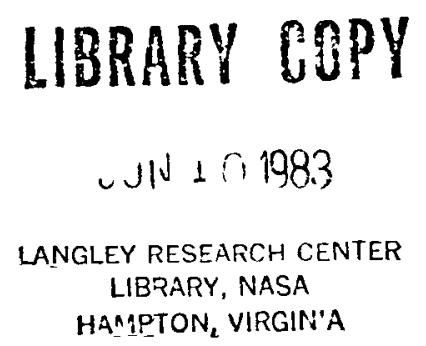




\section{Test Program to Demonstrate the Stability of Hydrazine in Propellant Tanks}

\section{Final Report}

Clifford M. Moran

Roy A. Bjorklund

April 1983

Prepared for

United Kingdom Treasury and

Supply Delegation

Washington, D.C.

through an agreement with

National Aeronautics and Space Administration

by

Jet Propulsion Laboratory

California Institute of Technology

Pasadena, California 
The research described in this publication was carried out by the Jet Propulsion Laboratory, California Institute of Technology, and was sponsored by the United Kingdom Treasury and Supply Delegation through an agreement with NASA.

Reference to any specific commercial product, process, or service by trade name or manufacturer does not necessarily constitute an endorsement by the United States Government or the Jet Propulsion Laboratory, California Institute of Technology. 
Acknowledgements

Abstract

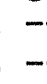

-

Acronyms

$\mathrm{V}$

vi

vii

I. INTRODUCTION

A. COUPON TEST PROGRAM

$1-1$

B. BACKGROUND-RELATED TECHNICAL WORK

C. OBJECTIVES OF THE COUPON TEST PROGRAM -

D. MATERIAL COUPON SOURCE

II. TEST PROCEDURES

A. TEST UNIT PREPARATION - $2-1$

B. STORAGE TESTING - 2-4

C. POSTTEST ANALYSIS - 2-4

1. Discussion - 2-4

2. Procedure - Complete Analysis - 2-6

3. Procedure - Limited Analysis - 2-6

4. Gases of Decomposition - 2-6

5. Residual Hydrazine -_- 2-10

III. TEST RESULTS -

A. DESCRIPTION OF TEST SPECIMENS - $3-1$

B. DETAILS AND SUMMARIES OF POSTTEST ANALYSES AND RESULTS ---- 3-3

C. PROPELLANT CONTROLS - 3-4

D. SURFACE ANALYSIS - 3-4

1. Introduction - 3-4

2. XPS Techniques - 3-4

3. Resu1ts - 3-6

4. Discussion - 3-8

5. Scanning Electron Microscopy (SEM) Examination --_-- 3-8

6. Conclusions - 3-8

IV. CONCLUSIONS - 4-1

A. PROGRAM A: 6 MONTHS STORAGE

B. PROGRAM B: 24 MONTHS STORAGE - 4-2

$\mathrm{V} \cdot$ DATA TABLES -

VI. REFERENCES -

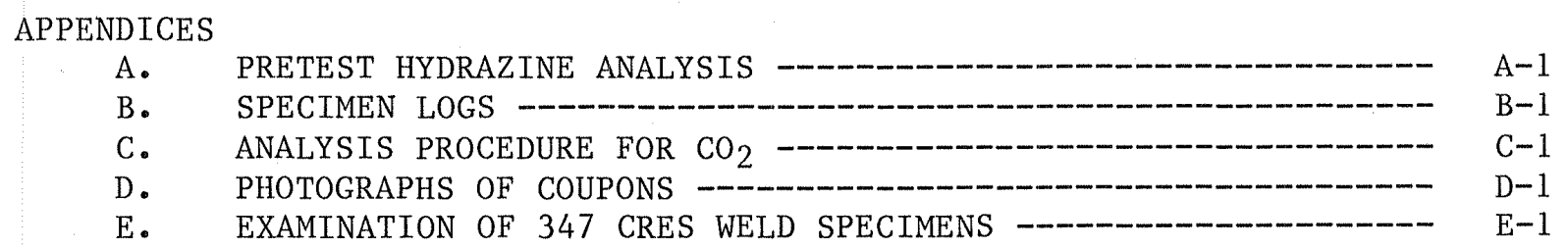




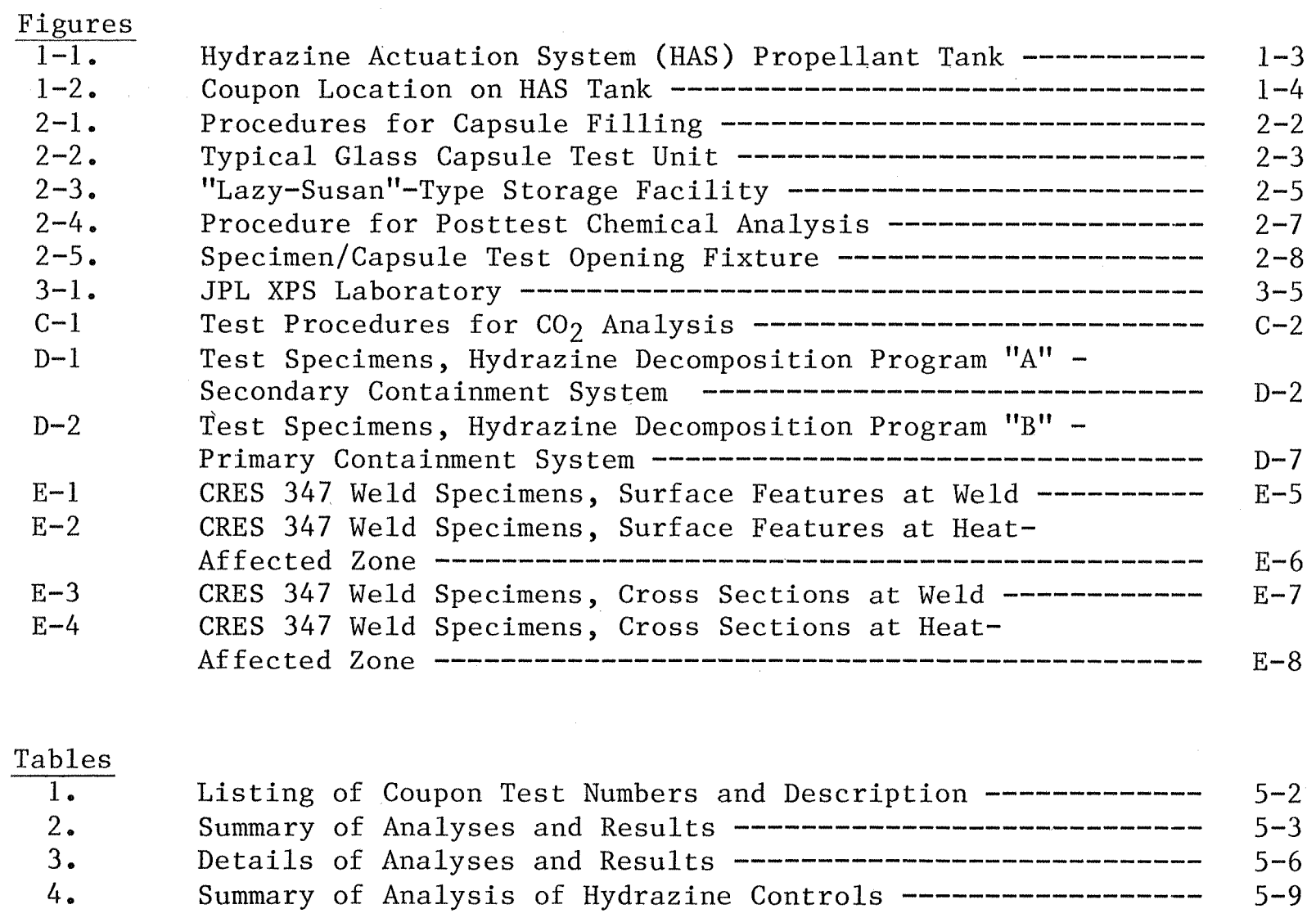


The authors acknowledge the support and contributions of the following JPL personne1:

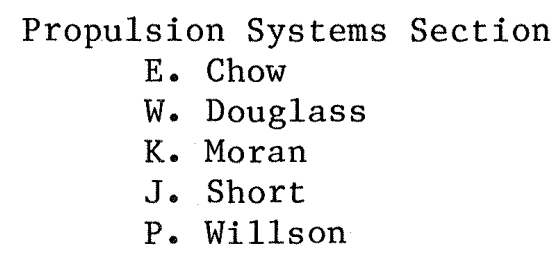

Analytical Laboratory

G. Blue

R. Haack

L. Taylor

XPS Laboratory

F. Grunthaner

P. Grunthaner

P. Zajicek

Instrumentation Section

H. Conway

D. Griffin

K. MacDavid

Materials Laboratory

M. Bickler

Glass Shop

J. Linke

SEM Laboratory

J. Collier

Documentation Section

M. F. Buehler

P. Lem

I. Struthers

Particular recognition is given to Louis $\mathrm{R}$. Toth who initiated this program and was responsible for establishing the test procedures. 
This document reports the analyses and results of a 24-month coupon test program to evaluate the decomposition of hydrazine by metallic components of propellant tanks. The propellant fuel evaluated was monopropellant-grade hydrazine $\left(\mathrm{N}_{2} \mathrm{H}_{4}\right)$, which is normally a colorless, fuming, corrosive, strongly reducing liquid. The degree of hydrazine decomposition was determined by means of chemical analyses of the liquid and evolved gases at the end of the test program. The experimental rates of hydrazine decomposition were determined to be within acceptable limits.

The propellant tank materials and material combinations were not degraded by a 2-year exposure to hydrazine propellant. This was verified using changeof-weight determinations and microscopic examination of the specimen surfaces before and after exposure, and by posttest chemical analyses of hydrazine liquid for residual metal content. 


\section{ACRONYMS}

$\begin{array}{ll}\text { ACS } & \text { attitude control system } \\ \text { ARDE } & \text { ARDE, Inc., Mahawah, NJ } \\ \text { BAT } & \text { Bel1 Aerospace Division of Textron, Inc., Buffalo, NY } \\ \text { BE } & \text { binding energy } \\ \text { Caltech } & \text { California Institute of Technology } \\ \text { CRES } & \text { corrosion-resistant stee1 } \\ \text { CPR } & \text { coupon preparation requirement } \\ \text { EB } & \text { electron beam } \\ \text { EPR } & \text { ethylene propylene rubber } \\ \text { ETS } & \text { Edwards Test Station, JPL } \\ \text { FEP } & \text { fluorinated ethylene propylene (Teflon) } \\ \text { HAS } & \text { hydrazine actuation system } \\ \text { HAZ } & \text { heat-affected zone } \\ \text { JPL } & \text { Jet Propulsion Laboratory } \\ \text { NASA } & \text { National Aeronautics and Space Administration } \\ \text { OAST } & \text { NASA Office of Aeronautics and Space Technology } \\ \text { OSS } & \text { NASA office of Space Sciences } \\ \text { PES } & \text { photoelectron spectra } \\ \text { SEM } & \text { scanning electron microscope } \\ \text { STP } & \text { standard temperature and pressure } \\ \text { TBD } & \text { to be defined/determined/done } \\ \text { TIG } & \text { tungsten inert gas } \\ \text { UKTSD } & \text { United Kingdom Treasury and Supply Delegation, Washington, D.C. } \\ \text { XPS } & \text { X-ray photoelectron spectroscopy } \\ & \end{array}$




\section{SECTION I}

\section{INTRODUCTION}

\section{A. COUPON TEST PROGRAM}

The Coupon Test Program has been an investigation of the reactive compatibility of hydrazine with various metallic components of a propellant storage tank. The hydrazine/material compatibility research reported here was performed by the Jet Propulsion Laboratory (JPL), California Institute of Technology (Caltech), under Contract NAS7-198 with the National Aeronautics and Space Administration (NASA) for the United Kingdom Treasury and Supply Delegation (UKTSD) in accordance with the UKTSD Letter Agreement F-2479, dated July 5, 1979.

This coupon test program is an extension of the ongoing JPL/NASA 1ong-term propellant/material compatibility program. The same procedures, test methods, and test facilities developed under the JPL/NASA program have been applied to this program.

This document is the final report for the Coupon Test Program. An interim report from Program A was prepared in October 1981 (Reference 1).

\section{B. BACKGROUND-RELATED TECHNICAL WORK}

JPL has collaborated with other agencies on a variety of research, development, test, and evaluation projects. The laboratory, with its Pasadena facility and Edwards Test Station (ETS) at Edwards Air Force Base, California, maintains an institutional capability and technical expertise in evaluating and testing Earth- and space-storable liquid propellants and materials for spacecraft propulsion system applications. Specifically, JPL has been investigating material compatibility involving Earth-storable propellants, including hydrazine, since 1962 under sponsorship of the NASA Offices of Aeronautics and Space Technology (OAST) and of Space Sciences (OSS). The details of the JPL material compatibility program and interim experimental results of the longterm storage testing are reported in References 2 and 3. The long-term exposure testing continues, and the accumulated time for some test specimens exceeds 12 years.

The results obtained have provided reliable data for designing and qualifying chemical propulsion systems and components for long-life spacecraft. The work performed has directly supported the early JPL planetary flight projects such as Ranger, Surveyor, and Mariner, and the Viking 1975 and Voyager 1977 (Jupiter-Saturn-Uranus).

The general technology areas involved are propellant chemistry, metallurgy, long-term (10-year) propellant/material compatibility, metal fracture/ toughness characteristics, and fracture mechanics design of pressurized systems. Typical Earth-storable propellants are hydrazine, refined-grade hydrazine (monopropellant grade), hydrazine-hydrazine nitrate, monomethylhydrazine, and nitrogen tetroxide. Spacecraft propulsion system materials include aluminum alloys, corrosion-resistant steels (CRES), titanium alloys, and elastometric materials, for example, AF-E-332. 


\section{OBJECTIVES OF THE COUPON TEST PROGRAM}

The overall objective of the coupon test program was to verify the longterm compatibility of hydrazine actuation system (HAS) propellant tank materials and other material combinations with monopropellant-grade hydrazine. To accomplish this overal1 objective, the program was divided into two parts.

Program A was intended to evaluate short-term compatibility of the secondary propellant containment system shown in Figure 1-1. It should be noted that the secondary containment system will be exposed to hydrazine only if there is leakage from the primary containment system. The program objectives were:

(1) Determine rates of hydrazine decomposition at $43^{\circ} \mathrm{C}$ by means of pressure rise monitoring throughout the term of the test program.

(2) Verify that pressure containment materials and material combinations are not degraded by 6-month exposure to hydrazine propellant, using weight determinations and microscopic examination of specimen surfaces, after exposure.

Program B was intended to evaluate long-term compatibility of the primary propellant containment system shown in Figure 1-1. The program objectives were:

(1) Determine rates of hydrazine decomposition at $43^{\circ} \mathrm{C}$ and $60^{\circ} \mathrm{C}$ by monitoring pressure rise throughout the term of the test program.

(2) Determine degree of hydrazine decomposition by means of chemical analysis of liquid and evolved gases at the end of the test program.

(3) Verify that primary containment materials and material combinations were not degraded by 2-year exposure to hydrazine propellant, using weight determinations and microscopic examination of specimen surfaces, after exposure, and also by posttest chemical analysis of hydrazine liquid for metal content.

\section{MATERIAL COUPON SOURCE}

The material coupons used in this program were provided by the UKTSD. They were obtained from sections cut out of a HAS tank fabricated by Bell Aerospace Division of Textron (BAT). A total of 82 coupons from 26 different locations are listed in Table 1.1 The locations on the tank from which the coupons were cut are shown in Figure 1-2. Each coupon was processed, weighed, cleaned, and individually sealed in a plastic bag by BAT before delivery to JPL. The coupons remained sealed until they were removed and placed immediately into glass capsule test units prepared at JPL.

\footnotetext{
${ }^{1} \mathrm{~A} 11$ tables are contained in section $\mathrm{V}$.
} 


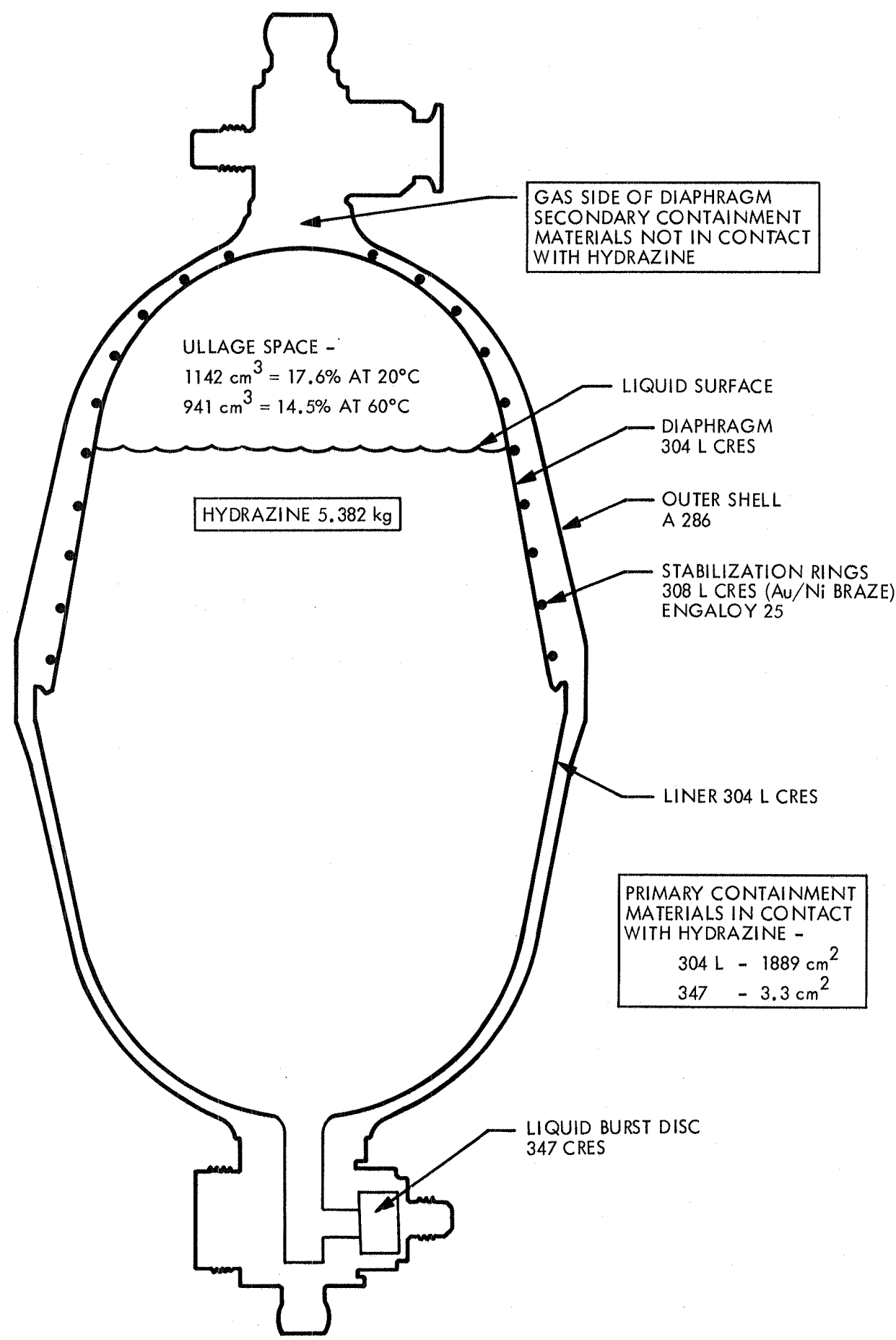

Figure 1-1. Hydrazine Actuation System (HAS) Propellant Tank Configuration 


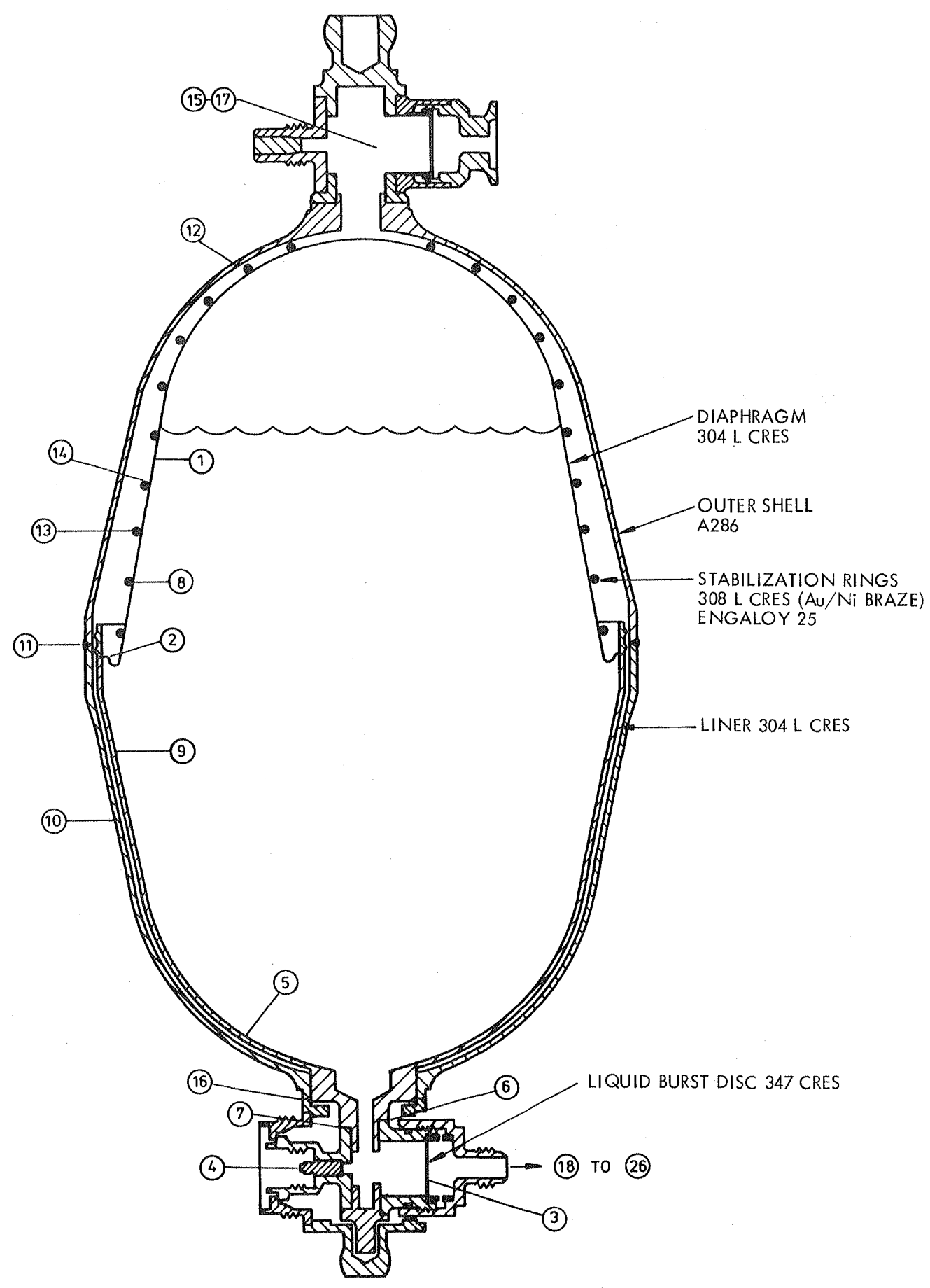

Figure 1-2. Coupon Location on HAS Tank 


\section{SECTION II}

TEST PROCEDURES

\section{A. TEST UNIT PREPARATION}

Eighty-two hermetically sealed, glass-encapsulated test units were prepared by JPL with the materials specified and in accordance with the priorities established by the sponsor. All units were prepared in accordance with the procedures shown in Figure 2-1.

The test requirements for this program were specified in JPL Proposal 90-965, Revision 2, October 11, 1978 and are summarized below.

(1) Purified hydrazine (VL-75 grade) was supplied by JPL. Pretest analysis of this propellant is shown in Appendix A. This propellant met the BAT material specification (Reference 4 ).

(2) Al1 test coupons were supplied by UKTSD, together with appropriate documentation prepared by BAT. For Program A, 38 coupons were designated; for Program B, 44 coupons were designated. The distribution of coupons by test storage temperatures was also designated.

(3) The test containers were Pyrex capsules, as described in Reference 2, and designed to have an internal volume, when sealed, of about $80 \mathrm{~cm}^{3}$. Figure 2-2 is a photograph of a typical test unit.

Test equipment, instrumentation, and techniques duplicated those employed in the JPL 10-year test program and reported in Reference 2. The pretest procedures are summarized below.

(1) Strain gauges used to measure internal pressure buildup were mounted on the open capsules. A preliminary pressure calibration was used to check the sensitivities of the strain gauges.

(2) Test specimens were installed into the clean capsules in "as received" condition from BAT except for the EPR-515 0-rings which were coated with Krytox lubricant by JPL.

(3) Funnel necks were fused onto the capsules, with care taken not to overheat the strain gauges. Final pressure calibration of the gauges was then made.

(4) Internal volumes of the test capsules were measured by the expanding volume technique using high-purity gaseous nitrogen at ambient temperature.

(5) Capsules were then loaded with enough hydrazine so that the combined volume of propellant and specimen was $40+0.5 \mathrm{~cm}^{3}$, and the specimen was fully immersed. Three of the specimens were found to be oversized and additional quantities of hydrazine were added. 

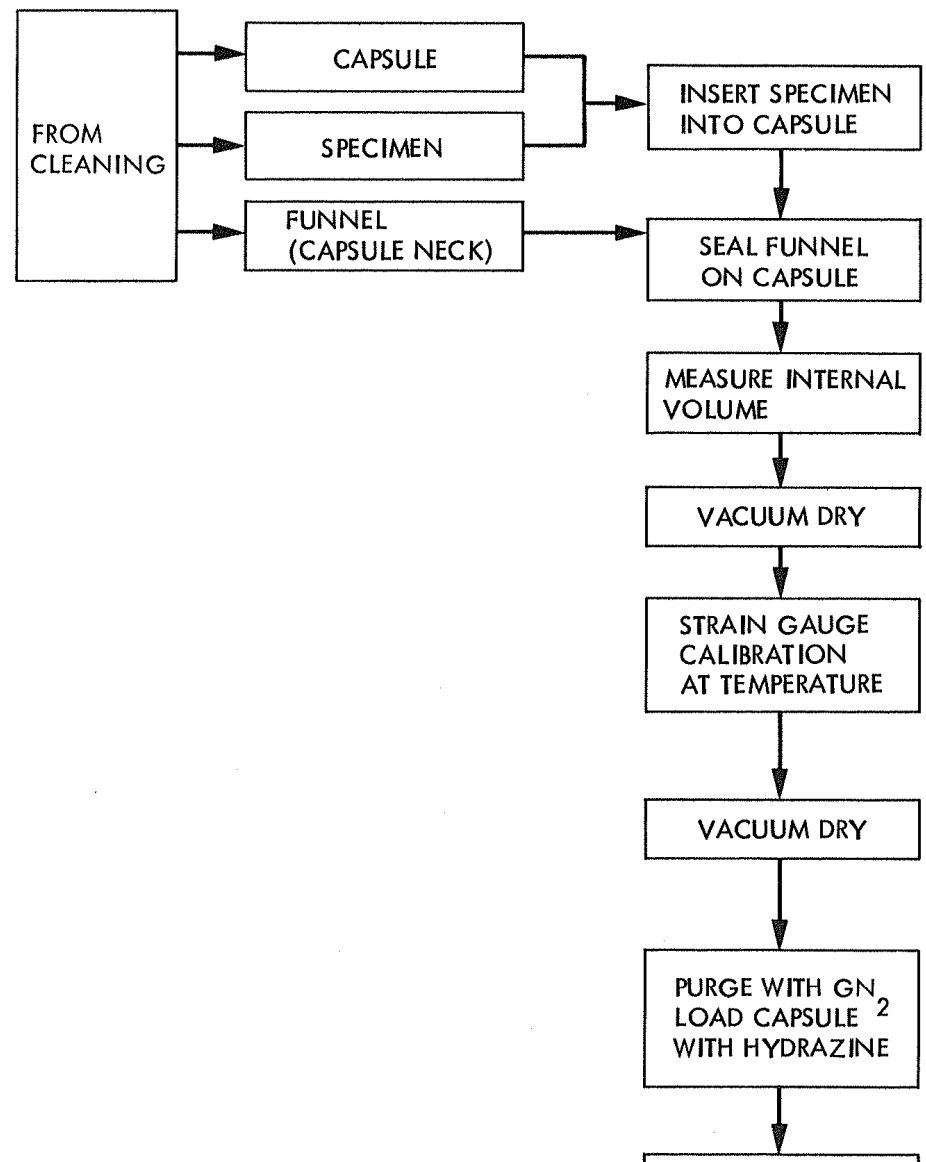

ATTACH RUBBER TUBE AND PINCH CLAMP TO FUNNEL.

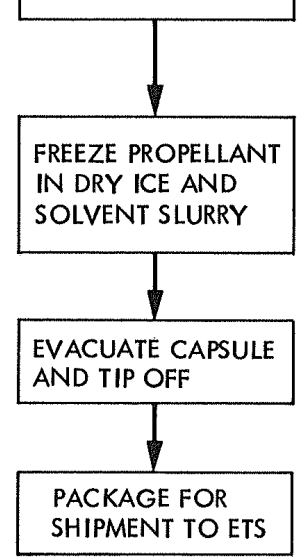

Figure 2-1. Procedures for Capsule Filling 


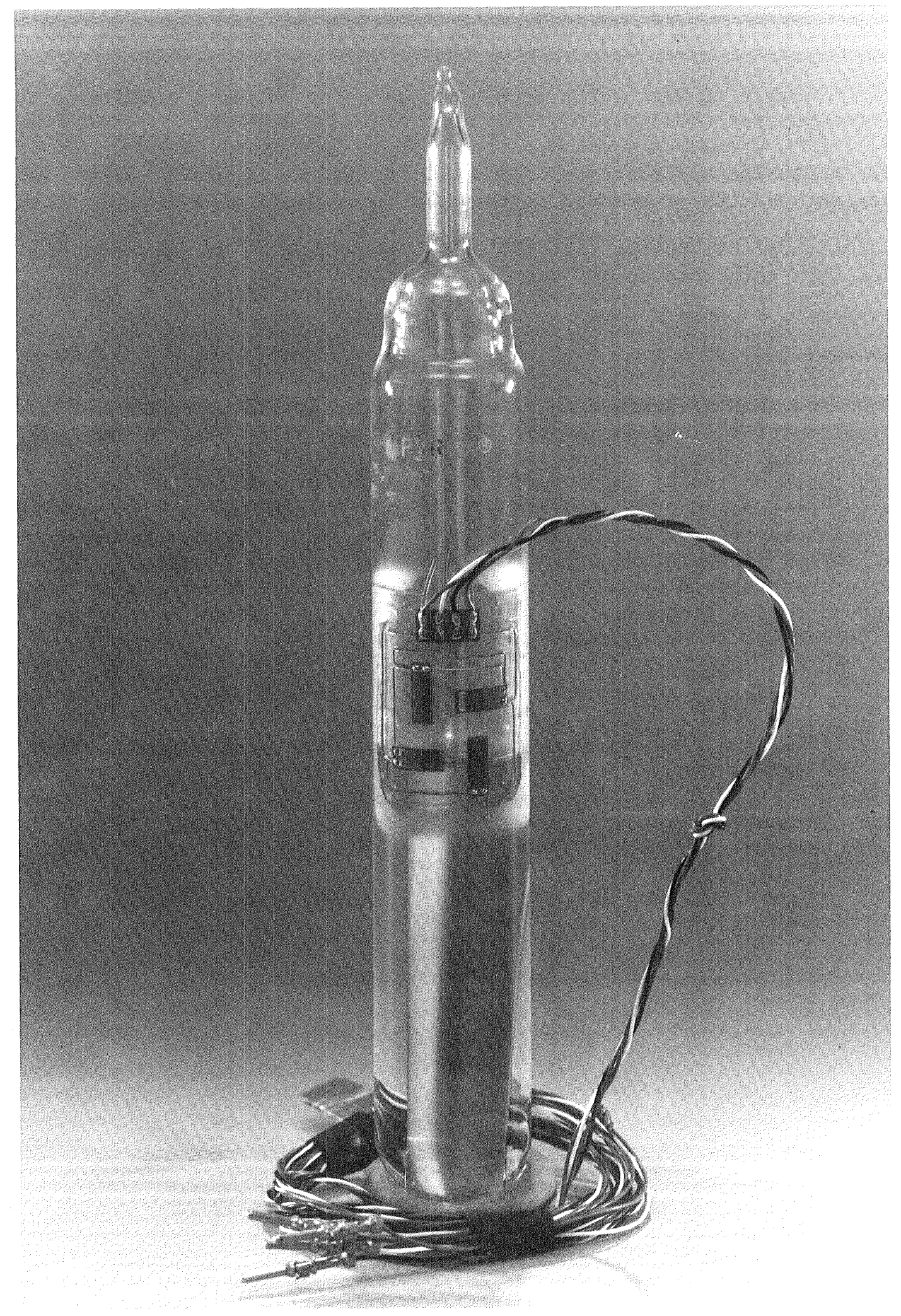

Figure 2-2. Typica1 Glass Capsule Test Unit 
(6) The hydrazine was frozen in a dry-ice/alcohol slurry and the capsules were pumped down to a pressure of less than $1 \mathrm{~mm} \mathrm{Hg}$.

(7) The capsule necks were sealed off by fusing the glass tube, and the completed test units were made ready for shipment to Edwards Test Station (ETS).

The hydrazine was pretest-analyzed for purity in accordance with the JPL standard methods (Reference 2). A special $\mathrm{CO}_{2}$ analysis of hydrazine in one test unit, representative of a typical encapsulation, was performed to verify the exclusion of air during filling. (See Appendix A). No examination or analyses were performed on the coupons.

\section{B. STORAGE TESTING}

The experimental storage phase was conducted at ETS to determine the compatibility of the hydrazine propellant with the materials. A photograph of the "Lazy-Susan" type of storage facility is shown in Figure 2-3. The exposure tests on the 82 units were conducted for a period of up to 24 months (730 days) at temperatures of either $43 \pm 3^{\circ} \mathrm{C}\left(110 \pm 5^{\circ} \mathrm{F}\right)$ or $60 \pm 1{ }^{\circ} \mathrm{C}\left(140 \pm 2 \mathrm{OF}^{\circ}\right.$. The temperature of $43^{\circ} \mathrm{C}$ was used in the JPL long-term program (Reference 2 ) as the "normal" temperature of a noncryogenic propellant in space. The higher temperature was chosen as being the highest temperature likely to be experienced by the propellant in service. During the 24 -month exposure term, the following was accomplished:

(1) Pressure readings were taken once per week for the first month.

(2) Pressure readings were taken once per month for the next five months.

(3) Pressure readings were taken bimonthly for the remaining eighteen months.

(4) Test units were visually inspected after taking the pressure readings.

(5) All results were recorded for the above observations.

Details of all test units are presented in specimen logs in Appendix B.

\section{POSTTEST ANALYSIS}

\section{Discussion}

At the completion of the storage tests, all test units were analyzed in accordance with the JPL standard methods (from Reference 2). The capsules were opened and the decomposition gases, hydrazine, and coupons removed. The test coupons were weighed and their surfaces were visually examined at $50 \mathrm{x}$ magnification. The decomposition gases and hydrazine were analysed using posttest procedures developed and used in JPL's original program. The procedure 


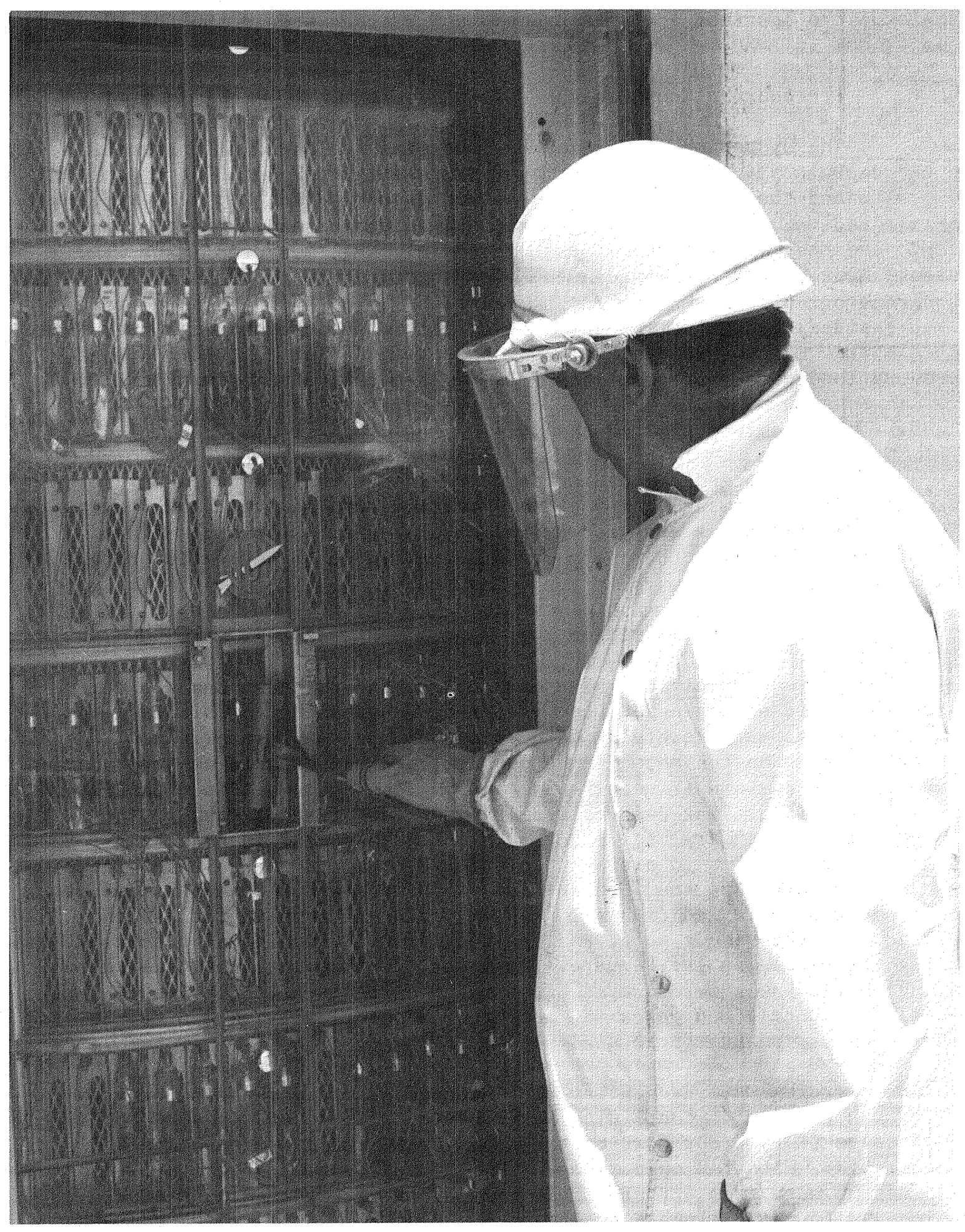

Figure 2-3. "Lazy-Susan"-Type Storage Facility 
(Figure 2-4) provides for an analysis of all components. The choice of the posttest analyses to be applied is dependent on the test-unit history and the level of information required to permit satisfactory assessment of results. Details of the posttest aralysis procedure are discussed in the following subsections.

\section{Procedure - Complete Analysis}

The hydrazine was frozen by immersion in liquid nitrogen $\left(\mathrm{LN}_{2}\right)$, and the capsule placed in the opening fixture (Figure 2-5). The capsule tip was broken and the volume of noncondensable gases $\left(\mathrm{N}_{2}\right.$ and $\left.\mathrm{H}_{2}\right)$ measured in a calibrated vacuum system. The hydrazine was thawed and refrozen at $-30^{\circ} \mathrm{C}$ $\left(-22 \mathrm{O}^{\mathrm{F}}\right)$ and the gas at that temperature, mainly $\mathrm{NH}_{3}$, measured. The residual hydrazine was removed using a syringe and the purity determined by a gas-chromatographic technique which measures $\mathrm{NH}_{3}$ and $\mathrm{H}_{2} \mathrm{O}$. Metal content in the residual hydrazine was analyzed by atomic absorption techniques. A turbidimetric method was used for low concentrations of chloride; higher concentrations were titrated. Fluoride was determined colorimetrically.

\section{Procedure - Limited Analysis}

This procedure measures only the noncondensable gases, hydrogen and nitrogen. After thawing, the residual hydrazine was removed from the capsule using a syringe and was analyzed by gas chromatography for $\mathrm{NH}_{3}$ and $\mathrm{H}_{2} \mathrm{O}$. If the $\mathrm{NH}_{3}$ content is low, there may be an error due to $\mathrm{NH}_{3}$ evolution before analysis.

\section{Gases of Decomposition}

a. Composition. The contents of the posttest capsule were frozen in liquid nitrogen and then prepared for sampling as follows: The strain gauge was very carefully scraped off with a sharp razor blade, a small scratch was made on the neck of the capsule, and the capsule was then enclosed in the opening fixture (Figure 2-5). The system was pumped down for several hours until moisture was removed from the outside of the capsule. The fixture was then filled with dry helium to 0.5 atmosphere to aid in heat transfer, and then immersed into liquid nitrogen to a depth equal to one-half the length of the capsule. After an hour, the helium was pumped out. When a satisfactory vacuum had been attained $\left(1.3 \times 10^{-2} \mathrm{~N} / \mathrm{m}^{2}\right)$, the gas sampling system was isolated from the vacuum pump, and the neck of the capsule was broken by turning the handle on the fixture. By means of a Toepler pump, the released noncondensable gases were pumped off through a liquid-nitrogen trap. The volume of the collected gases was measured manometrically, and a sample was taken for mass spectrometric analysis.

The nitrogen-to-hydrogen ratio of noncondensable gas was determined in most of the test units containing more than 5 to $10 \mathrm{cc}$ at standard temperature and pressure (STP). For most of these analyses, the hydrogen content was undetectable. With few exceptions, the hydrogen content of the remaining test units was no more than $4 \%$, and these exceptions were welded or brazed specimens. An unexplainable exception was test unit 4019, which contained a Lee plug, and for which the hydrogen content of the noncondensable gas was $12.5 \%$. The total amount of gas was also high, 4 to 5 times the quantity found with the other three Lee-plug test units. 
POST TEST

CAPSULE

(FROZEN IN LN ${ }_{2}$ )

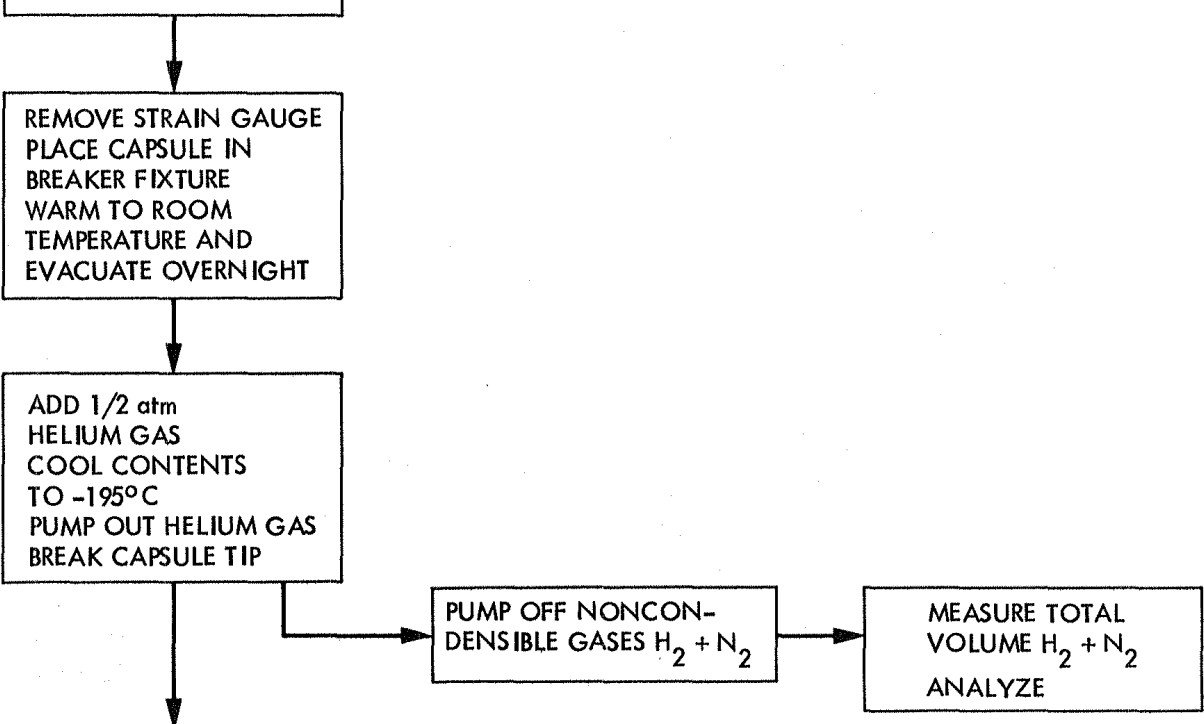

WARM CAPSULE TO ROOM TEMPERATURE OPEN BREAKER FIXTURE REMOVE PROPELLANT

WITH SYRINGE

VISUAL INSPECTION

OF PROPELLANT

ANALYZE FOR CO

$\mathrm{N}_{2} \mathrm{H}_{4}, \mathrm{NH}_{3}, \mathrm{H}_{2} \mathrm{O}$

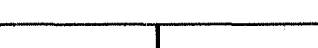

RINSE SPECIMEN AND

TILLED $\mathrm{H}_{2} \mathrm{O}$

COMBINE PROPELLANT

AND WATER RINSINGS

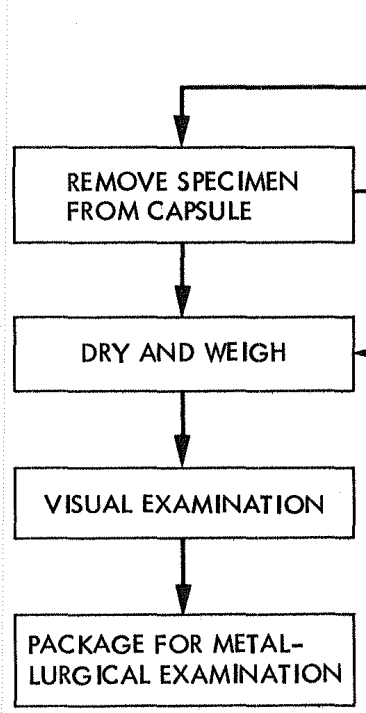

Figure 2-4. Procedure for Posttest Chemical Analysis 


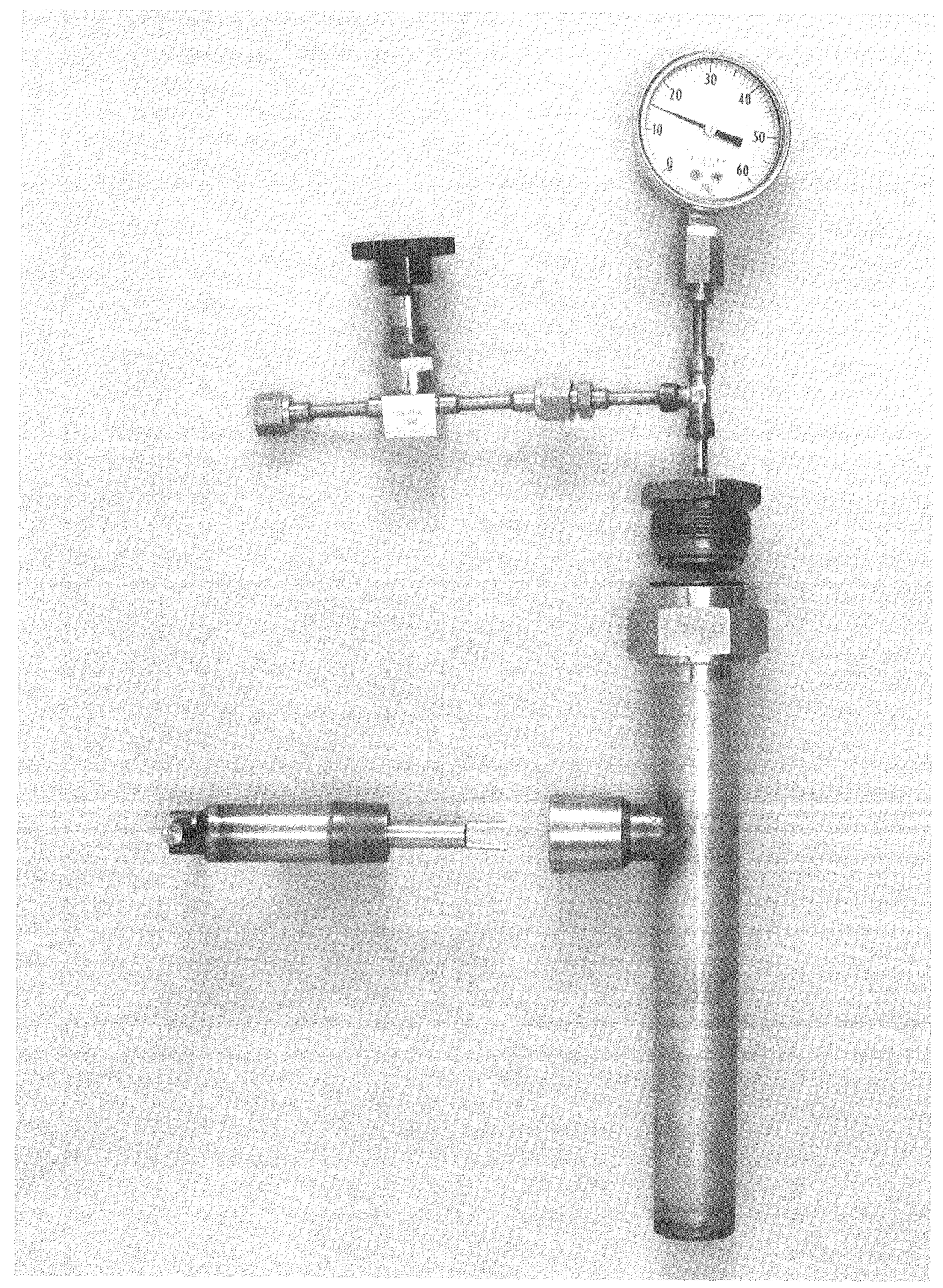

Figure 2-5. Specimen/Capsule Test Opening Fixture 
The liquid nitrogen traps were replaced by traps at $-30^{\circ} \mathrm{C}\left(-22^{\circ} \mathrm{F}\right)$. After repeated thawing and refreezing of the hydrazine, the remaining condensable gases (mainly $\mathrm{NH}_{3}$ ) were pumped off, measured, and sampled. The fixture was opened and the hydrazine removed using a syringe.

b. Calculated Fina1 Capsule Pressure. The mean volume of the test capsules was $82 \mathrm{~cm}^{3}$. With $40 \mathrm{~g}$ of hydrazine and a standard metal coupon, the ullage was about $40 \mathrm{~cm}^{3}$. The pressure calculations depend upon the volume of nitrogen plus hydrogen (assuming negligible solubility in the hydrazine) and the volume of ammonia in the vapor phase.

The contributions of nitrogen and hydrogen were calculated from the perfect gas law:

$$
\mathrm{P}_{1}=\frac{\mathrm{NRT}}{\mathrm{V}}
$$

where

$$
\begin{aligned}
\mathrm{P}_{1} & =\text { partial pressure of gas in atmospheres } \\
\mathrm{N} & =\text { moles of gas }=\mathrm{cm}^{3} \text { gas }(\mathrm{STP}) / 22,400 \\
\mathrm{R} & =\text { universal gas constant }=82.05 \mathrm{~cm}^{3} \text {-atm/deg-mole } \\
\mathrm{T} & =316.6 \mathrm{~K}\left(110^{\circ} \mathrm{F}\right) \text { or } 333 \mathrm{~K}\left(140^{\circ} \mathrm{F}\right) \\
\mathrm{V} & =\text { ullage volume of capsule, } \mathrm{cm}^{3} .
\end{aligned}
$$

The calculation of pressure due to the ammonia is not so simple and straightforward. Ammonia is highly soluble in hydrazine, and may not necessarily be an ideal gas at the temperatures and pressures considered.

Fortunately, solubility data for ammonia in hydrazine are available (Refexence 5). Although the data do not cover the temperatures of interest, viz., $43^{\circ} \mathrm{C}$ and $60^{\circ} \mathrm{C}$, it was possible to extrapolate the data of the above-referenced report. It can be shown that for the ammonia dissolved in hydrazine, the following relationship can be used to determine a close approximation of the ammonia pressure:

$$
P \cong \frac{N / m}{K}
$$

where
$\mathbf{P}=$ partial pressure of ammonia, atm
$\mathrm{N}=$ moles of ammonia in system
$\mathrm{m}=$ moles of hydrazine in system
$\mathrm{K}=$ equilibrium constant $\left(0.0455 \mathrm{~atm}^{-1} \mathrm{at} 43^{\circ} \mathrm{C}, 110^{\circ} \mathrm{F}\right)$, $\left(0.0295 \mathrm{~atm}^{-1}\right.$ at $\left.60^{\circ}, 140^{\circ} \mathrm{F}\right)$ 
c. Pressure Rise Rate. It would be of interest, both practically and theoretically, to have curves expressing pressure as a function of time for each test capsule. Unfortunately, due to aging of the bonding material, some of the strain-gauge data have proven to be unreliable.

d. Percentage of Hydrazine Decomposed. The percentage of hydrazine decomposed is calculated from the total weight of the gaseous products of decomposition - viz, nitrogen and ammonia. Some hydrogen may arise from the attack of metals by acidic constituents, but the error, if any, is insignificant because of the low molecular weight of hydrogen.

\section{Residua1 Hydrazine}

The residual hydrazine was removed from the capsule and analyzed as

follows:

a. Impurities: $\mathrm{NH}_{3}$ and $\mathrm{H}_{2} \mathrm{O}$. The $\mathrm{NH}_{3}$ and $\mathrm{H}_{2} \mathrm{O}$ contents of the hydrazine were analyzed by gas chromatography using a 0.0065 -m-diam x 2-m-long (1/4-in.-diam x 6-ft-long) column filled with powdered Teflon coated with 15 wt\% tri-ethanolamine. The inlet and column temperatures were held at $90^{\circ} \mathrm{C}$ $\left(194^{\circ} \mathrm{F}\right)$ and the helium flow set at $100 \mathrm{~cm} / \mathrm{min}$. This column separates $\mathrm{NH}_{3}$, $\mathrm{H}_{2} \mathrm{O}$, and $\mathrm{N}_{2} \mathrm{H}_{4}$, in that order.

\section{b. Contaminants: Metals, Halogen and $\mathrm{CO}_{2}$.}

(1) Metals. The capsule was cut open and the metal sample rinsed with water, while any adhering material was rubbed loose with a rubber policeman. Any residue in the capsule was also rinsed out. A11 washings and residue were acidified with $5 \% \mathrm{HNO}_{3}$, diluted to a known volume with water and analyzed for the appropriate metals by atomic absorption.

(2) Halogens. An aliquot of the acidified washings was checked for chloride by turbidimetry. If the chloride content was high, titration was used. The fluoride ion content was determined by a spectrophotometric method based on the bleaching of a zirconium alizarin color complex by fluoride ion. The absorbance was measured at $525 \mathrm{~nm}$.

(3) Carbon dioxide. Hydrazine reacts with carbon dioxide to form the salt, hydrazinium carbazate. The equation for this reaction is

$$
\mathrm{CO}_{2}+2 \mathrm{~N}_{2} \mathrm{H}_{4} \rightarrow\left(\mathrm{N}_{2} \mathrm{H}_{5}\right)\left(\mathrm{NH}_{2} \mathrm{NHCOO}\right. \text {. }
$$

The method of analysis involved the addition of a sample of hydrazine to an excess of sulfamic acid. The sulfamic acid liberates $\mathrm{CO}_{2}$ from the hydrazinium carbazate. Sulfamic acid was selected for use in the analysis because hydrazinium sulfamate is soluble in water and sulfamic acid is nonvolatile.

The liberated $\mathrm{CO}_{2}$ was swept out of solution with helium gas, through a trap containing concentrated sulfuric acid to remove the water, and then through a special trap containing small glass beads where the $\mathrm{CO}_{2}$ present was frozen out at the temperature of liquid nitrogen. 
The trap containing the frozen $\mathrm{CO}_{2}$ was provided with a special four-way stopcock that permits the $\mathrm{CO}_{2}$ to be isolated in its loop. This trap is attached to a special sample introduction system on a custom-built chromatograph that permits the collected $\mathrm{CO}_{2}$ to be quantitatively transferred through a chromatographic column for separation and assay. (Refer to Appendix $\mathrm{C}$ for details of this method.) 


\section{SECTION III}

TEST RESULTS

\section{A. DESCRIPTION OF TEST SPECIMENS}

To determine the hydrazine/tank material compatibility, tests were performed on 26 types of metallic and nonmetallic coupons obtained from a fabricated tank, as shown in Figure 1-2. A detailed description of these coupons by CPR numbers and the results of the posttest visual examination are discussed in this section and are compiled in Table 2. Photographs of al1 test coupons in the posttest condition are presented in Appendix D. Additional data on 347 CRES weld specimens from the JPL/NASA long-term program are presented in Appendix E. A summary of posttest visual examination of coupons is presented below.

a. CPR 1. Specimens 001 to 008 are Type-304L corrosion-resistant stee1 (CRES) coupons from the ARDE, Inc., diaphragm. A11 specimens were observed to have a matte finish with no visible corrosion on their surfaces.

b. CPR 2. Specimens 014 to 017 are Type-304L CRES coupons from the ACS tank 1iner/diaphragm assemblies, which were girth-welded. Al1 four specimens were shiny in appearance with no surface corrosion apparent. Specimen 014 had a very thin film along the heat-affected zone (HAZ) of the liner. Specimens 015 and 016 also had thin films along the HAZ of the diaphragm.

c. CPR 3. Specimens 023 to 026 are coupons from burst-disc assemblies made of Type-347 CRES preformed sheet stock, which was electron-beam (EB) welded to a ring made of Type-304L CRES. Each specimen was shiny and bright with no evidence of corrosion on its surface. Each diaphragm had identification numbers and symbols inscribed on it, in addition to the preformed scoring marks. A11 specimens were observed to have very sma11 parallel scratches on the surfaces.

d. CPR 4. Specimens 034 to 037 are commercial Lee plugs made of Type304L CRES. A11 four specimens had shiny and bright surfaces with no corrosion evident.

e. CPR 5. Specimens 045 to 048 are coupon sections from the Type-304L CRES liner/diaphragm liquid outlet housing, which was tungsten-inert-gas (TIG) welded. All specimens appeared bright and shiny with no signs of surface corrosion apparent.

f. CPR 6. Specimens 056 to 059 are coupon sections from the Type-304L CRES EB weld joint No. 407. All specimens' metallic surfaces were shiny and bright with no signs of visible corrosion.

g. CPR 7. Specimens 067 to 070 are coupon sections from the Type-304L CRES EB weld joint No. 406. All coupons' metallic surfaces were shiny and bright with no signs of visible corrosion. 
h. CPR 8. Specimens 078 to 081 are coupon sections of Types 308L and 304L CRES from the stiffening ring/diaphragm spot-welded subassemblies. A11 were shiny and bright with no evidence of surface corrosion.

i. CPR 9. Specimens 300 to 307 are coupon sections of Type-304L CRES from the ACS tank 1iner. All samples were shiny, with a matte finish. No corrosion was noted on these coupons.

j. CPR 10. Specimens 100 to 103 are coupon sections from the tank she11 composed of Type-A286 CRES. The metal was still shiny with a minor amount of gray discoloration. No corrosion on the coupon was evident at $45 \mathrm{x}$ magnification.

k. CPR 11. Specimens 109 and 110 are coupon sections from TIG-welded joint No. 411 of Type-A286 CRES, which was a part of the ACS tank girth weld. The metal was shiny except for a gray discoloration in the HAZ along each side of the weld. No corrosion was evident.

1. CPR 12. Specimens 112 and 113 are coupon sections of the TIG-welded joint No. 417 composed of Type-A286 CRES, which was welded to Type-304L CRES. The specimen metal surfaces were shiny and bright with no evidence of corrosion.

m. CPR 13. Specimens 115 and 116 are sections of Type-308L CRES filler wire used in the diaphragm stiffening ring. The wire was shiny except for dark-gray bands about 1/2 in. from each end. No other corrosion was evident.

n. CPR 14. Specimens 118 to 121 are coupon sections of Type-304L CRES from the 1iner-diaphragm assembly with a gold-nicke1 brazed Type-308L CRES filler wire. All coupons were shiny and bright with no evidence of corrosion.

o. CPR 15. Specimens 127 and 128 are pieces of the Mylar plastic sensor disc from the vapor-detection assembly. Both specimens dissolved in the hydrazine propellant after three hours of testing. (The hydrazine became 1ight yellow in color and contained $0.016 \mathrm{mg}$ of iron.)

p. CPR 16. Specimens 130 and 131 are coupon sections of Type-304L CRES from the liquid outlet housing to the tank-half EB-welded joint No. 404. Specimen 130 was shiny except for some etching on the bottom of the coupon and a gray discoloration in the HAZ along each side of the weld. Specimen 131 's surface was shiny and bright except for an irregular surface on the top. No corrosion was seen on either coupon.

q. CPR 17. Specimens 133 and 134 are fluorinated-ethylenepropylene(Teflon-) coated samarium-cobalt magnets from the vapor-detection assembly. The Specimen 133 coating was intact, but uneven. No corrosion was evident. The posttest weight was significantly lower than the pretest weight. A reason for the loss was not readily apparent. However, it was observed that the magnet did influence the action of the scale balance; an accurate weight was obtained only after neutralizing the magnetic influence. The specimen-134 Teflon coating was irregular but apparently intact. There were dark spots on the magnet surface, but it was not possible to identify them as corrosion spots. 
r. CPR 18. Specimens 200 and 201 are coupon sections of Type-17-4 PH CRES, $H 1050$ temper, and electropolished, from the piston in the flow-equalizer valve. The surface of the specimens was bright with no evidence of corrosion.

s. CPR 19. Specimens 210 and 211 are electropolished and chrome-plated sections of Type-17-4 PH CRES, H 1050 temper, from the shaft end of the flowequalizer valve. The specimens were shiny and bright with no corrosion evident.

t. CPR 20. Specimens 220 and 221 are springs of electropolished Type17-4 PH CRES, CH 900 temper, from the flow-equalizer valve. Specimen 220 is bright with a light-gray tarnish. No other corrosion was evident. Specimen 221 was shiny with no corrosion evident.

u. CPR 21. Specimens 230 and 231 are coupon sections of Type-17-4 PH CRES, TIG welded and electroplated, from the shaft end assembly of the flowequalizer valve. The metal was shiny and bright with some etching near the coupon identifying number. No corrosion was seen.

v. CPR 22. Specimens 240 and 241 are bourdon tubes of Incone1 902 (Ni Span C) from the pressure-switch assembly. The metal surfaces have an even gray oxidized coating with no corrosion evident.

w. CPR 23. Specimens 250 and 251 are coupon sections and pieces of Type-347 CRES bar stock from the propellant distribution manifold fitting. Specimen 250 was shiny with a very light-gray mottling perceptible on the surfaces. No corrosion was apparent. Specimen 251, with circular machining marks, was shiny and bright. No corrosion was seen.

x. CPR 24. Specimens 260 and 261 are of Type-347 CRES tubing. A light-gray tarnish was evident on the surface, but no corrosion can be seen.

y. CPR 25. Specimens 270 and 271 are coupon sections of Type-347 CRES tubing Astroarc welded (Weld No. 78) to Type-347 CRES tubing. The tubing was shiny except for a gray discoloration in the HAZ on each side of the weld. No corrosion was evident.

z. CPR 26. Specimens 280 and 281 are 0 -rings made of Parker seal compound EPR 515. Microscopic examination of the 0-rings revealed no crazing or cracking; the surface appeared smooth and unbroken. There was no Krytox $240 \mathrm{AC}$ coating on the specimens before cleaning.

\section{B. DETAILS AND SUMMARIES OF POSTTEST ANALYSES AND RESULTS}

The posttest analyses and results are summarized in Table 2. The duration of the test units in storage, test temperatures in degrees Celsius, and capsule posttest pressures at test temperature in $\mathrm{N} / \mathrm{cm}^{2}$ are given. The specimen material, configuration, and weight change in milligrams are 1isteḑ. The percentage decomposition of hydrazine and the gas evolution rate in $\mathrm{cm}^{3} \times 10^{-3}$ $\mathrm{day}^{-1} \cdot \mathrm{cm}^{-2}$ are also given. 
Data on the individual test units, test specimens, and the hydrazine propellant is given in Table 3. The BAT number is identified with the test unit number. The initial weight in grams and the change in weight is given for each specimen. The analysis of the hydrazine is given in milligrams for dissolved iron $(\mathrm{Fe})$ and by percent for water $\left(\mathrm{H}_{2} \mathrm{O}\right)$ and ammonia $\left(\mathrm{NH}_{3}\right)$. The hydrazine decomposition into the noncondensable gases nitrogen $\left(\mathrm{N}_{2}\right)$ and hydrogen $\left(\mathrm{H}_{2}\right)$ is given as total volume $\left(\mathrm{cm}^{3}\right)$ at standard temperature and pressure (STP); the gas evolution rate, both uncorrected and control corrected, is in $\mathrm{cm}^{3} \mathrm{x}$ $10^{-3^{8}} \cdot \mathrm{day}^{-1} \cdot \mathrm{cm}^{-2}$.

\section{PROPELLANT CONTROLS}

Table 4 presents data on the hydrazine propellant, unit number, days on test, temperature in degrees Celsius, capsule pressure at test temperature, and the $\mathrm{H}_{2} \mathrm{O}$ and $\mathrm{NH}_{3}$ analyses, by percent, along with information on hydra$z$ ine decomposition. The noncondensable gases $\left(\mathrm{N}_{2}\right.$ and $\left.\mathrm{H}_{2}\right)$ are 1isted as total volume $\mathrm{cm}^{3}$ at STP and the rate as $\mathrm{cm}^{3} \times 10^{-3} \cdot \mathrm{day}^{-1}$.

\section{SURFACE ANALYSIS}

\section{Introduction}

As noted in Table 2, in a few pairs (or groups) of specimens, one of the test units shows a significantly higher gas evolution than the others in that group. For example, specimen BA 008 had twice the gas evolution rate of any of the others in the CPR 1 group. In the CPR 4 group, one of the Lee plugs greatly enhanced the decomposition of hydrazine. Other examples can be seen in Table 2 .

Two sets of specimens were chosen for very scrupulous examination by $X$-ray photoelectron spectroscopy (XPS) and the scanning electron microscope (SEM). Both sets are from the primary containment system (Program $B$ ) and both are of 304L CRES. The specimens examined were BA 005 and BA 008 of the CPR 1 group, and BA 305 and BA 307 of the CPR 9 group. In each case an untreated specimen, i.e., one not exposed to hydrazine, was used as a control in the analysis.

\section{XPS Techniques}

The six specified stainless-steel samples were submitted for surface analysis by the XPS technique; Figure 3-1 shows the JPL XPS laboratory. The samples were cut from the original strips using metal shears. Then, immediately prior to insertion into the XPS spectrometer, each sample was cleaned ultrasonically in absolute ethanol for 10 minutes and dried with flowing nitrogen. The following samples were analyzed:

\begin{tabular}{l} 
Set I \\
\hline CPR 1 \\
BA 005 \\
BA 008
\end{tabular}

Set II CPR 9 (CONTROL) BA 305 BA 307 


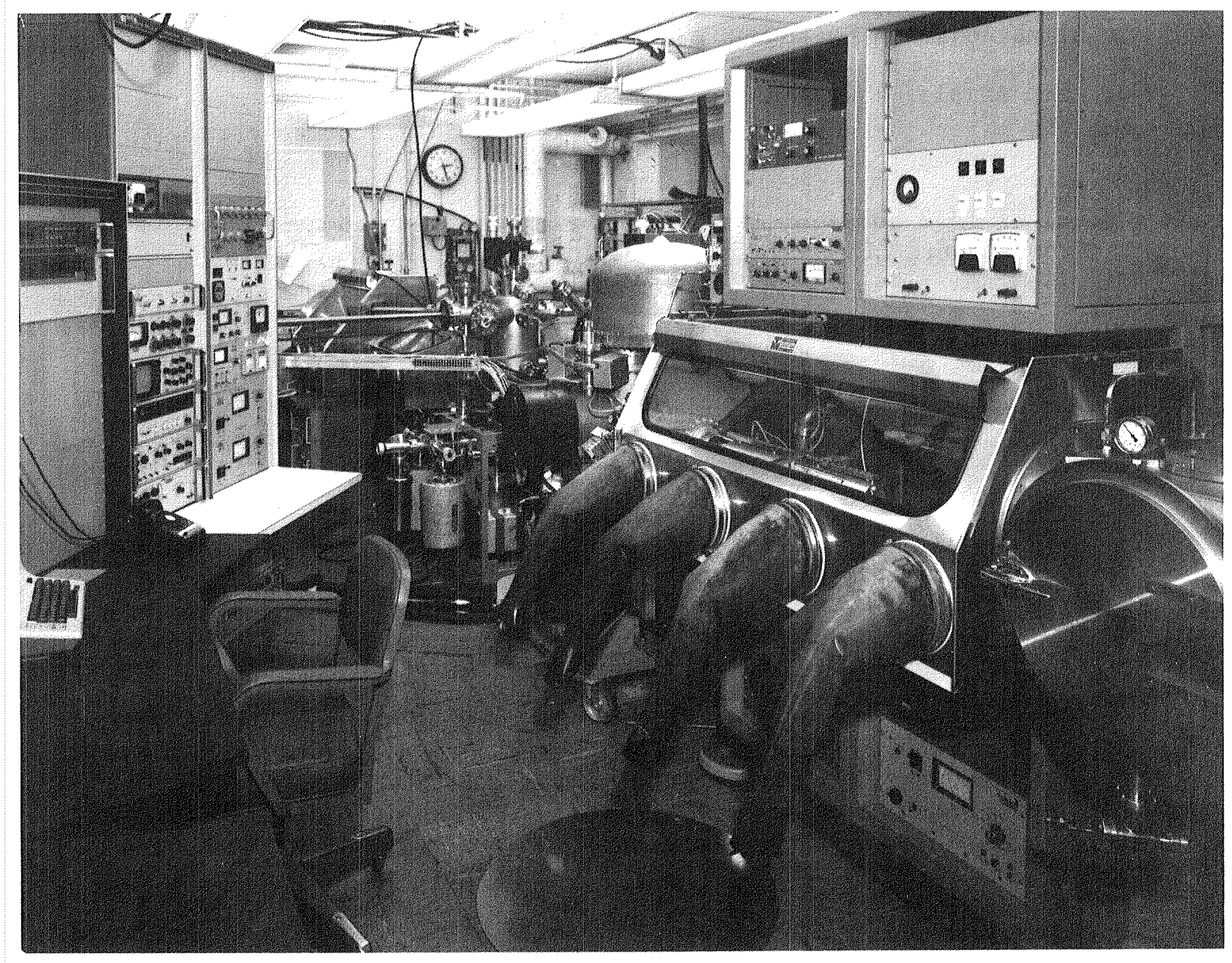

Figure 3-1. JPL XPS Laboratory 
Analyses were performed with a modified Hewlett-Packard 5950A electron spectrometer under computer controi. Photoemitted electrons, characteristic of the surface composition of the sample, were formed by interaction with $1486.6-\mathrm{eV}$ incident photons from an aluminum $\mathrm{K} \alpha$ radiation source. For the instrumentation employed, the measured photoemission represents an average signal over an area of approximately $1 \mathrm{~mm} \times 5 \mathrm{~mm}$. Although the photoemitted electrons from a given atomic core level may sometimes originate as much as $100 \AA$ below the sample surface, the immediate surface region of the sample will actually contribute significantly more to the measured signal due to an exponential attenuation (with depth) of photoelectrons by the solid.

For each sample, a wide energy-range (100 to $1300 \mathrm{eV}$ ) scan was run to determine the major contributors to the total photoelectron spectrum, followed by careful measurement of a 20 to $40 \mathrm{eV}$ binding energy-range characteristic of each of eight elements of major interest. Each such run for a given sample took a total of 15.2 hours of instrument time to obtain adequate statistics. Photoelectron spectra (PES) of the following elements were obtained:

\begin{tabular}{ccc} 
Element & $\begin{array}{c}\text { Energy } \\
\text { Levels }\end{array}$ & $\begin{array}{c}\text { Measured Binding } \\
\text { Energy Range, eV }\end{array}$ \\
\cline { 2 - 3 } & $1 \mathrm{~s}$ & 275 to 295 \\
$\mathrm{C}$ & $1 \mathrm{~s}$ & 390 to 410 \\
$\mathrm{~N}$ & $1 \mathrm{~s}$ & 523 to 543 \\
$\mathrm{Or}$ & $2 \mathrm{p}_{3 / 2}, 2 \mathrm{p}_{1 / 2}$ & 560 to 600 \\
$\mathrm{Cr}$ & $2 \mathrm{p}_{3 / 2}, \mathrm{p}_{1 / 2}$ & 625 to 665 \\
$\mathrm{Fe}$ & $2 \mathrm{p}_{3 / 2}, 2 \mathrm{p} 1 / 2$ & 695 to 735 \\
$\mathrm{Ni}$ & $2 \mathrm{p}_{3 / 2}, 2 \mathrm{p}_{1 / 2}$ & 845 to 895 \\
$\mathrm{Zn}$ & $2 \mathrm{p}_{3 / 2}, 2 \mathrm{p}_{1 / 2}$ & 1010 to 1050
\end{tabular}

The XPS BE (binding energy) spectra can be used to identify different elements on a surface and to distinguish between the same element in different chemical environments. For example, oxidation of a metal causes an effective unbalanced positive change localized on the metal atom and the remaining electrons are therefore held more tightly; i.e., their binding energy increases.

\section{Results}

For the various spectral regions examined in this investigation, some general observations are presented below.

a Carbon 1s Region. Carbon is the major constituent of the surface of all samples, amounting to $40+4$ atomic percent (at.\%) for five samples and to a significantly higher 68.8 at.\% for CPR 1 (which also gave anomalous results in almost all the other measurements). The primary peak in the carbon spectra comes from aliphatic carbon compounds, while there are also substantial intensities in the regions expected for carbon-nitrogen compounds $(\approx 286 \mathrm{eV})$ and carbon-oxygen compounds $(\approx 288 \mathrm{eV})$. A quantitative measure of the relative amounts of these three carbon species may be obtained from the application of computer curve-fitting routines to the individual spectra. 
b. Oxygen 1s Region. The apparent surface concentration of oxygen is approximately the same $(46 \pm 3$ at.\%) for all samples, with the exception of CPR 1(24.7\%). In the case of oxygen, a variety of metal oxides and hydroxides contribute to the measured signals and, in the absence of adequate reference data, it is very difficult to make any specific assignments to the various peaks and shoulders observed. It should be noted that the oxygen 1 s binding energy for CPR 1 is shifted to a higher energy than that observed for the other five samples, suggesting a significantly different distribution of metal oxides/hydroxides for this particular sample, when compared to the others.

c. Nitrogen 1s Region. The apparent surface concentration of nitrogen is observed to be approximately the same $(2.8+0.5$ at.\%) for all six samples. The measured binding energy of the nitrogen peak is, for all samples, consistent with that to be expected for protonated amines and amino polymers.

d. Chromium 2p Region. In both Sets I and II, the apparent surface concentration of chromium for the samples exposed of the contro1 specimens, CPR $9(4.3$ at.\%) or CPR 1 ( 0.8 at.\%, anomalously low). The predominant species present in all samples are metallic chromium (relatively smal1) and chromium oxide or hydroxide (relatively large). The ratio of metallic to oxidized chromium is approximately the same for all samples.

e. Manganese 2p Region. In both Sets I and II, the apparent surface concentration of manganese for the samples exposed to hydrazine ( 1.0 \pm 0.2 at.\%) is found to be greater than that for either of the control specimens CPR $9(0.5$ at.\%) or CPR $1(0.1$ at.\%, again low). The predominant species present in all samples is oxidized manganese as the monoxide; hydroxides may be present as well, due to the close similarity of binding energies.

f. Iron $2 p$ Region. The dominant surface species present in all samples are metallic iron and ferric oxide; iron hydroxides are also possible since oxides and hydroxides exhibit similar binding energies. In both Sets I and II, the ratio of metallic iron to oxidized iron is much greater for the samples subjected to hydrazine than for the control specimens. In Set II, the control specimen CPR 9 has a greater total iron surface concentration (3.9 at. $\%$ ) than that for the samples contacted by hydrazine $(3.1+0.8$ at.\%). In Set I just the opposite occurs; the total surface iron for $\overline{C P R} 1$ (1.0 at.\%) appears to be anomalously low.

g. Nicke1 2p Region. In all cases, the primary peak in the nickel spectrum is due to metallic nickel; a much less intense peak at higher binding energy is due to the monoxide. In both Sets I and II, the apparent surface concentration of nickel was approximately the same $(0.3$ at.\%) for the samples exposed to hydrazine. The nickel concentration for control sample CPR 9 was somewhat lower $(0.1$ at.\%), while for CPR 1 it was exceptionally low $(0.2$ at.\%).

h. Zinc $2 p$ Region. In all cases, the surface zinc is present in oxidized form, probably as the simple oxide. In Set I, the apparent surface concentration of zinc is approximately equal $(0.2$ at.\%) for al1 three samples. In Set II, the control specimen, CPR 9, shows 2 to 3 times more zinc $(0.6 \mathrm{at. \%})$ than the samples subjected to hydrazine. 
4. Discussion

Both the carbon and nitrogen binding energy spectra give strong evidence of surface contamination by carbon-nitrogen compounds such as amino polymers. It should be noted that although these samples were apparently stored in polyethylene bags in pretreatment steps, the final pretest step consisted of heat-sealing in nylon, a process which could readily provide the observed amino polymers on the surface.

The anomalous results for control CPR 1 were confirmed by a second run which gave results identical to the original run. This specimen was more reduced in oxygen and metals concentration, but more heavily contaminated by carbon than any of the other five samples. Therefore, more meaningful comparison may probably be made using CPR 9 as a control for both sets of samples subjected to hydrazine.

The overall picture is that, upon exposure to hydrazine, oxidized iron is removed, leaving a surface richer in the protective chromium oxide. A more thoughtful analysis may be aided by taking into account the information presented in Reference 6 , and the references contained therein.

\section{Scanning Electron Microscopy (SEM) Examination}

These same specimens were then examined by SEM to look for differences in surface morphology. The surfaces of specimens BA 005 and BA 008 were identical in appearance when examined at $50 \mathrm{x}$ and $500 \mathrm{x}$ magnifications. When compared to the CPR 1 control, the specimens exposed to hydrazine appeared to have very minor surface pitting. The surfaces of specimens BA 305 and BA 307 also were identical and no differences could be seen when compared to the CPR 9 control.

In addition, the specimen BA 036, Lee plug, was thoroughly examined by SEM because of the greater decomposition rate of its test unit compared to the three other replicates. A direct comparison to specimen control BA 038 indicated no differences.

\section{Conclusions}

These highly detailed and sensitive analyses failed to indicate the causes for differences observed in the rates of hydrazine decomposition between pairs of nominally identical specimens. Some of the more subtle differences in surface character were unfortunately masked by the presence of significant contamination by carbon-nitrogen compounds from the sealed nylon storage bags. The thickness of this carbon-nitrogen layer is such $(<100 \AA)$ that it would have no effect on either the rate of hydrazine decomposition or the effect of corrosion of the coupons. SEM examination of the above-mentioned six coupons and Lee plug BA 036 again revealed no cause for the difference in decomposition rates. 
With few exceptions, mainly attributable to catalysis, possible contamination, or inherent sample-to-sample variation, the rate of hydrazine decomposition in these tests was very low -- producing less than $1.0 \mathrm{cc}$ of gas per year per $\mathrm{cm}^{2}$ of specimen area.

The degree of corrosion of the metal coupons was virtually unmeasurable in all instances. The elastomer EPR-515 did not appear to degrade, and the Mylar film dissolved as expected.

\section{A. PROGRAM A: 6 MONTHS STORAGE}

The rates of hydrazine decomposition were low in most test units -- less than $1.0 \mathrm{~cm}^{3}$ gas per year per $\mathrm{cm}^{2}$ of specimen area. The following were a few exceptions to the low rates:

(1) 304L liner-diaphragm with Au-Ni brazed 308L filler wire (BA 118-121), 1.0 to $3.7 \mathrm{~cm}^{3} / \mathrm{yr} / \mathrm{cm}^{2}$

(a) Possible catalysis by Au-Ni braze

(b) Rate based on total coupon area.

(2) FEP-coated Sm-Co magnets (BA 133-134), 3.7 to $13.2 \mathrm{~cm}^{3} / \mathrm{yr} / \mathrm{cm}^{2}$

(a) FEP coating intact

(b) Possible permeation and catalysis.

(3) ERP-515 0-rings

(a) Catalysis by carbon black used in compounding elastomer

(b) Very rapid decomposition, but area rate not meaningful.

(4) Mylar film (BA 127-128), $3.5 \mathrm{~cm}^{3} / \mathrm{yr} / \mathrm{cm}^{2}$

(a) Film dissolved

(b) Area rate not meaningful.

The corrosion of metallic coupons was minimal and only very light tarnish was seen on a few specimens. The weight changes of coupons were negligible, and dissolved iron in the propellant was almost unmeasurable. Two nonmetals were included in Program A: 
(1) Mylar film (BA 127-128), which dissolved as expected.

(2) EPR-515 0-rings (BA 280-281), which appeared unchanged after exposure to hydrazine.

\section{B. PROGRAM B: 24 MONTHS STORAGE}

The rates of hydrazine decomposition were low in most test units -- less than $1.0 \mathrm{~cm}^{3}$ gas per year per $\mathrm{cm}^{2}$ of specimen area. There were a few exceptions to low rates, but the results were not consistent:

(1) 304L liner/diaphragm girth weld (BA 017), $1.3 \mathrm{~cm}^{3} / \mathrm{yr} / \mathrm{cm}^{2}$

(a) Only one of four specimens produced an anomalously large volume of gas

(b) Possible contamination or sample-to-sample variation.

(2) $304 \mathrm{~L}$ Lee plug (BA 036), $5.2 \mathrm{~cm}^{3} / \mathrm{yr} / \mathrm{cm}^{2}$

(a) Only one of four specimens showed a high rate of decomposition

(b) Possible contamination or sample-to-sample variation.

(3) 304L EB weld No. 407 (BA 058-BA 059), $2.3-3.3 \mathrm{~cm}^{3} / \mathrm{yr} / \mathrm{cm}^{2}$

(a) Two specimens at $43^{\circ} \mathrm{C}$ showed low rate of gas formation

(b) Possible effect of $60^{\circ} \mathrm{C}$ storage

(c) Possible contamination or sample-to-sample variation.

(4) 304L EB weld No. 406 (BA 070), $1.8 \mathrm{~cm}^{3} / \mathrm{yr} / \mathrm{cm}^{2}$

(a) Only one of two at $60^{\circ} \mathrm{C}$ was high

(b) Possible contamination or sample-to-sample variation.

None of the specimens appeared to corrode, and only a very light tarnish was seen on a few specimens. Weight changes of the coupons were negligible, and the dissolved iron in the propellant was almost unmeasurable.

In general, the results of this study agree very we11 with the JPL/NASA long-term compatibility program (References 2 and 3). The Type-304L CRES chosen for the primary containment of hydrazine in the propellant tank appears to be entirely suitable for use in systems requiring at least a 2-year service 1ife. In the secondary containment side of the tank, the A286 CRES used in the outer pressure vessel is compatible with hydrazine for 6 to 12 months exposure. The Au-Ni braze material, FEP-coated Sm-Co magnets, and the EPR 515 0-rings have been shown to cause hydrazine decomposition that could result in an undesirable gas pressure buildup which must be accomodated in the system design. However, these materials would be in contact with hydrazine only if a leak occurred in the primary containment system. 


\section{SECTION $V$}

DATA TABLES

The tables are, generally, self-explanatory. The following comments are given to expand on certain topics.

The strain gauge data shown in Table 2 indicate that this is not a reliable method of determining capsule pressures of less than one atmosphere. The strain gauges are normally calibrated at positive pressure only, and an extrapolation is made to zero pressure. Attempts to calibrate a capsule-mounted strain gauge at subatmospheric pressure produced results that indicated random shifting of the calibration line. At pressures greater than one atmosphere, the strain gauge data agree very well with the actual pressures found in the capsules. Posttest recalibration of several capsules indicates that while the zero point may shift, the sensitivity is maintained during handling and testing.

The decomposition of hydrazine in the control capsules (Table 4) presumably occurs through homogeneous (bulk) catalysis; glass should not act as an active surface for hydrazine decomposition. Purified hydrazine contains very little dissolved iron (a known catalyst) and, therefore, the rate of decomposition is predictably slow. With the introduction of a metallic specimen, there is the possibility of an active surface and heterogeneous (surface) catalysis. If metal is dissolved from the surface of the specimen, it is possible for both reaction mechanisms to occur. Obviously, from an inspection of some of the results (Tables 2 and 3 ), there are metallic surfaces which are not catalytically active towards hydrazine, especially Type-304L CRES A1loy. 
Table 1. Listing of Coupon Test Numbers and Description

Test Numbers

\begin{tabular}{|c|c|c|}
\hline CPR & BAT & Test Unit \\
\hline 1 & $001-008$ & $4001-4008$ \\
\hline 2 & 014-017 & $4009-4012$ \\
\hline 3 & $023-026$ & $4013-4016$ \\
\hline 4 & $034-037$ & $4017-4020$ \\
\hline 5 & $045-048$ & $4021-4024$ \\
\hline 6 & $056-059$ & $4025-4028$ \\
\hline 7 & $067-070$ & $4029-4032$ \\
\hline 8 & $078-081$ & $4033-4036$ \\
\hline 9 & $300-307$ & $4037-4044$ \\
\hline 10 & $100-103$ & $4045-4048$ \\
\hline 11 & $109-110$ & $4049-4050$ \\
\hline 12 & $112-113$ & $4051-4052$ \\
\hline 13 & $115-116$ & $4053-4054$ \\
\hline 14 & $118-121$ & $4055-4058$ \\
\hline 15 & $127-128$ & $4059-4060$ \\
\hline 16 & $130-131$ & $4061-4062$ \\
\hline 17 & $133-134$ & $4063-4064$ \\
\hline 18 & $200-201$ & $4065-4066$ \\
\hline 19 & $210-211$ & $4067-4068$ \\
\hline 20 & $220-221$ & $4069-4070$ \\
\hline 21 & $230-231$ & $4071-4072$ \\
\hline 22 & $240-241$ & $4073-4074$ \\
\hline 23 & $250-251$ & $4075-4076$ \\
\hline 24 & $260-261$ & $4077-4078$ \\
\hline 25 & $270-271$ & $4079-4080$ \\
\hline 26 & $280-281$ & 4081.4082 \\
\hline
\end{tabular}

Material Compatibility Test Specimen Description

304L Arde diaphragm

304L/304L liner/diaphragm girth weld

347 burst disc

304L Lee plug

304L/304L liner/diaphragm outlet housing TIG weld

304L/304L EB weld \$407

304L/304L EB weld \#406

308L/304L ring/diaphragm spot welded

304L liner

A286 tank shell

A286/A286 girth TIG weld \#411

$304 \mathrm{~L} / \mathrm{A2} 86$ polar TIG weld $\# 417$

308L stiffening ring

308L/304L wire/diaphragm, Au-Ni braze

Mylar sensor disc

304L/304L EB weld \#404, liquid outlet housing to tank half

Samarium-cobalt magnet, FEP coated

17-4 PH, H 1050 temper, electropolished

17-4 PH, H 1050 temper, electropolished, chrome plated

17-4 PH, CH900 temper, spring

17-4 PH/1 7-4 PH, TIG weld, shaft end

Inconel 902, $\mathrm{Ni}$ span $\mathrm{C}$, Bourdon tube

347 manifold fitting

347 tube, annealed

347/347 Astro-arc weld $\# 78$

EPR 515, Parker seal, O-ring, Krytox coated 
Table 2. Summary of Analyses and Results

\begin{tabular}{|c|c|c|c|c|c|c|c|c|c|c|}
\hline \multirow[b]{2}{*}{$\begin{array}{l}\text { BAT } \\
\text { No. }\end{array}$} & \multirow[b]{2}{*}{$\begin{array}{l}\text { Test } \\
\text { Unit }\end{array}$} & \multirow[b]{2}{*}{$\begin{array}{l}\text { Days } \\
\text { on } \\
\text { Test }\end{array}$} & \multirow[b]{2}{*}{$\begin{array}{l}\text { Test } \\
\text { Temp., } \\
\text { oC }\end{array}$} & \multirow[b]{2}{*}{$\begin{array}{l}\text { Capsule Pressure } \\
\text { at Test Temp., } \\
\mathrm{N} / \mathrm{cm}^{2}\end{array}$} & \multicolumn{4}{|c|}{ Specimen } & \multicolumn{2}{|c|}{ Propellant } \\
\hline & & & & & $\begin{array}{l}\text { (Strain } \\
\text { Gage } \\
\text { Reading) }\end{array}$ & Material & Configuration & $\begin{array}{l}\text { Weight } \\
\text { Change } \\
\text { mg }\end{array}$ & $\begin{array}{l}\text { Decompo- } \\
\text { sition, } \\
\%\end{array}$ & $\begin{array}{c}\text { Gas Evolution } \\
\mathrm{cc} \times 10^{-3} \cdot \text { day }^{-1} \\
\cdot \mathrm{cm}^{-2}\end{array}$ \\
\hline BA001 & 4001 & 807 & 43 & 0.77 & (0) & 304L CRES & ACS Diaphragm & -0.4 & 0.02 & 0.01 \\
\hline BA002 & 4002 & 807 & 43 & 0.72 & (0) & $"$ & $"$ & 0.0 & 0.02 & -0.01 \\
\hline BA003 & 4003 & 807 & 43 & 0.99 & (0) & $"$ & $"$ & -0.2 & 0.03 & 0.06 \\
\hline BA004 & 4004 & 807 & 43 & 0.65 & (0) & $"$ & $"$ & -0.1 & 0.01 & -0.01 \\
\hline BA005 & 4005 & 765 & 60 & 1.70 & (0) & $"$ & $"$ & +2.5 & 0.02 & -0.10 \\
\hline BA006 & 4006 & 765 & 60 & 2.85 & (0) & $"$ & $"$ & -0.2 & 0.05 & 0.10 \\
\hline BA007 & 4007 & 765 & 60 & 2.12 & (0) & $"$ & $"$ & 0.0 & 0.04 & -0.03 \\
\hline BA008 & 4008 & 765 & 60 & 3.10 & (0) & $"$ & $"$ & -0.3 & 0.06 & 0.19 \\
\hline BA014 & 4009 & 807 & 43 & 0.89 & (0) & $"$ & Liner/diaphragm, & -0.8 & 0.02 & 0.02 \\
\hline BA015 & 4010 & 807 & 43 & 1.41 & (0) & $"$ & Girth weld & -1.2 & 0.02 & 0.10 \\
\hline BA016 & 4011 & 807 & 60 & 3.25 & (0) & $"$ & $"$ & -0.9 & 0.06 & 0.10 \\
\hline BA017 & 4012 & 765 & 60 & 33.39 & (35.1) & $"$ & $"$ & -0.5 & 0.97 & 3.52 \\
\hline BA023 & 4013 & 378 & 43 & 2.07 & $(5.0)$ & CRES 347 & Burst Disc & -0.4 & 0.12 & 0.74 \\
\hline BA024 & 4014 & 378 & 43 & 2.48 & (0) & $"$ & $"$ & -0.4 & 0.16 & 0.95 \\
\hline BA025 & 4015 & 378 & 60 & 9.81 & (0) & $"$ & $"$ & -0.4 & 0.41 & 3.91 \\
\hline BA026 & 4016 & 378 & 60 & 8.24 & (0) & $"$ & $"$ & -0.1 & 0.35 & 3.14 \\
\hline BA034 & 4017 & 835 & 43 & 1.05 & (0) & 304L CRES & Lee Plug & -0.4 & 0.03 & 0.61 \\
\hline BA035 & 4018 & 835 & 43 & 1.95 & (0) & $"$ & $"$ & -0.3 & 0.04 & 2.40 \\
\hline BA036 & 4019 & 835 & 60 & 10.98 & (5.5) & $"$ & $"$ & +15.5 & 0.26 & 14.10 \\
\hline BA037 & 4020 & 835 & 60 & 3.77 & $(0)$ & $"$ & $"$ & +7.1 & 0.04 & 2.62 \\
\hline BA045 & 4021 & 835 & 43 & 1.12 & (8.0) & $"$ & TIG weld & +0.1 & 0.03 & 0.29 \\
\hline BA046 & 4022 & 835 & 43 & 1.30 & (0) & $"$ & $"$ & -0.3 & 0.04 & 0.33 \\
\hline BA047 & 4023 & 835 & 60 & 2.80 & $(0)$ & $"$ & $"$ & -0.2 & 0.06 & 0.28 \\
\hline BA048 & 4024 & 835 & 60 & 7.44 & (2.5) & $"$ & $"$ & 0.0 & 0.14 & 2.90 \\
\hline BA056 & 4025 & 771 & 43 & 2.73 & (0) & $"$ & EB weld \#407 & -1.0 & 0.09 & 0.44 \\
\hline BA057 & 4026 & 771 & 43 & 6.81 & $(2.1)$ & $"$ & $"$ & -1.0 & 0.25 & 1.18 \\
\hline BA058 & 4027 & 729 & 60 & 49.35 & $(38.6)$ & $"$ & $"$ & -1.1 & 1.40 & 9.00 \\
\hline BA059 & 4028 & 715 & 60 & 35.34 & $(29.6)$ & $"$ & $"$ & -1.2 & 1.09 & 6.22 \\
\hline
\end{tabular}


Table 2. Summary of Analyses and Results (continuation 1)

\begin{tabular}{|c|c|c|c|c|c|c|c|c|c|c|}
\hline & & & & & & & Specimen & & & pellant \\
\hline $\begin{array}{l}\text { BAT } \\
\text { No. }\end{array}$ & $\begin{array}{l}\text { Test } \\
\text { Unit }\end{array}$ & $\begin{array}{l}\text { Days } \\
\text { on } \\
\text { Test }\end{array}$ & $\begin{array}{c}\text { Test } \\
\text { Temp., } \\
\text { oC }\end{array}$ & $\begin{array}{c}\text { Capsule Pressure } \\
\text { at Test Temp., } \\
\mathrm{N} / \mathrm{cm}^{2}\end{array}$ & $\begin{array}{l}\text { (Strain } \\
\text { Gage } \\
\text { Reading) }\end{array}$ & Material & Configuration & $\begin{array}{c}\text { Weight } \\
\text { Change } \\
\text { mg }\end{array}$ & $\begin{array}{c}\text { Decompo- } \\
\text { sition, } \\
\%\end{array}$ & $\begin{array}{c}\text { Gas Evolution } \\
\operatorname{cc} \times 10^{-3} \cdot \text { day }^{-1} \\
\cdot \mathrm{cm}^{-2}\end{array}$ \\
\hline BA068 & 4030 & 771 & 43 & 2.97 & (3.4) & $"$ & $"$ & -0.8 & 0.10 & 0.49 \\
\hline BA069 & 4031 & 757 & 60 & 8.10 & (0) & $"$ & $"$ & $+142.2^{\mathrm{a}}$ & 0.28 & 1.28 \\
\hline BA070 & 4032 & 715 & 60 & 25.15 & (16.5) & $"$ & $"$ & -0.8 & 0.77 & 4.80 \\
\hline BA080 & 4035 & 785 & 60 & 6.17 & (0) & $"$ & $"$ & 0.0 & 0.16 & 0.57 \\
\hline BA081 & 4036 & 785 & 60 & 9.37 & (1.8) & $"$ & $"$ & 0.0 & 0.26 & 1.07 \\
\hline BA300 & 4037 & 807 & 43 & 0.85 & (0) & 304L CRES & Liner & -0.9 & 0.02 & 0.03 \\
\hline BA301 & 4038 & 765 & 43 & b & $(14.0)$ & $"$ & $"$ & +0.5 & - & - \\
\hline BA302 & 4039 & 807 & 43 & 0.70 & (0) & $"$ & $"$ & -0.6 & 0.01 & $<0.01$ \\
\hline BA303 & 4040 & 807 & 43 & 0.74 & (0) & $"$ & $"$ & -1.2 & 0.02 & $<0.01$ \\
\hline BA304 & 4041 & 765 & 60 & c & (0) & $"$ & $"$ & -0.7 & - & - \\
\hline BA101 & 4046 & 245 & 43 & 2.02 & (0) & $"$ & $"$ & -0.3 & 0.15 & 0.68 \\
\hline BA102 & 4047 & 308 & 43 & 1.21 & (0) & $"$ & $"$ & -0.9 & 0.10 & 0.14 \\
\hline BA103 & 4048 & 365 & 43 & 1.02 & (0) & $"$ & $"$ & +0.2 & 0.04 & 0.14 \\
\hline BA109 & 4049 & 245 & 43 & 1.43 & (2:1) & $"$ & TIG weld \#411 & -0.7 & 0.10 & 0.31 \\
\hline BA110 & 4050 & 365 & 43 & 1.74 & (1.0) & $"$ & $"$ & -0.3 & 0.07 & 0.41 \\
\hline BA112 & 4051 & 245 & 43 & 3.04 & (2.8) & A286/304L & TIG weld \#417 & -0.9 & 0.03 & 3.67 \\
\hline BA113 & 4052 & 365 & 43 & 3.57 & (1.5) & $"$ & $"$ & -0.4 & 0.13 & 2.60 \\
\hline BA115 & 4053 & 245 & 43 & 1.31 & (1.7) & $308 \mathrm{~L}$ & Wire & -0.7 & 0.01 & 2.07 \\
\hline BA116 & 4054 & 365 & 43 & 0.99 & (0) & $"$ & $"$ & +0.1 & 0.08 & 0.14 \\
\hline BA118 & 4055 & 220 & 43 & 7.48 & (11.6) & $308 \mathrm{~L} / 304 \mathrm{~L}$ & Liner/diaphragm, & -1.1 & 0.36 & $3.46 \mathrm{~d}$ \\
\hline BA119 & 4056 & 281 & 43 & 11.39 & (10.0) & $"$ & Au-Ni Braze & -0.3 & 0.40 & $5.05^{d}$ \\
\hline BA120 & 4057 & 344 & 43 & 10.53 & (10.7) & $”$ & $"$ & -0.8 & 0.29 & $3.63^{\mathrm{d}}$ \\
\hline
\end{tabular}


Table 2. Summary of Analyses and Results (continuation 2)

\begin{tabular}{|c|c|c|c|c|c|c|c|c|c|c|c|}
\hline \multirow{2}{*}{\multicolumn{2}{|c|}{$\begin{array}{l} \\
\text { BAT } \\
\text { No. }\end{array}$}} & \multirow[b]{2}{*}{$\begin{array}{l}\text { Test } \\
\text { Unit }\end{array}$} & \multirow[b]{2}{*}{$\begin{array}{l}\text { Days } \\
\text { on } \\
\text { Test }\end{array}$} & \multirow[b]{2}{*}{$\begin{array}{l}\text { Test } \\
\text { Temp., } \\
\text { oC }\end{array}$} & \multirow[b]{2}{*}{$\begin{array}{l}\text { Capsule Pressure } \\
\text { at Test Temp., } \\
\quad \mathrm{N} / \mathrm{cm}^{2}\end{array}$} & \multirow[b]{2}{*}{$\begin{array}{l}\text { (Strain } \\
\text { Gage } \\
\text { Reading) }\end{array}$} & \multicolumn{3}{|c|}{ Specimen } & \multicolumn{2}{|l|}{ Propellant } \\
\hline & & & & & & & Material & Configuration & $\begin{array}{c}\text { Weight } \\
\text { Change } \\
\text { mg }\end{array}$ & $\begin{array}{l}\text { Decompo- } \\
\text { sition, } \\
\%\end{array}$ & $\begin{array}{l}\text { Gas Evolution } \\
\mathrm{cc} \times 10^{-3} \cdot \text { day }^{-1} \\
\cdot \mathrm{cm}^{-2}\end{array}$ \\
\hline \multirow{28}{*}{ u } & BA121 & 4058 & 401 & 43 & 29.04 & $(29.1)$ & $308 \mathrm{~L} / 304 \mathrm{~L}$ & Au-Ni Braze & -0.2 & 0.70 & $9.98^{d}$ \\
\hline & BA127 & 4059 & 365 & 43 & 2.70 & $(2.4)$ & Mylar Film & (Specimen Dissolved) & - & 0.16 & $9.15^{\mathrm{e}}$ \\
\hline & BA128 & 4060 & 365 & 43 & 2.44 & (1.4) & $"$ & $"$ & - & 0.09 & $9.43^{\mathrm{e}}$ \\
\hline & BA130 & 4061 & 308 & 43 & 1.61 & (0) & $304 \mathrm{~L}$ & EB weld \#404 & -1.1 & 0.01 & 0.53 \\
\hline & BA131 & 4062 & 340 & 43 & 0.97 & $(0)$ & $"$ & $"$ & -1.3 & 0.08 & 0.05 \\
\hline & BA133 & 4063 & 308 & 43 & 4.67 & $(0)$ & Samarium-Cobalt & Magnet, FEP- & -28.7 & 0.11 & 36.17 \\
\hline & BA134 & 4064 & 365 & 43 & 2.25 & (0) & $"$ & Coated & +0.8 & 0.11 & 10.46 \\
\hline & SE200 & 4065 & 308 & 43 & 2.10 & $(0)$ & 17-4 PH, H1050 & Valve, Electro- & -0.5 & 0.02 & 0.90 \\
\hline & SE201 & 4066 & 365 & 43 & 0.92 & (0) & $"$ & Polished & +0.1 & 0.04 & 0.08 \\
\hline & SE210 & 4067 & 365 & 43 & 0.88 & (3.4) & $"$ & Valve, E.P., & 0.0 & 0.05 & 0.04 \\
\hline & SE211 & 4068 & 184 & 43 & 0.58 & $(0)$ & $"$ & Chrome plated & -1.1 & $<0.05$ & 0.03 \\
\hline & SE220 & 4069 & 184 & 43 & 0.81 & (6.9) & 17-4 PH, CH900 & Spring & -2.4 & $<0.05$ & 0.26 \\
\hline & SE221 & 4070 & 365 & 43 & 1.05 & (5.5) & $"$ & $"$ & +0.6 & 0.05 & 0.16 \\
\hline & SE230 & 4071 & 308 & 43 & 0.56 & (0) & 17-4 PH & Valve, TIG weld & -0.4 & - & 0.01 \\
\hline & SE231 & 4072 & 365 & 43 & 0.76 & (0) & " & $"$ & -0.4 & 0.04 & 0.01 \\
\hline & SC240 & 4073 & 308 & 43 & 1.29 & $(0)$ & Inconel 902 & Bourdon tube & -0.3 & 0.01 & 0.11 \\
\hline & SC241 & 4074 & 365 & 43 & 1.71 & $(0)$ & $"$ & $"$ & -0.8 & 0.08 & 0.10 \\
\hline & BA250 & 4075 & 245 & 43 & 1.04 & (1.7) & 347 & Bar Stock & -1.2 & 0.06 & 0.18 \\
\hline & BA251 & 4076 & 365 & 43 & 1.52 & (0) & $"$ & $"$ & -0.2 & 0.06 & 0.35 \\
\hline & BA260 & 4077 & 245 & 43 & 0.76 & $(4.5)$ & $"$ & Tube, annealed & -0.8 & $<0.01$ & 0.16 \\
\hline & BA261 & 4078 & 365 & 43 & 0.81 & (3.4) & $"$ & " & -0.2 & 0.04 & 0.04 \\
\hline & BA270 & 4079 & 245 & 43 & 1.97 & (3.8) & $"$ & Astro arc weld $\# 78$ & -0.1 & 0.16 & 0.68 \\
\hline & BA271. & 4080 & 365 & 43 & 7.34 & $(2.1)$ & $"$ & $"$ & -0.4 & 0.26 & 3.41 \\
\hline & BA280 & 4081 & 37 & 43 & 27.34 & $(27.5)$ & EPR 515 & "O" Ring, & +2.1 & 0.93 & $416.3^{f}$ \\
\hline & BA281 & 4082 & 65 & 43 & 44.07 & $(44.0)$ & " & Krytox Coated & +3.5 & 1.62 & $370.0^{f}$ \\
\hline & \multicolumn{6}{|c|}{${ }^{a}$ Probable error in pretest weighing. } & \multicolumn{5}{|c|}{$\mathrm{d}_{\text {Rate of decomposition is proportional to the area of exposed gold-nickel braze. }}$} \\
\hline & \multicolumn{6}{|c|}{${ }^{b} C_{\text {apsule tip had microscopic leak; gas data meaningless. }}$} & \multicolumn{5}{|c|}{${ }^{e}$ Mylar film dissolved in propellant; area rate is not relevant. } \\
\hline & \multicolumn{6}{|c|}{${ }^{\mathrm{c}}$ Capsule broke in breaker fixture; gas lost. } & \multicolumn{5}{|c|}{$\begin{array}{l}\text { Decomposition catalyzed by carbon black used in compounding; area rate values } \\
\text { are meaningless. }\end{array}$} \\
\hline
\end{tabular}


Table 3. Details of Analyses and Results

\begin{tabular}{|c|c|c|c|c|c|c|c|c|c|c|c|c|}
\hline \multirow[b]{4}{*}{$\begin{array}{l}\text { BAT } \\
\text { No. }\end{array}$} & \multirow[b]{4}{*}{$\begin{array}{l}\text { Test } \\
\text { Unit }\end{array}$} & \multirow{3}{*}{\multicolumn{2}{|c|}{ Specimen Weight }} & \multirow{2}{*}{\multicolumn{4}{|c|}{ Analysis of Propellant ${ }^{a, b}$}} & \multicolumn{5}{|c|}{ Noncondensable Gas $\left(\mathrm{N}_{2}+\mathrm{H}_{2}\right)$} \\
\hline & & & & & & & & \multirow[b]{3}{*}{$\begin{array}{l}\text { Total } \\
\text { cc STP }\end{array}$} & \multicolumn{2}{|l|}{ Rate } & \multirow{3}{*}{$\begin{array}{c}\text { Specimen } \\
\text { Surface Area } \\
\mathrm{cm}^{2}\end{array}$} & \multirow[b]{3}{*}{$\begin{array}{c}\text { Area Rate } \\
\mathrm{cc} \times 10^{-3} \cdot \text { day }^{-1} \cdot \mathrm{cm}^{-2}\end{array}$} \\
\hline & & & & \multicolumn{2}{|c|}{$\mathrm{Fe}$} & \multirow[b]{2}{*}{$\underset{\%}{\mathrm{H}_{2} \mathrm{O}}$} & \multirow[b]{2}{*}{$\underset{\%}{\mathrm{NH}_{3}}$} & & \multirow[b]{2}{*}{$\begin{array}{l}\text { Uncorrected } \\
\text { cc } \times 10^{-3} \cdot \text { day }^{-1}\end{array}$} & \multirow{2}{*}{$\begin{array}{c}\text { Corrected } \\
\text { for Control } \\
\text { cc } \times 10^{-3} \cdot \text { day }^{-1}\end{array}$} & & \\
\hline & & $\begin{array}{l}\text { Initial } \\
\mathbf{g}\end{array}$ & $\begin{array}{l}\text { Change } \\
\text { g }\end{array}$ & mg & ppm & & & & & & & \\
\hline BA001 & 4001 & 1.8307 & -0.0004 & $<0.02$ & $<0.5$ & 0.63 & 0.02 & 0.67 & 0.83 & 0.16 & 19.4773 & 0.01 \\
\hline BA002 & 4002 & 1.8808 & 0.0000 & $<0.02$ & $<0.5$ & 0.66 & 0.02 & 0.45 & 0.56 & -0.11 & 19.4926 & -0.01 \\
\hline BA003 & 4003 & 1.8674 & -0.0002 & $<0.02$ & $<0.5$ & 0.66 & 0.02 & 1.51 & 1.87 & 1.20 & 19.4926 & 0.06 \\
\hline BA004 & 4004 & 1.8745 & -0.0001 & $<0.02$ & $<0.5$ & 0.68 & 0.01 & 0.39 & 0.48 & -0.19 & 19.4773 & -0.01 \\
\hline BA005 & 4005 & 1.8774 & +0.0025 & $<0.02$ & $<0.5$ & 0.68 & 0.01 & 1.59 & 2.08 & -1.92 & 19.4621 & -0.10 \\
\hline BA006 & 4006 & 1.8189 & -0.0002 & $<0.02$ & $<0.5$ & 0.65 & 0.03 & 4.60 & 6.01 & 2.01 & 19.4926 & 0.10 \\
\hline BA007 & 4007 & 1.8308 & 0.0000 & $<0.02$ & $<0.5$ & 0.84 & 0.03 & 2.58 & 3.37 & -0.63 & 19.4926 & -0.03 \\
\hline BA008 & 4008 & 1.8121 & -0.0003 & $<0.02$ & $<0.5$ & 0.65 & 0.04 & 5.88 & 7.69 & 3.69 & 19.4773 & 0.19 \\
\hline BA014 & 4009 & 17.9183 & -0.0008 & $-\mathbf{c}$ & & 0.58 & 0.02 & 1.15 & 1.43 & 0.76 & 36.55 & 0.02 \\
\hline BA015 & 4010 & 19.7705 & -0.0012 & - & & 2.95 & 0.01 & 3.52 & 4.36 & 3.69 & 37.59 & 0.10 \\
\hline BA016 & 4011 & 20.5209 & -0.0009 & - & & 0.56 & 0.04 & 6.57 & 8.14 & 4.14 & 39.57 & 0.10 \\
\hline BA017 & 4012 & 19.8750 & -0.0005 & 0.125 & 3.1 & 0.86 & 0.60 & 110.57 & 144.54 & 140.54 & 39.92 & 3.52 \\
\hline BA023 & 4013 & 10.5977 & -0.0004 & 0.02 & 0.5 & 0.63 & 0.10 & 6.17 & 16.32 & 15.65 & 21.1697 & 0.74 \\
\hline BA024 & 4014 & 9.8477 & -0.0004 & 0.02 & 0.5 & 0.50 & 0.14 & 7.69 & 20.34 & 19.67 & 20.7925 & 0.95 \\
\hline BA025 & 4015 & 10.4620 & -0.0004 & 0.02 & 0.5 & 0.62 & 0.32 & 32.86 & 86.93 & 82.93 & 21.2021 & 3.91 \\
\hline BA026 & 4016 & 10.5614 & -0.0001 & 0.02 & 0.5 & 0.70 & 0.27 & 28.31 & 74.89 & 70.89 & 22.5703 & 3.14 \\
\hline BA034 & 4017 & 0.6948 & -0.0004 & $<0.02$ & $<0.5$ & 0.52 & 0.02 & 1.95 & 2.34 & 1.67 & 2.7429 & 0.61 \\
\hline BA035 & 4018 & 0.6995 & -0.0003 & $<0.02$ & $<0.5$ & 8.21 & 0.02 & 5.99 & 7.17 & 6.50 & 2.7040 & 2.40 \\
\hline BA036 & 4019 & 0.6989 & +0.0155 & $<0.02$ & $<0.5$ & 0.76 & 0.16 & 35.60 & 42.63 & 38.63 & 2.7392 & 14.10 \\
\hline BA037 & 4020 & 0.7015 & +0.0071 & $<0.02$ & $<0.5$ & 0.71 & 0.02 & 9.27 & 11.10 & 7.10 & 2.7068 & 2.62 \\
\hline BA045 & 4021 & 2.0661 & +0.0001 & $<0.02$ & $<0.5$ & 0.57 & 0.02 & 2.18 & 2.61 & 1.94 & 6.61 & 0.29 \\
\hline BA046 & 4022 & 2.1141 & -0.0003 & $<0.02$ & $<0.5$ & 2.33 & 0.03 & 2.50 & 2.99 & 2.32 & 7.04 & 0.33 \\
\hline BA047 & 4023 & 2.1348 & -0.0002 & $<0.02$ & $<0.5$ & 0.93 & 0.04 & 5.01 & 6.00 & 2.00 & 7.03 & 0.28 \\
\hline BA048 & 4024 & 2.0952 & 0.0000 & $<0.02$ & $<0.5$ & 0.90 & 0.08 & 19.80 & 23.71 & 19.71 & 6.80 & 2.90 \\
\hline BA056 & 4025 & 11.9468 & -0.0010 & $<0.02$ & $<0.5$ & 1.03 & 0.06 & 7.86 & 10.19 & 9.52 & 21.75 & 0.44 \\
\hline BA057 & 4026 & 12.4409 & -0.0010 & $<0.02$ & $<0.5$ & 1.21 & 0.18 & 20.57 & 26.68 & 26.01 & 22.06 & 1.18 \\
\hline BA058 & 4027 & 12.3262 & -0.0011 & 0.050 & 1.3 & 0.70 & 0.89 & 155.32 & 201.45 & 197.45 & 21.93 & 9.00 \\
\hline BA059 & 4028 & 12.3092 & -0.0012 & 0.125 & 3.1 & 0.86 & 0.74 & 108.45 & 140.66 & 136.66 & 21.96 & 6.22 \\
\hline BA067 & 4029 & 10.5426 & -0.0007 & - & & 0.81 & 0.01 & 2.76 & 3.58 & 2.91 & 21.42 & 0.14 \\
\hline
\end{tabular}


Table 3. Details of Analyses and Results (continuation 1)

\begin{tabular}{|c|c|c|c|c|c|c|c|c|c|c|c|c|}
\hline \multirow[b]{3}{*}{$\begin{array}{l}\text { BAT } \\
\text { No. }\end{array}$} & \multirow[b]{3}{*}{$\begin{array}{l}\text { Test } \\
\text { Unit }\end{array}$} & & & \multirow{2}{*}{\multicolumn{4}{|c|}{ Analysis of Propellant $t^{a, b}$}} & \multicolumn{5}{|c|}{ Noncondensable Gas $\left(\mathrm{N}_{2}+\mathrm{H}_{2}\right)$} \\
\hline & & \multicolumn{2}{|c|}{ Specimen Weight } & & & & & \multicolumn{3}{|c|}{ Rate } & \multirow{2}{*}{$\begin{array}{c}\text { Specimen } \\
\text { Surface Area } \\
\mathrm{cm}^{2}\end{array}$} & \multirow[b]{2}{*}{$\begin{array}{l}\text { Area Rate } \\
\operatorname{cc} \times 10^{-3} \cdot \text { day }^{-1} \cdot \mathrm{cm}^{-2}\end{array}$} \\
\hline & & $\begin{array}{l}\text { Initial } \\
\mathbf{g}\end{array}$ & $\begin{array}{l}\text { Change } \\
\text { g }\end{array}$ & mg & ppm & $\underset{\%}{\mathrm{H}_{2} \mathrm{O}}$ & $\underset{\%}{\mathrm{NH}_{3}}$ & $\begin{array}{l}\text { Total } \\
\text { cc STP }\end{array}$ & $\begin{array}{c}\text { Uncorrected } \\
\operatorname{cc} \times 10^{-3} \cdot \text { day }^{-1}\end{array}$ & $\begin{array}{c}\text { Corrected } \\
\text { for Control } \\
\operatorname{cc} \times 10^{-3} \cdot \text { day }^{-1}\end{array}$ & & \\
\hline BA068 & 4030 & 11.2825 & -0.0008 & - & & 0.98 & 0.07 & 8.50 & 11.02 & 10.35 & 21.05 & 0.49 \\
\hline BA069 & 4031 & 11.6180 & $+0.1422^{d}$ & - & & 0.86 & 0.20 & 24.00 & 31.70 & 27.70 & 21.59 & 1.28 \\
\hline BA070 & 4032 & 11.5931 & -0.0008 & $<0.02$ & $<0.5$ & 0.92 & 0.52 & 76.87 & 107.51 & 103.51 & 21.56 & 4.80 \\
\hline BA078 & 4033 & 5.5458 & -0.0004 & $<0.02$ & $<0.5$ & 1.18 & 0.02 & 1.66 & 2.08 & 1.41 & 26.8885 & 0.05 \\
\hline BAC79 & 4034 & 5.6452 & 0.0000 & $<0.02$ & $<0.5$ & 1.26 & 0.02 & 0.99 & 1.24 & 0.57 & 28.3715 & 0.02 \\
\hline BA080 & 4035 & 5.6520 & 0.0000 & $<0.02$ & $<0.5$ & 0.52 & 0.11 & 15.23 & 19.40 & 15.40 & 27.0450 & 0.57 \\
\hline BA081 & 4036 & 5.5455 & 0.0000 & $<0.02$ & $<0.5$ & 0.55 & 0.18 & 26.42 & 33.66 & 29.66 & 27.7521 & 1.07 \\
\hline BA300 & 4037 & 5.2560 & -0.0009 & $<0.02$ & $<0.5$ & 0.80 & 0.02 & 1.06 & 1.31 & 0.64 & 20.0694 & 0.03 \\
\hline BA301 & 4038 & 4.9612 & +0.0005 & $<0.02$ & $<0.5$ & 0.65 & 0.04 & - & - & - & 20.0753 & - \\
\hline BA302 & 4039 & 4.3396 & -0.0006 & - & & 0.84 & 0.01 & 0.61 & 0.76 & 0.09 & 20.0754 & $<0.01$ \\
\hline BA303 & 4040 & 4.8056 & -0.0012 & - & & 1.56 & 0.02 & 0.55 & 0.68 & 0.01 & 20.1092 & $<0.01$ \\
\hline BA304 & 4041 & 5.1021 & -0.0007 & $<0.02$ & $<0.5$ & 0.83 & 0.04 & $-\mathbf{f}$ & - & - & 20.2661 & - \\
\hline BA305 & 4042 & 5.2821 & +0.0006 & 0.02 & 0.5 & 0.65 & 0.02 & 9.37 & 12.25 & 8.25 & 20.3587 & 0.41 \\
\hline BA306 & 4043 & 5.0690 & 0.0000 & $<0.02$ & $<0.5$ & 0.62 & 0.05 & 7.91 & 10.34 & 6.34 & 20.2475 & 0.31 \\
\hline BA307 & 4044 & 5.0142 & -0.0005 & $<0.02$ & $<0.5$ & 0.70 & 0.03 & 4.36 & 5.70 & 1.70 & 20.0859 & 0.08 \\
\hline BA100 & 4045 & 8.3294 & -0.0007 & - & & - & $<0.05$ & 0.63 & 3.42 & 2.75 & 21.2098 & 0.13 \\
\hline BA101 & 4046 & 8.3596 & -0.0003 & - & & - & 0.14 & 3.67 & 14.98 & 14.31 & 21.1961 & 0.68 \\
\hline BA102 & 4047 & 8.3758 & -0.0009 & - & & - & 0.10 & 1.10 & 2.90 & 2.90 & 21.1961 & 0.14 \\
\hline BA103 & 4048 & 8.3975 & +0.0002 & - & & - & 0.04 & 1.33 & 3.64 & 2.97 & 21.1825 & 0.14 \\
\hline BA109 & 4049 & 15.0951 & -0.0007 & - & & - & 0.10 & 1.97 & 8.04 & 7.37 & 23.9895 & 0.31 \\
\hline BA110 & 4050 & 14.6483 & -0.0003 & - & & - & 0.06 & 3.95 & 10.82 & 10.15 & 24.7093 & 0.41 \\
\hline BA112 & 4051 & 4.6890 & -0.0009 & - & & - & $<0.05$ & 9.32 & 38.04 & 37.37 & 10.1851 & 3.67 \\
\hline BA113 & 4052 & 4.7486 & -0.0004 & - & & - & 0.10 & 9.85 & 26.99 & 26.32 & 10.1216 & 2.60 \\
\hline BA115 & 4053 & 2.7318 & -0.0007 & - & & - & $<0.05$ & 3.15 & 12.86 & 12.19 & 5.8837 & 2.07 \\
\hline BA116 & 4054 & 2.7818 & +0.0001 & - & & - & 0.08 & 0.55 & 1.51 & 0.84 & 5.9570 & 0.14 \\
\hline BA118 & 4055 & 6.0872 & -0.0011 & - & & - & 0.30 & 21.89 & 99.50 & 98.83 & 28.58 & $3.46^{\mathrm{g}}$ \\
\hline BA119 & 4056 & 5.9381 & -0.0003 & - & & - & 0.29 & 38.47 & 136.90 & 136.23 & 27.00 & $5.05^{g}$ \\
\hline BA120 & 4057 & 5.8159 & -0.0008 & - & & - & 0.18 & 34.54 & 100.41 & 99.74 & 27.45 & $3.63^{\mathrm{g}}$ \\
\hline BA121 & 4058 & 5.8271 & -0.0002 & 0.020 & 0.5 & - & 0.08 & 110.08 & 274.51 & 273.84 & 27.45 & $9.98^{g}$ \\
\hline
\end{tabular}


Table 3. Details of Analyses and Results (continuation 2)

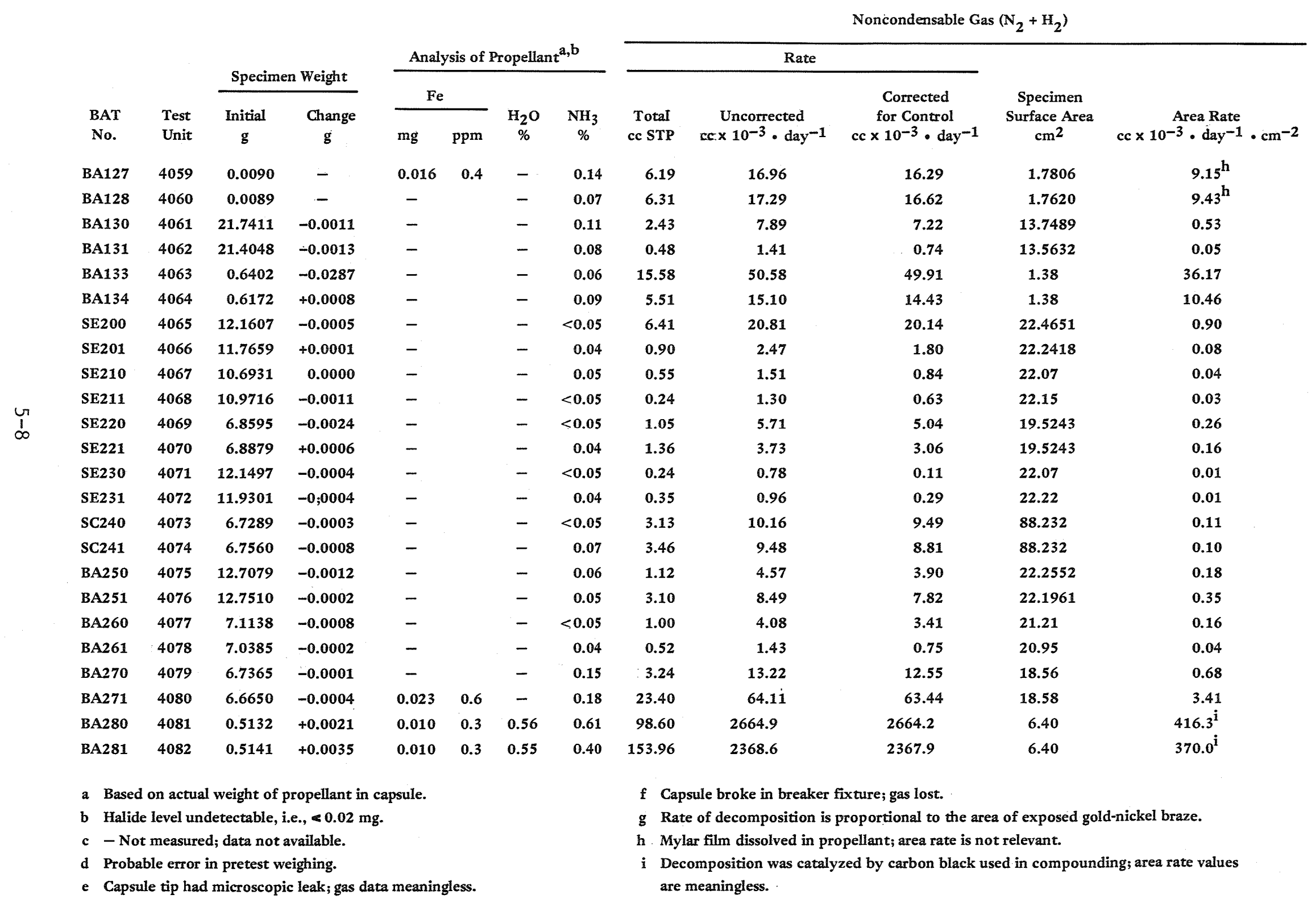


Table 4. Summary of Analysis of Hydrazine Controls

\begin{tabular}{|c|c|c|c|c|c|c|c|c|c|c|}
\hline & & & & & & & & opellant $^{a}$ & & \\
\hline & & & & & & & & & Condensable Gas $\left(\mathrm{N}_{2}\right.$ & \\
\hline $\begin{array}{l}\text { Test } \\
\text { Unit }\end{array}$ & $\begin{array}{l}\text { Days on } \\
\text { Test }\end{array}$ & $\begin{array}{c}\text { Test } \\
\text { Temp., } \\
{ }^{\circ} \mathrm{C}\end{array}$ & $\begin{array}{c}\text { Capsule Pressure } \\
\text { at Test Temp., } \\
\text { N/cm }\end{array}$ & $\begin{array}{l}\text { (Strain } \\
\text { Gage } \\
\text { Reading) }\end{array}$ & $\underset{\%}{\mathrm{H}_{2} \mathrm{O}}$ & $\begin{array}{c}\mathrm{NH}_{3}, \\
\%\end{array}$ & $\begin{array}{c}\text { Decomposition, } \\
\%\end{array}$ & $\begin{array}{l}\text { Total } \\
\text { cc STP }\end{array}$ & $\operatorname{cc} \times 10^{-3} \cdot$ day $^{-1}$ & Average \\
\hline 4100 & 220 & 43 & 0.81 & (6.0) & $-^{c}$ & $<0.05$ & $<0.05$ & 1.03 & $4.68^{f}$ & \\
\hline 4101 & 365 & 43 & 0.75 & (0) & 0.74 & 0.04 & 0.04 & 0.26 & 0.71 & \\
\hline 4102 & 549 & 43 & - & (0) & 0.72 & 0.02 & - & $-d$ & - & \\
\hline 4106 & 729 & 43 & - & (0) & 0.70 & 0.01 & - & $<0.25^{\mathrm{e}}$ & - & \\
\hline 4108 & 729 & 43 & 0.67 & (0) & 0.71 & 0.01 & 0.01 & 0.45 & 0.62 & 0.67 \\
\hline 4103 & 220 & 60 & $<1.0$ & (0) & - & $<0.05$ & $<0.01$ & 2.08 & $9.45^{\mathrm{f}}$ & \\
\hline 4104 & 401 & 60 & 2.21 & (0) & 0.56 & 0.10 & 0.11 & 1.26 & 3.14 & \\
\hline 4105 & 547 & 60 & 2.00 & (0) & 0.72 & 0.02 & 0.03 & 2.45 & 4.48 & \\
\hline 4107 & 729 & 60 & 1.71 & (0) & 1.55 & 0.01 & 0.02 & 2.82 & 3.87 & \\
\hline 4109 & 729 & 60 & 2.17 & (0) & 0.65 & 0.01 & 0.02 & 3.25 & 4.46 & 4.00 \\
\hline${ }^{a_{B a s e d}}$ & on $40.0 \mathrm{cc} \mathrm{hy}$ & azine. & & & & & & & & \\
\hline $\mathbf{b}_{\text {Metal }}$ & and halides $u$ & letectable. & & & & & & & & \\
\hline$c_{-N o}$ & measured; da & not availa & & & & & & & & \\
\hline${ }^{d}{ }_{\text {Caps }}$ & broke in tes & fixture; ga & & & & & & & & \\
\hline$e_{\text {Insuf }}$ & cient quantit & f gas to $\mathrm{m}$ & ure. & & & & & & & \\
\hline $\mathrm{f}_{\text {Val }}$ & inglo & & & & & & & & & \\
\hline
\end{tabular}


1. Moran, C. M., Coupon Test Program to Evaluate Decomposition of Hydrazine by Metallic Components of Propellant Tanks, Interim Report for Program 'A' July 1979 to August 1981, JPL Document 715-139, Jet Propulsion Laboratory, Pasadena, California, October 1, 1981 (JPL internal document).

2. Toth, L., et. a1., Propellant Material Compatibility Program and Results, Technical Memorandum 33-779, Jet Propulsion Laboratory, Pasadena, California, August 15, 1976.

3. Moran, C. M., and Bjorklund, R. A., Propellant/Material Compatibility Program and Results, Ten-Year Milestone, JPL Publication 82-62, Jet Propulsion Laboratory, Pasadena, California, Ju1y 15, 1982.

4. Material Specification, Anhydrous Hydrazine for the HAS System, Report 8803-947047, Revision A, Bell Aerospace Textron, Buffalo, New York, undated.

5. Chang, E. T., et a1., Solubilities of $\mathrm{NH}_{3}, \mathrm{CO}, \mathrm{CO}_{2}$, and $\mathrm{SF}_{6}$ in Liquid Propellants, The Aerospace Corp., El Segundo, Calif., Air Force Report SAMSO-TR-71-17, November 1970.

6. Adams, R. 0., "Review of the Stainless Steel Surface," Journal of Vacuum Science Technology, Vo1. 1, No. 12, 1983. 
The pretest analysis of Drum 48367 indicated a very high purity which even meets the requirements of the current MIL-P 26536C, Amendment 2, High Purity Grade. The drum was from JPL's supply of hydrazine at ETS and was chosen because of the low $\mathrm{CO}_{2}$ content. The full pretest analysis is presented in the report form contained in this appendix.

The handling of the propellant during the filling operation, and the process of removing it after completion of the storage period, can influence the $\mathrm{CO}_{2}$ content through inadvertent exposure to air. A special test capsule was designated as a $\mathrm{CO}_{2}$ control capsule. It was filled as part of a regular series of capsules being processed. After freezing and thawing, this contro1 capsule was opened and the propellant removed by the standard procedure. The $\mathrm{CO}_{2}$ content was determined to be $15 \mathrm{ppm}$, slightly higher than the $9 \mathrm{ppm}$ in the original hydrazine, but considerably lower than the $30 \mathrm{ppm}$ limit in the above-mentioned military specification. Although this determination was not normally part of the posttest procedure, two other test units were analyzed for $\mathrm{CO}_{2}$ : 4081 contained $5 \mathrm{ppm} \mathrm{CO} 2 ; 4082$ contained $19 \mathrm{ppm} \mathrm{CO}_{2}$.

The data from these three capsules indicated that the procedures employed in filling the capsule were adequate to maintain the desired 1 ow $\mathrm{CO}_{2}$ content. The greatest risk for exposure to air occurs during the opening of the capsule and removal and transfer of the hydrazine to the analysis vial. 


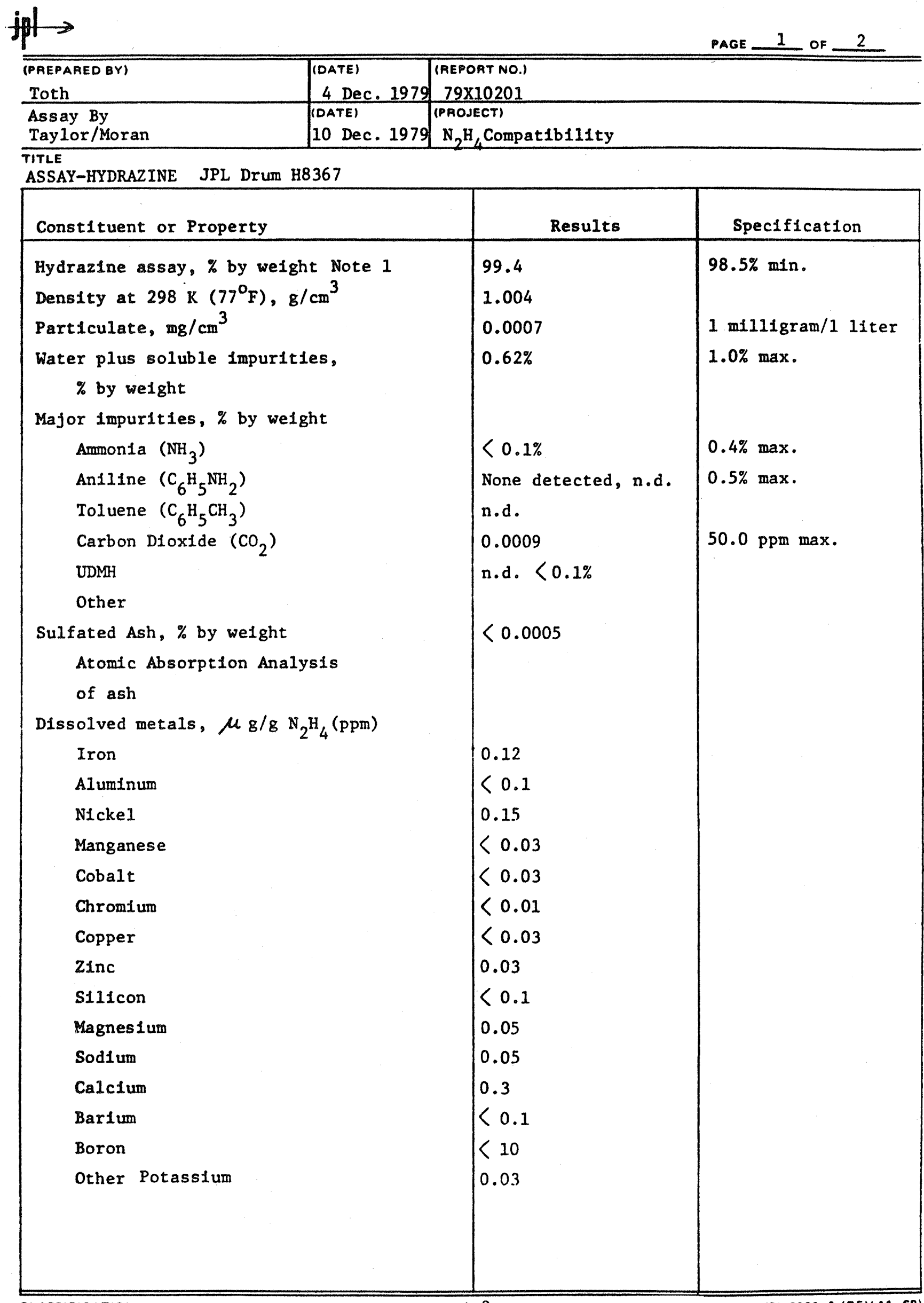




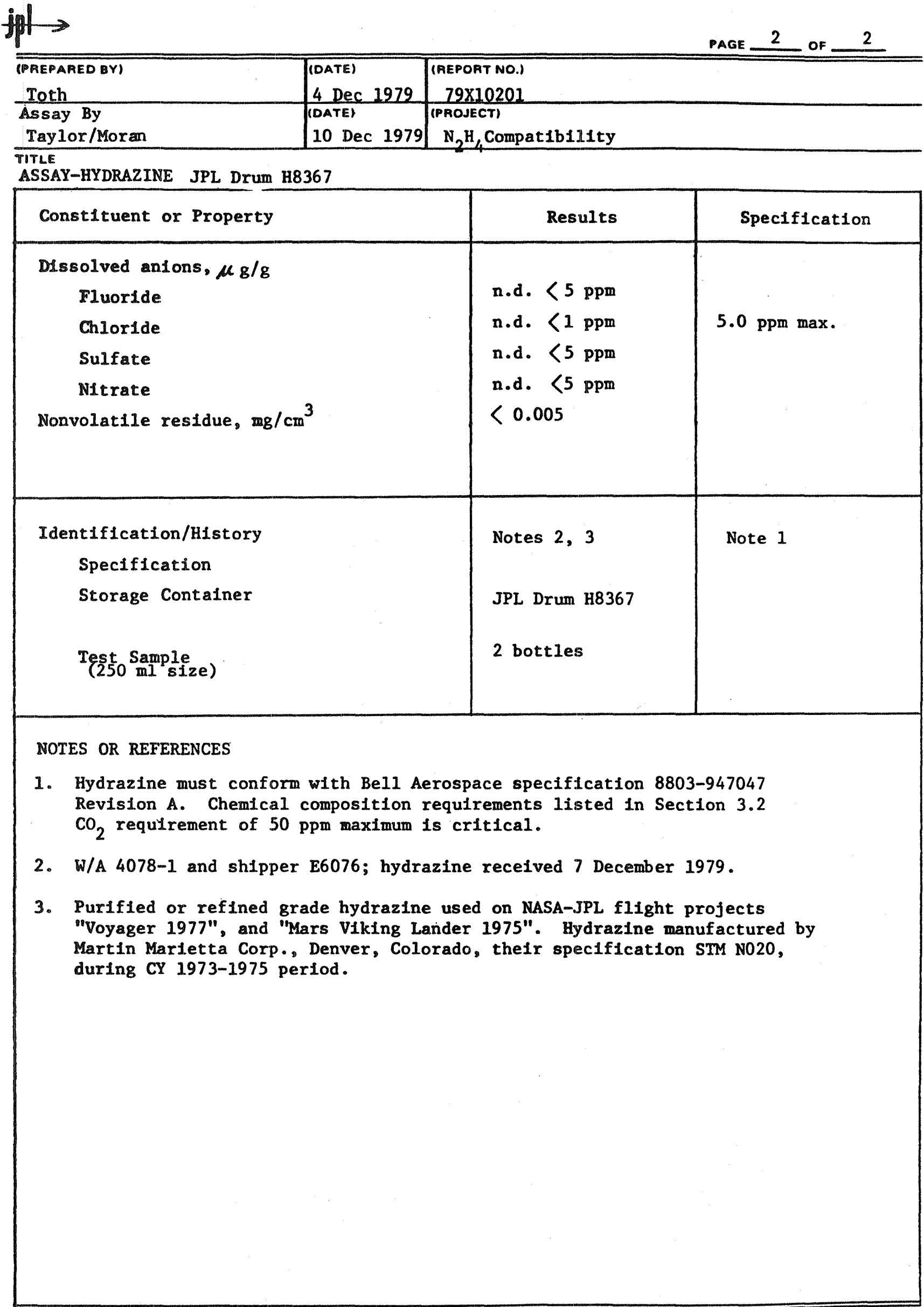




\section{APPENDIX B}

DETAILED LOGS OF ALL TEST UNITS

Log I is a listing of specimens grouped by specimen (BAT) numbers and test unit (JPL) numbers in ascending order. The "Material Description" column also lists the CPR number and the material scheduled for storage. The "Test Duration" column under "Ce11" gives the dates of storage at test temperature. The "Refrigeration" column lists the dates for posttest storage in the freezer before analysis. The "Analysis Document" column lists the JPL internal memoranda reporting results of analysis. The "Remark" column lists test temperature $\left(43^{\circ} \mathrm{C}\right.$ unless otherwise noted), and other information.

Log II is a listing of specimens by ascending capsule number. The "Capsule" column also includes the total internal volume of each capsule. The "Material Description" column lists the date and time of capsule filling. The capsules were then kept in a freezer until the date shown in the "Ce11"

column, i.e., the beginning of the storage at test temperature. The "Remarks" column lists the volume of hydrazine placed in each capsule. 


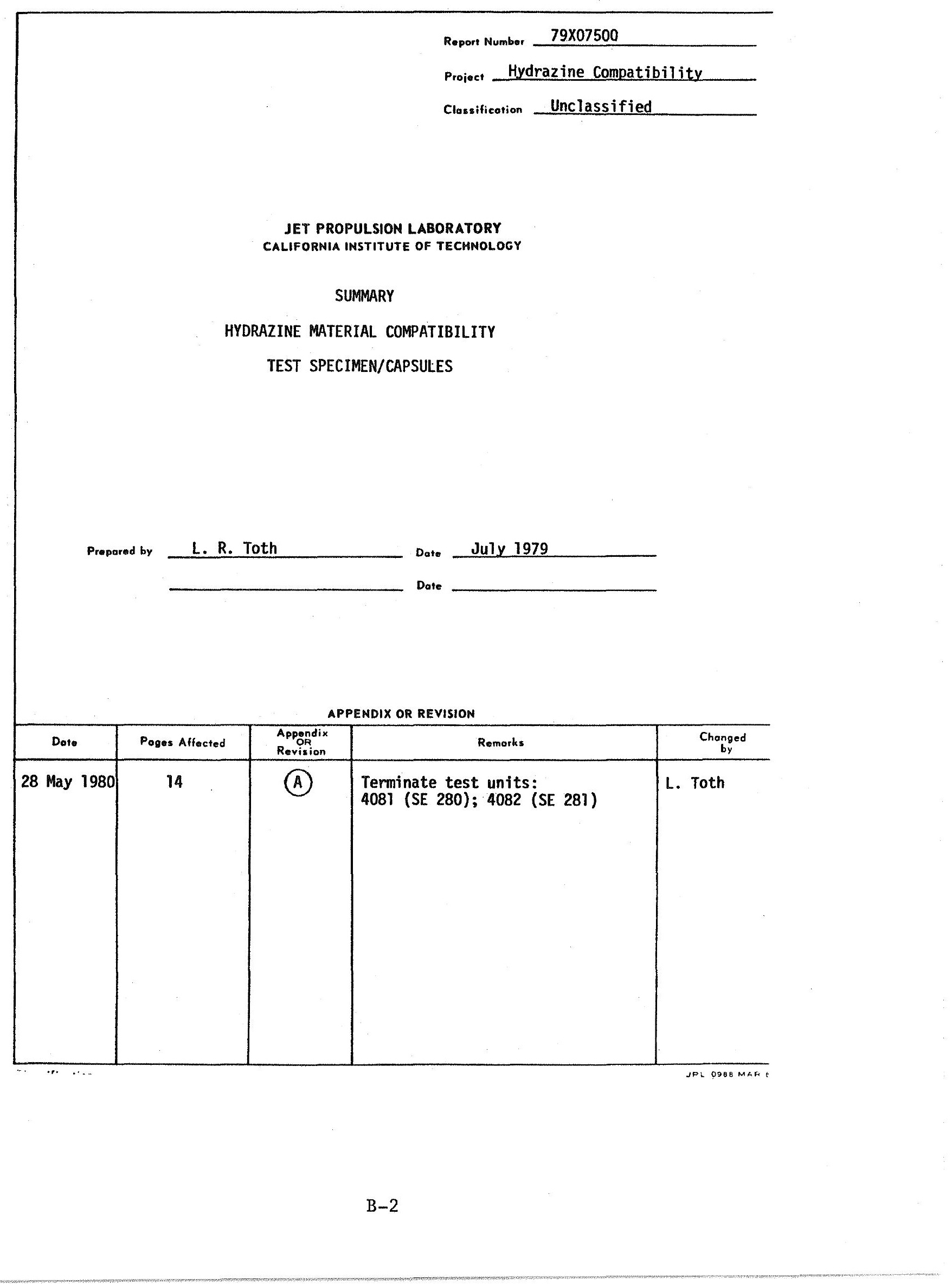




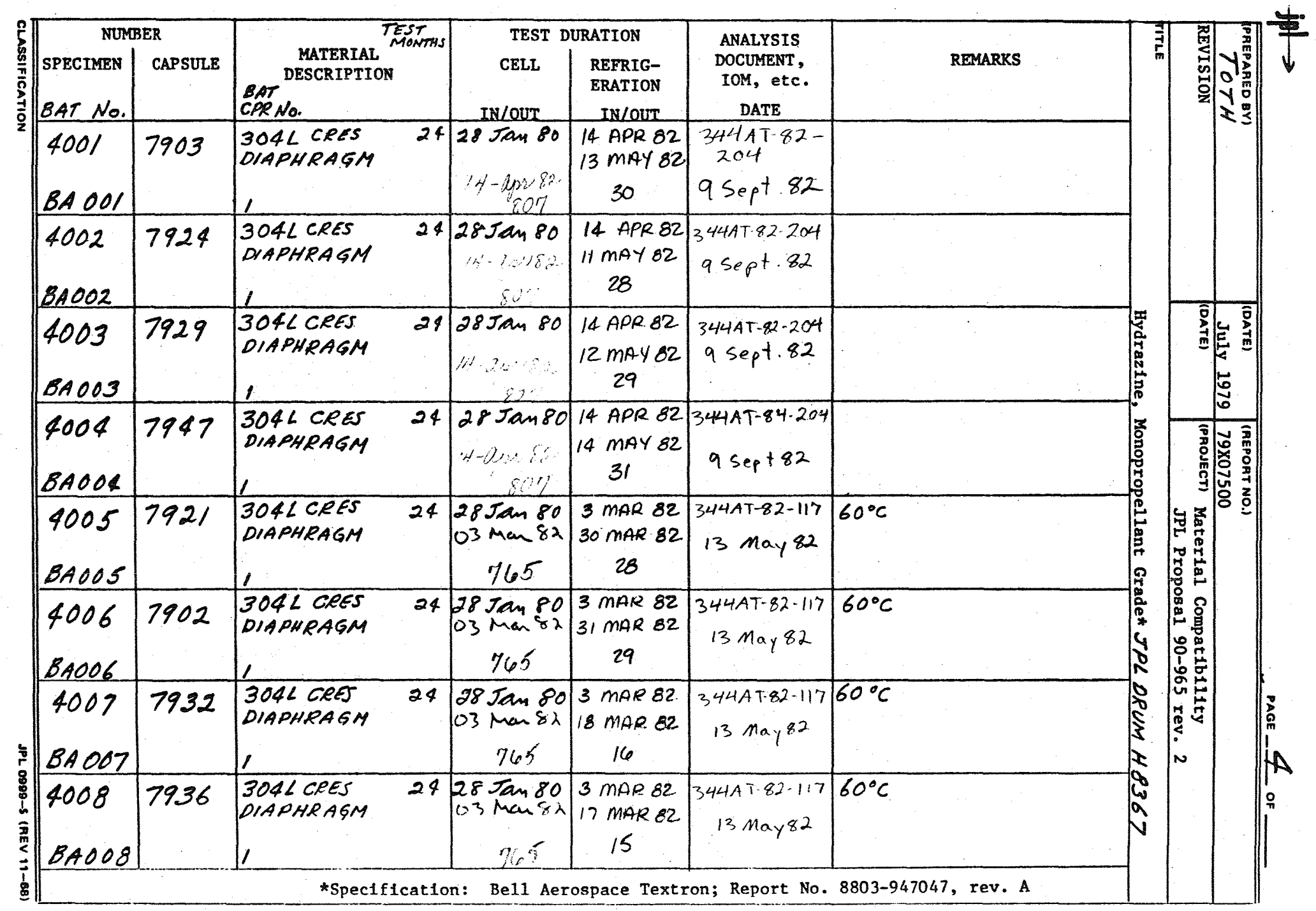




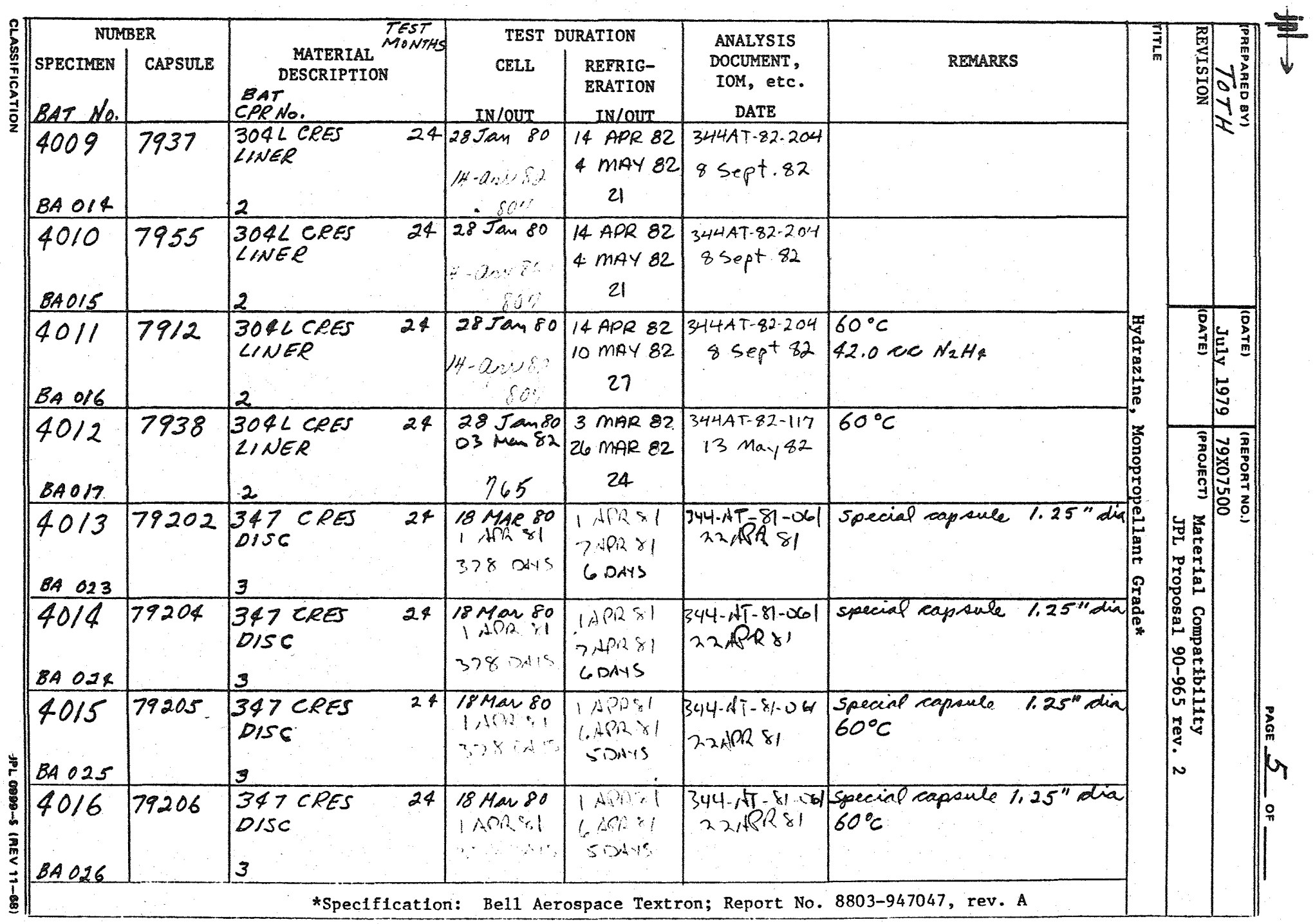




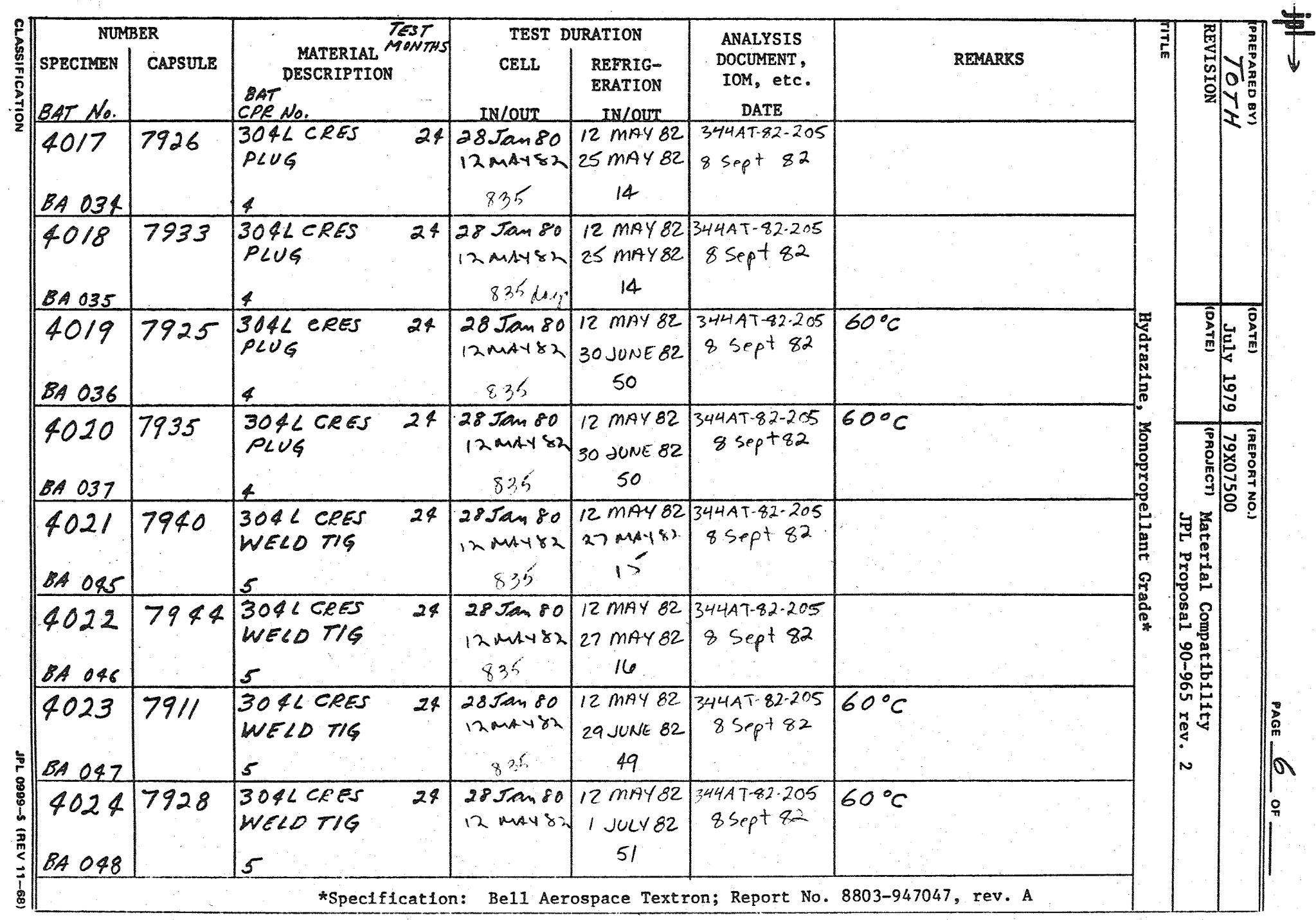




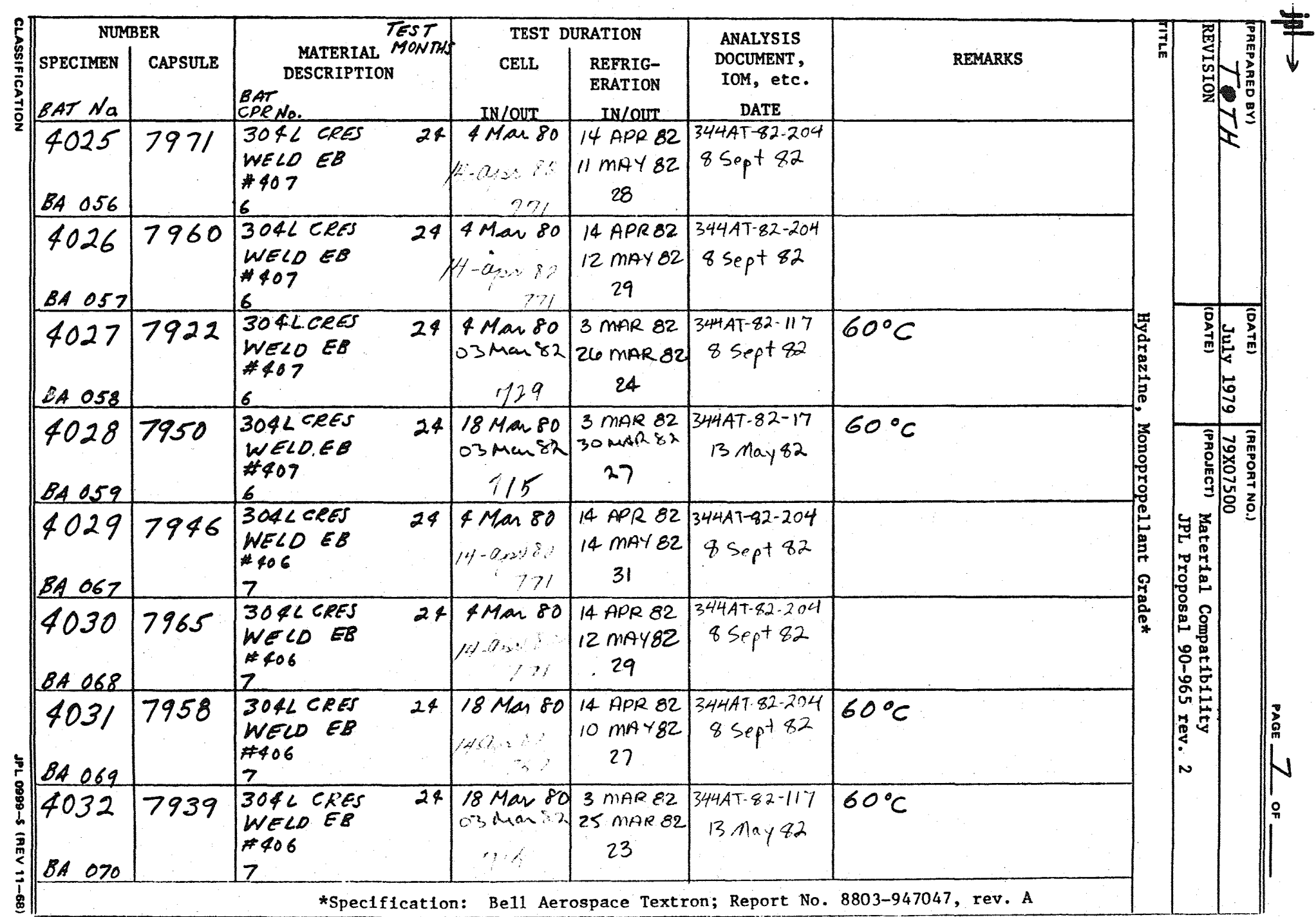




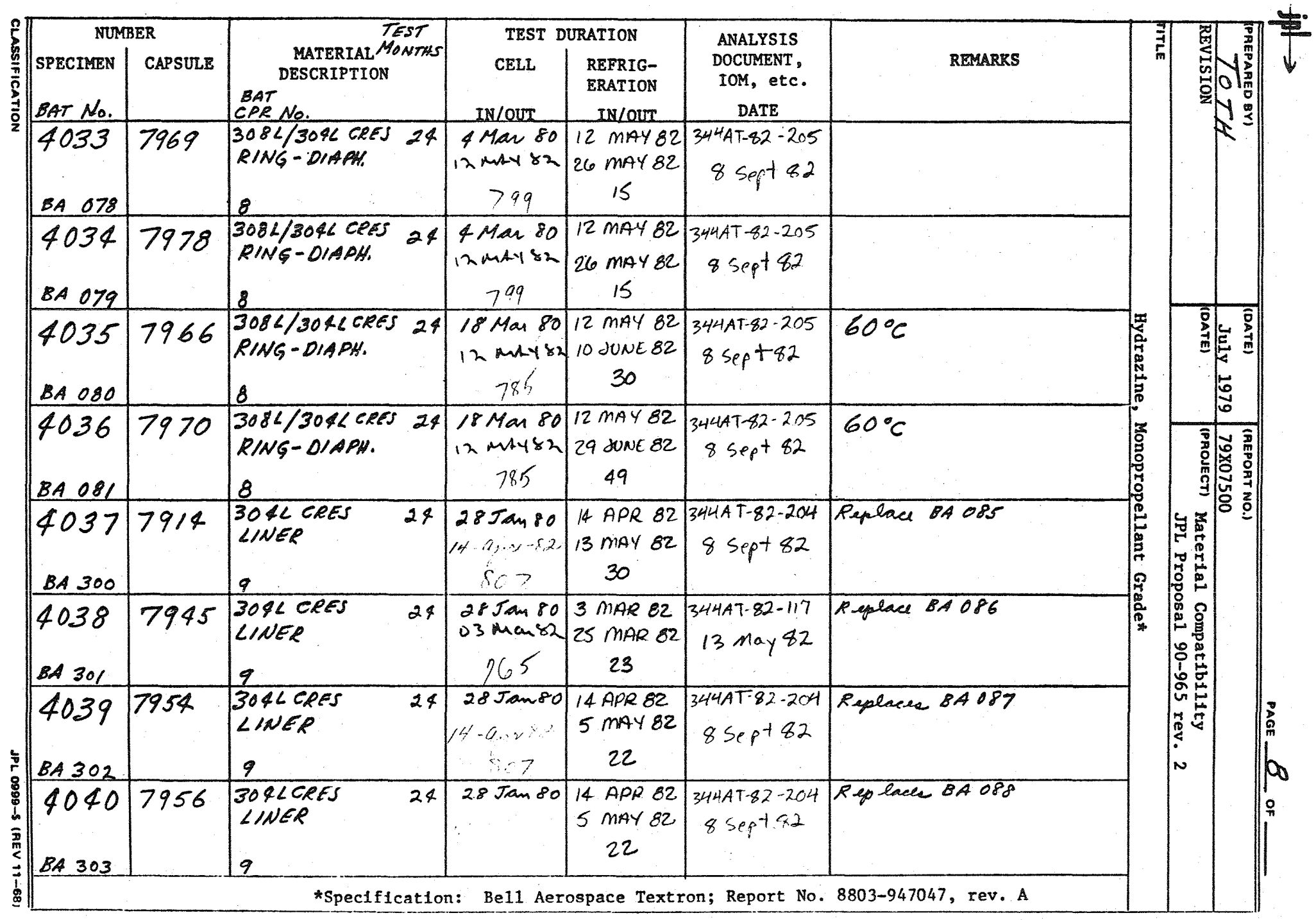




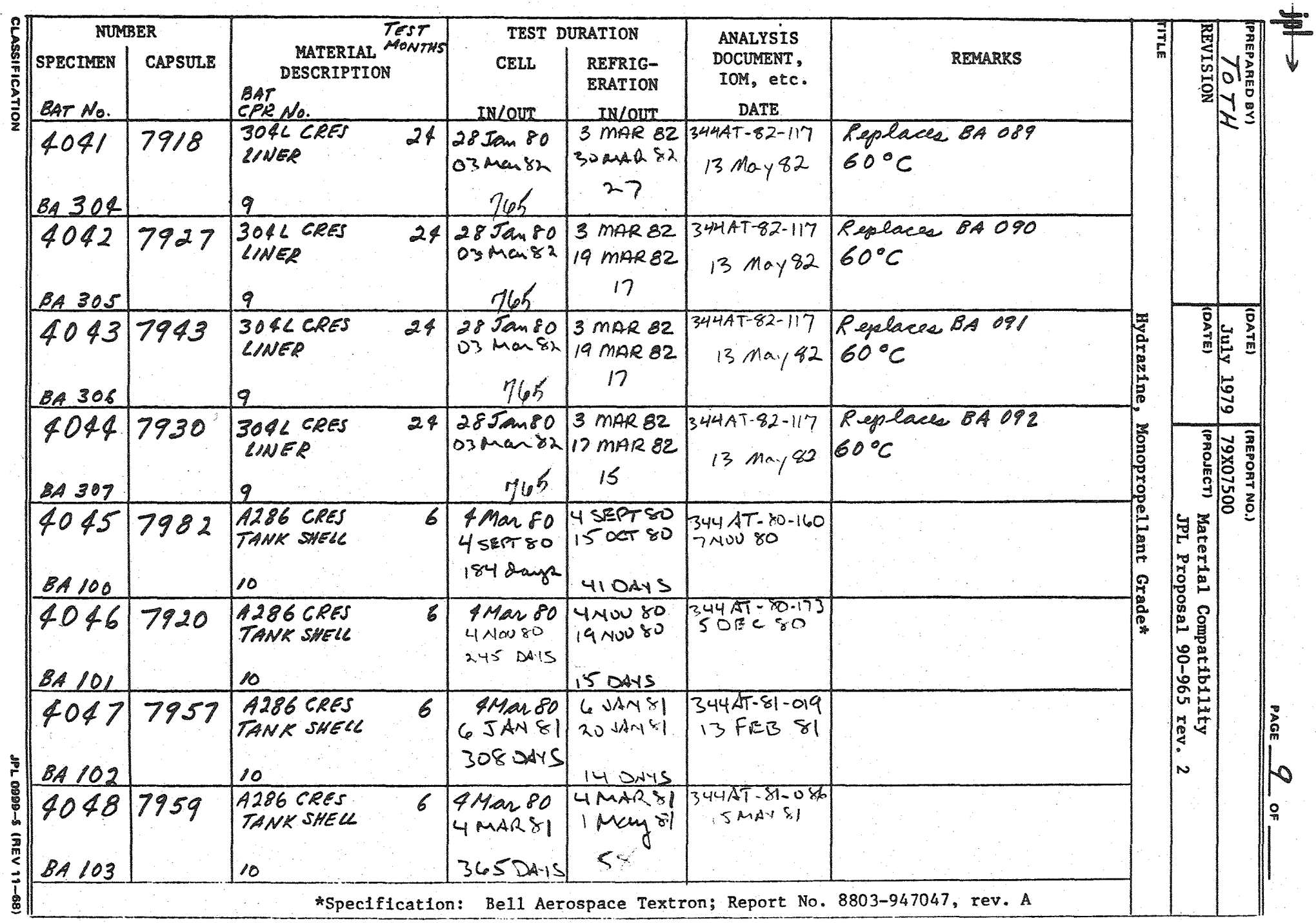




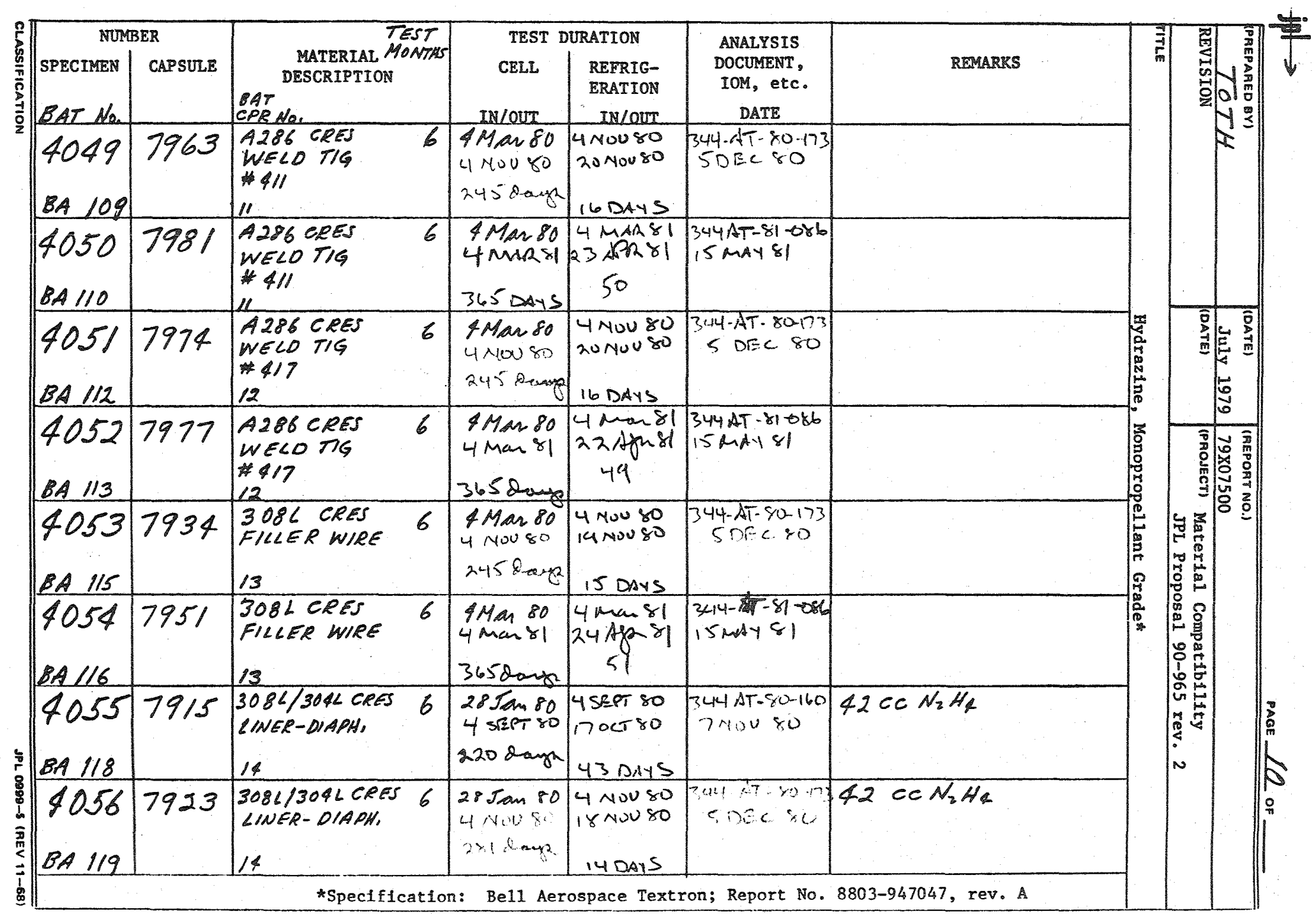




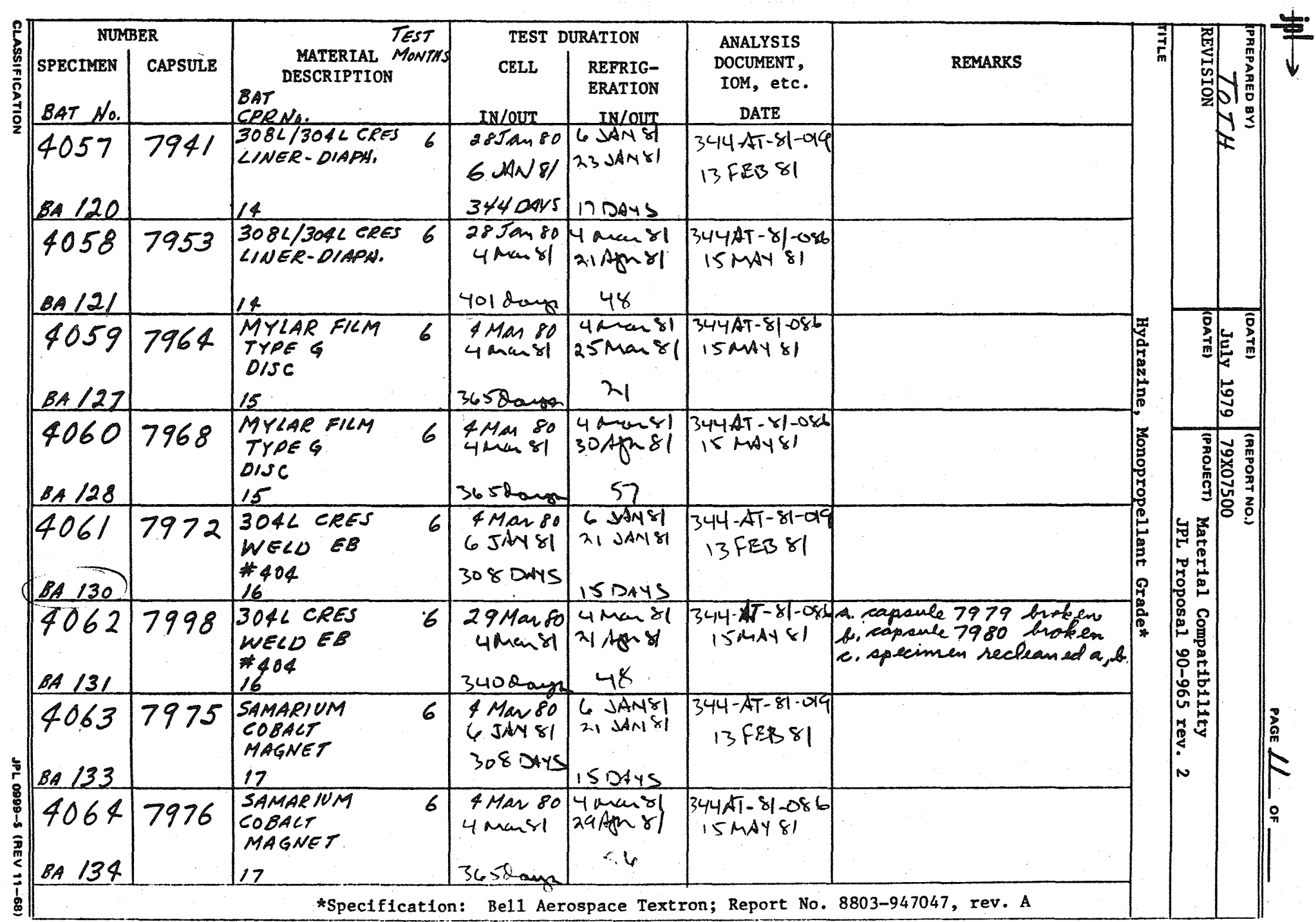




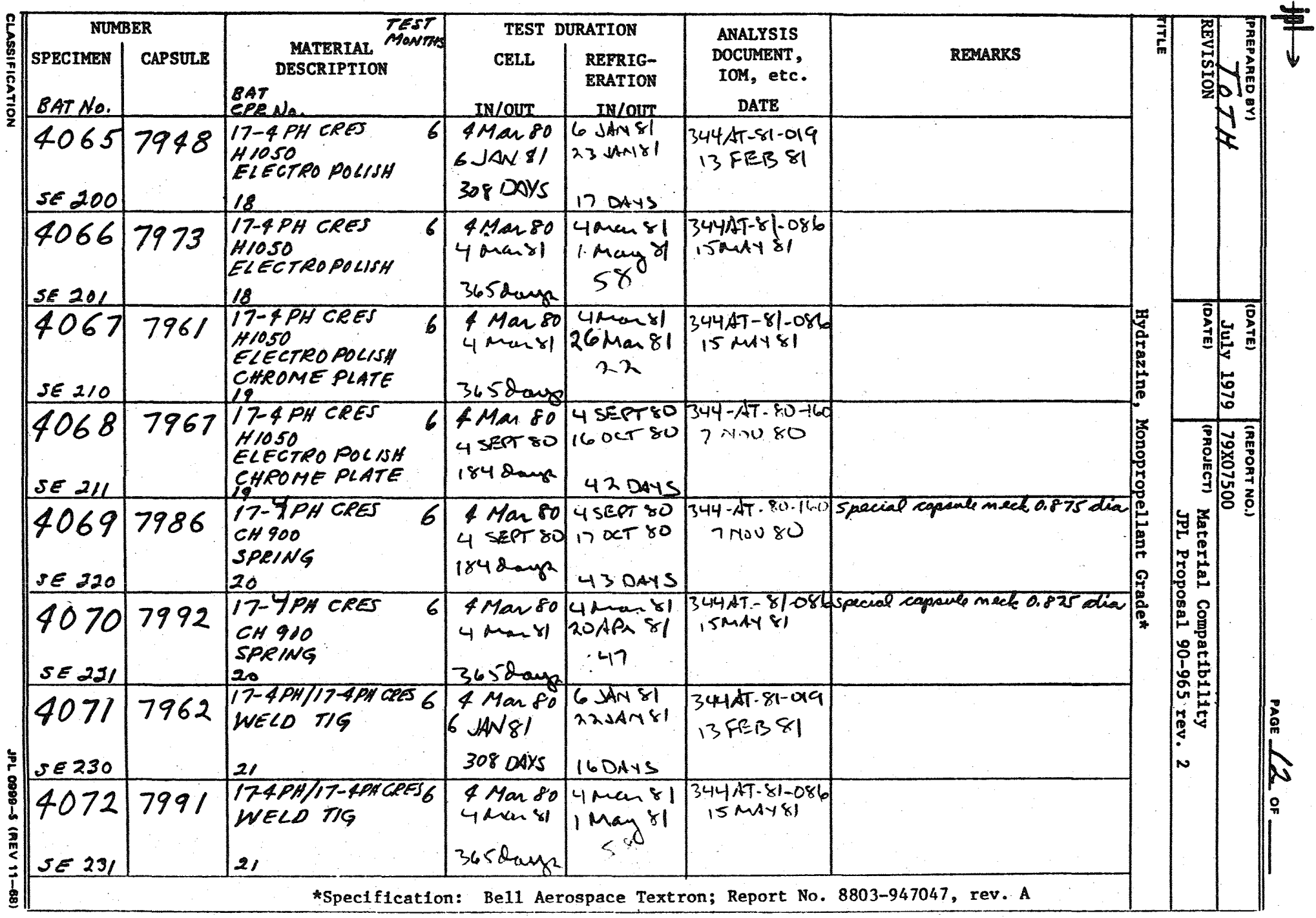




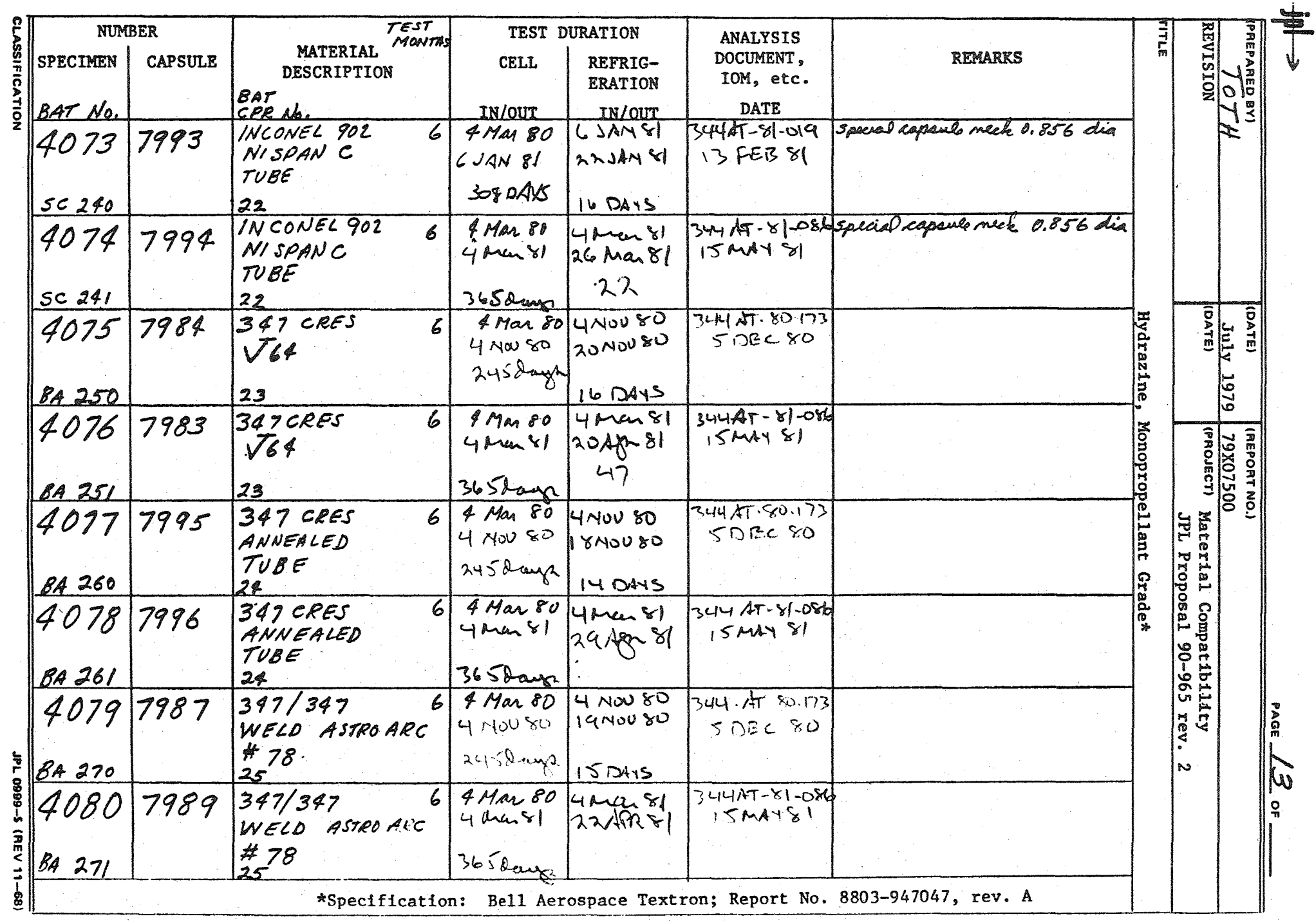




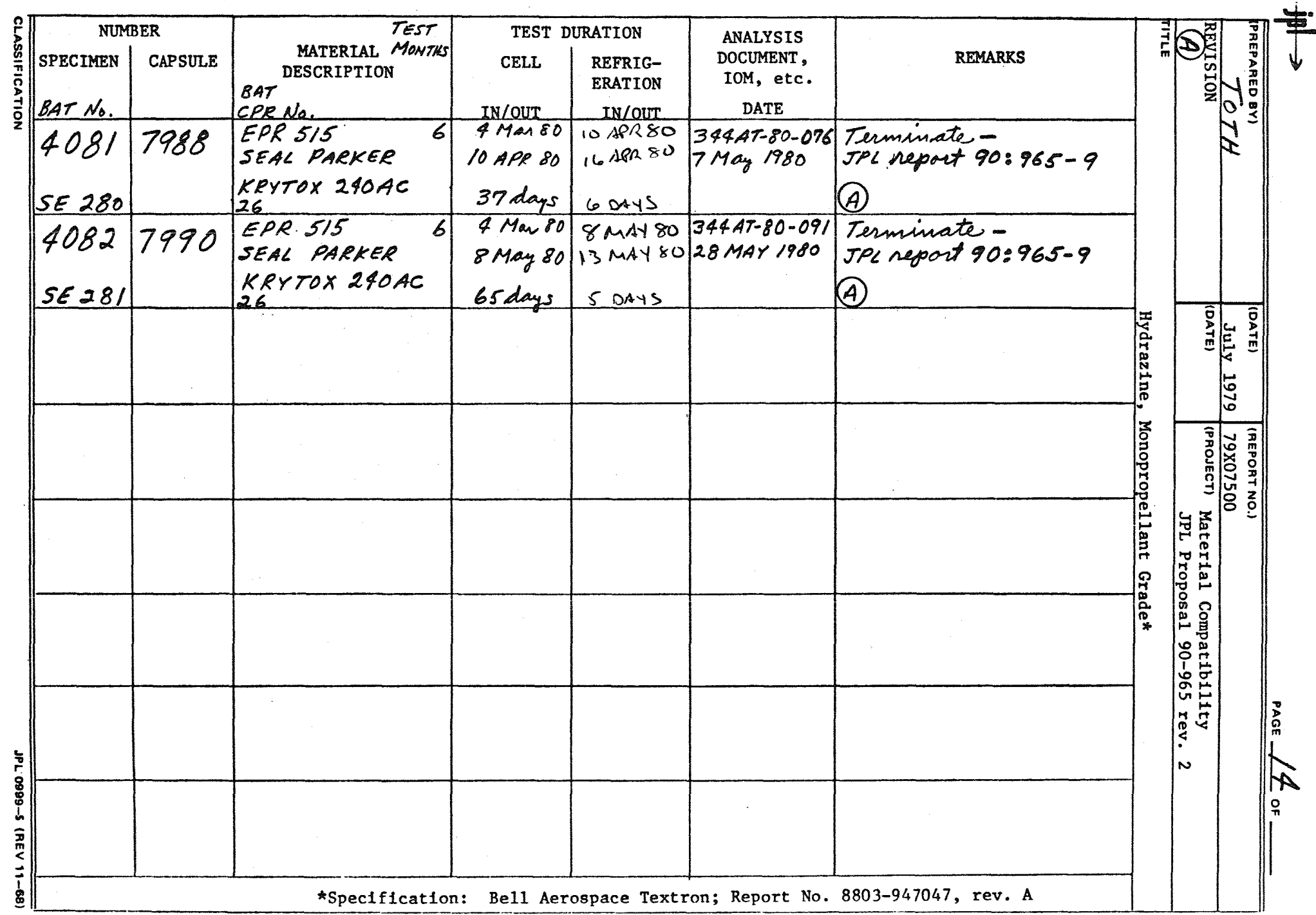




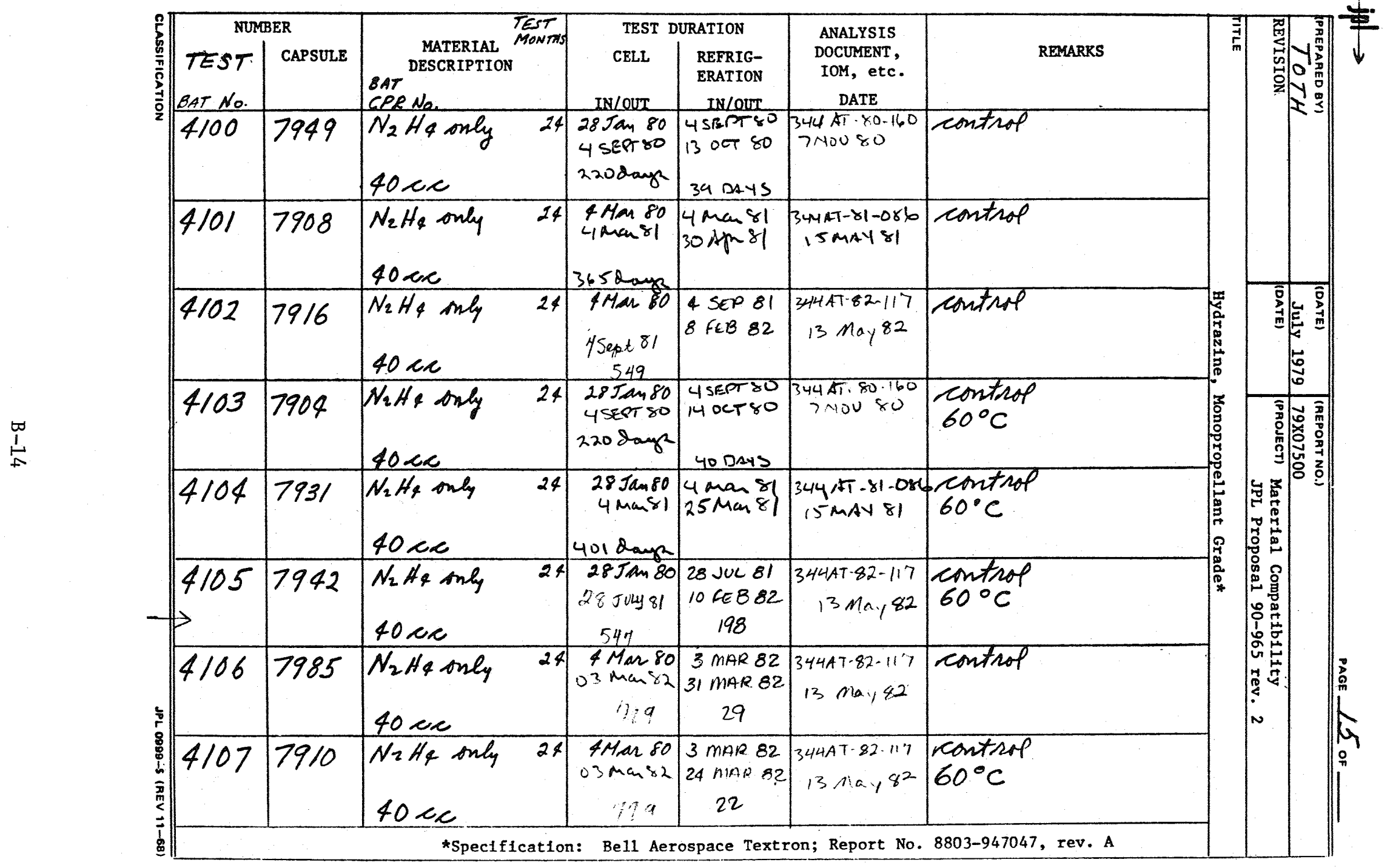




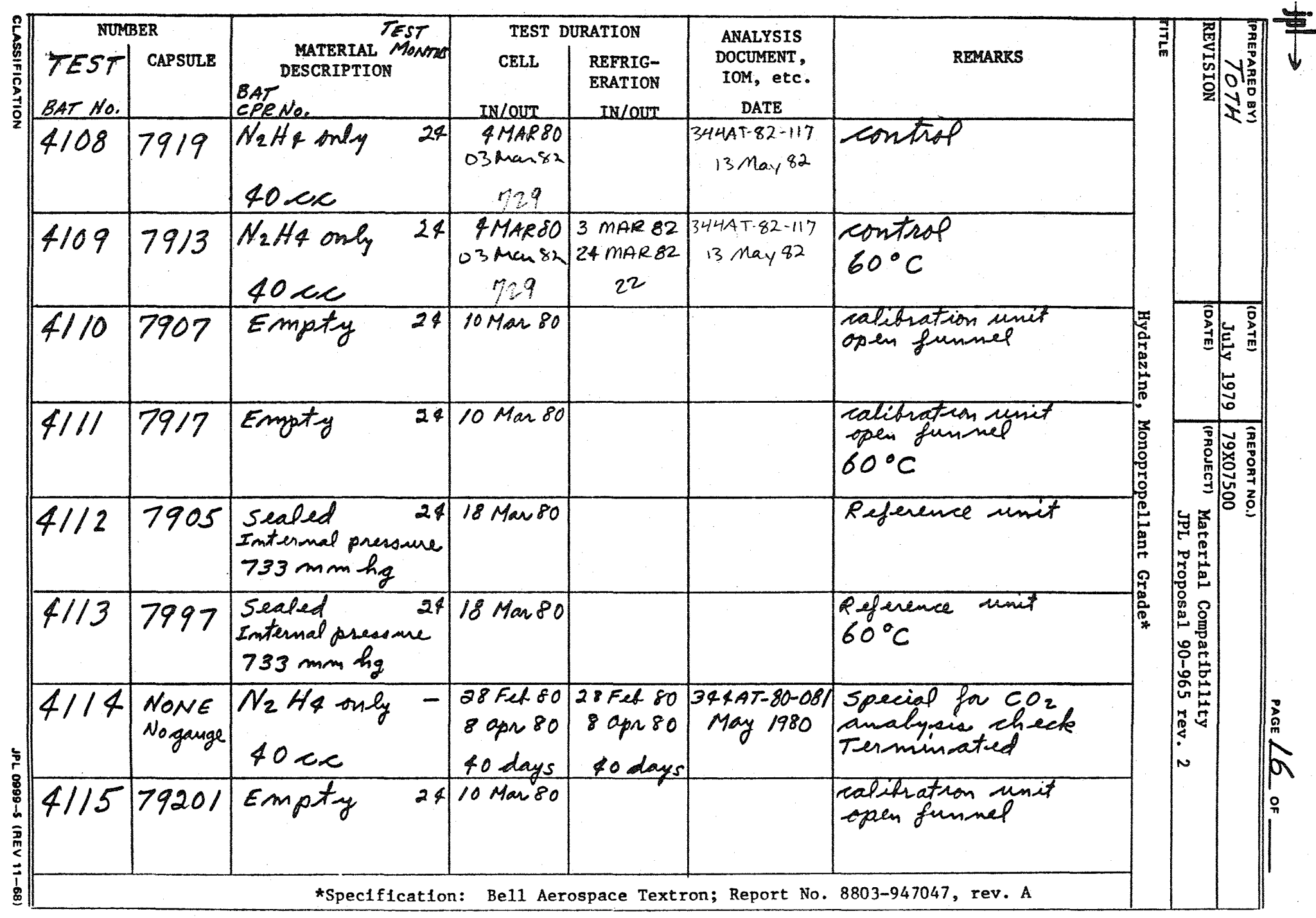




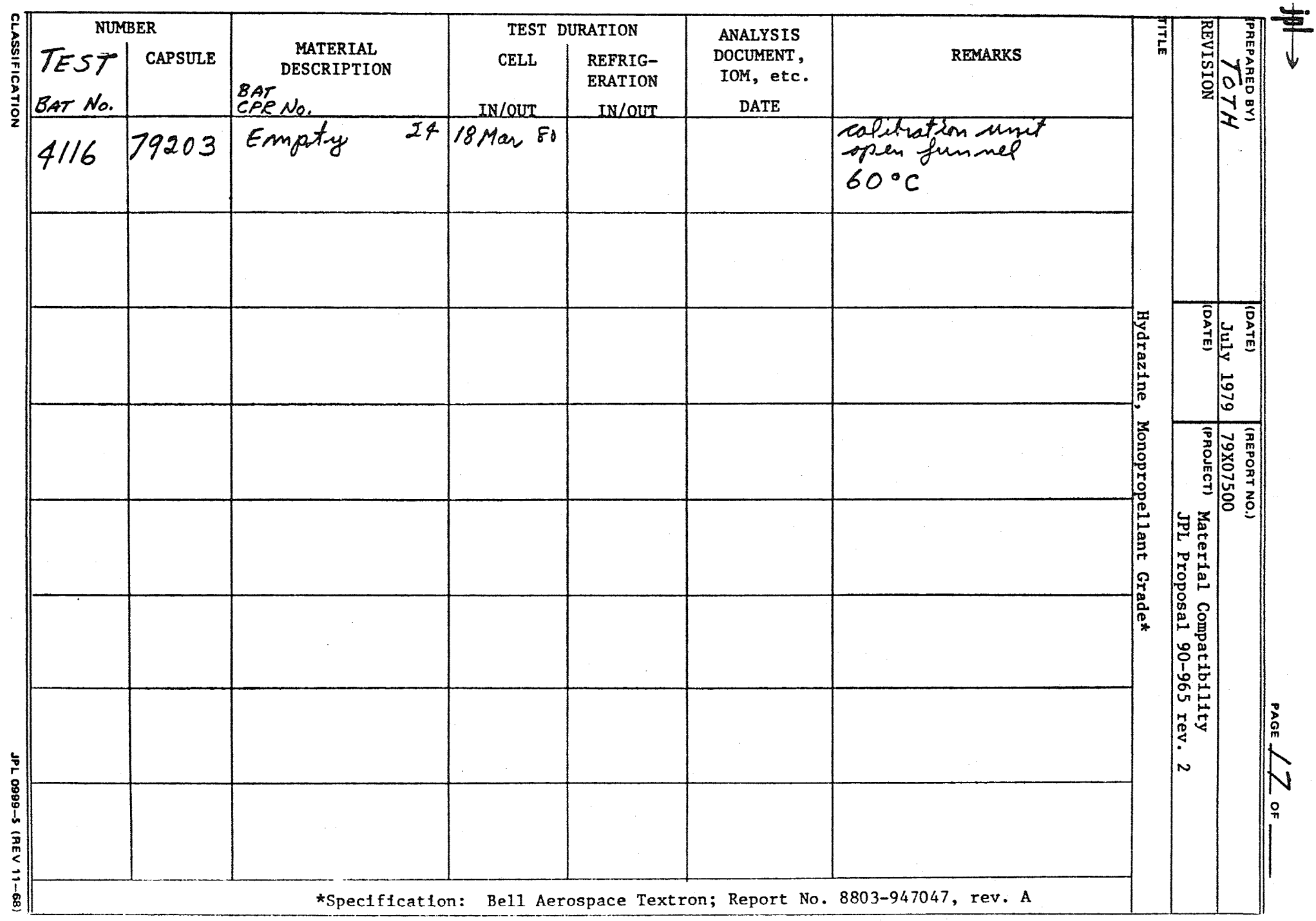




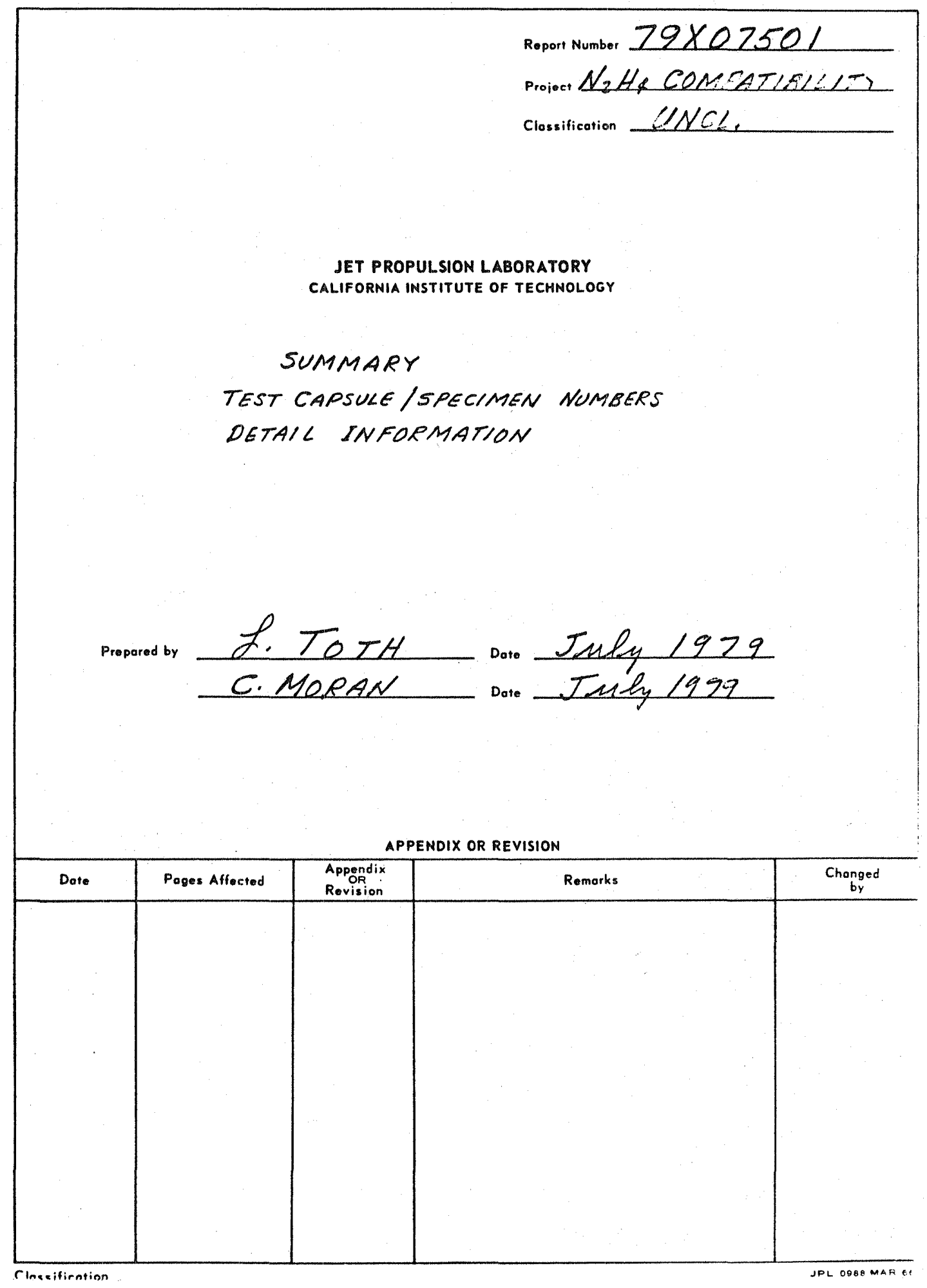




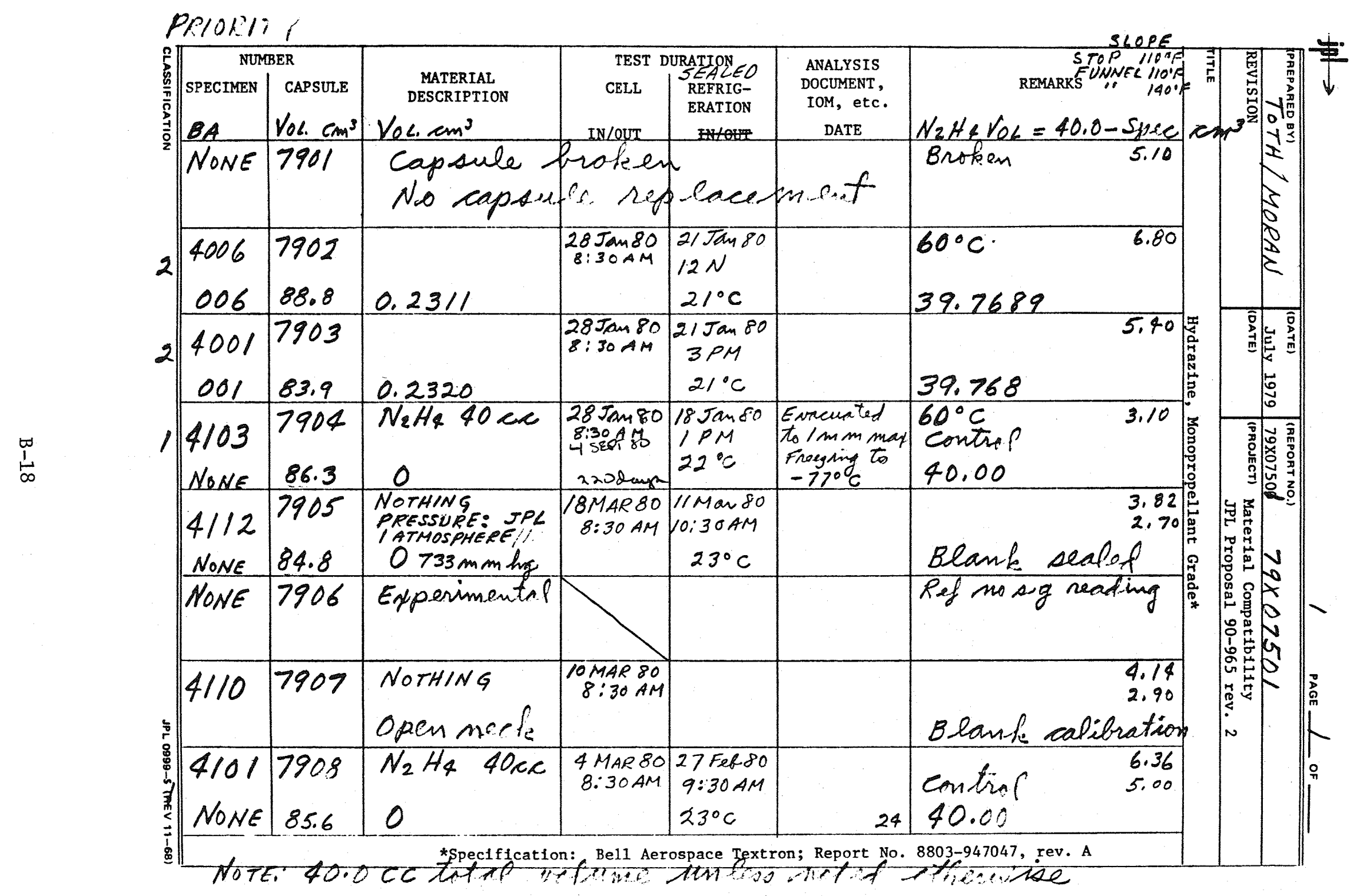





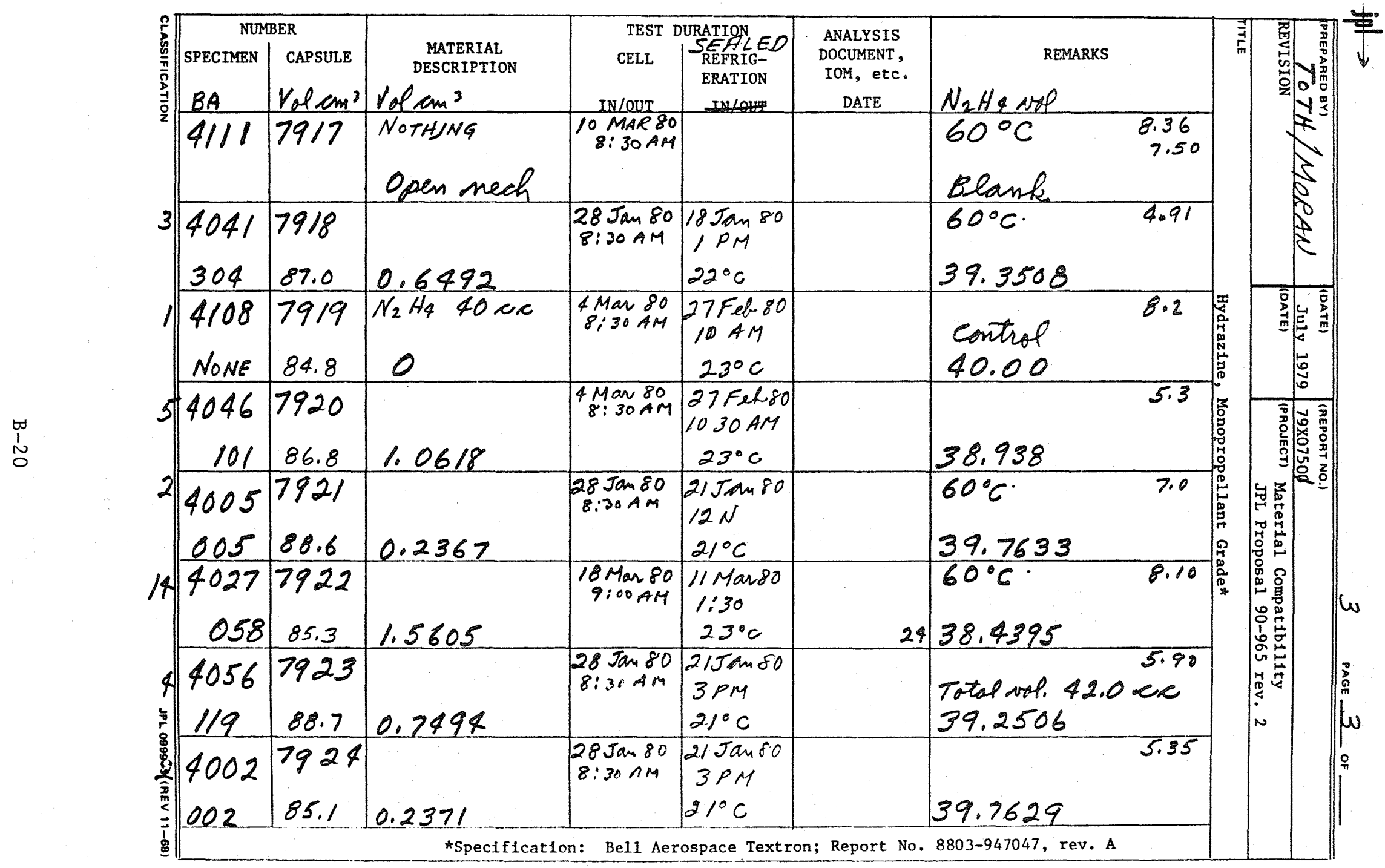




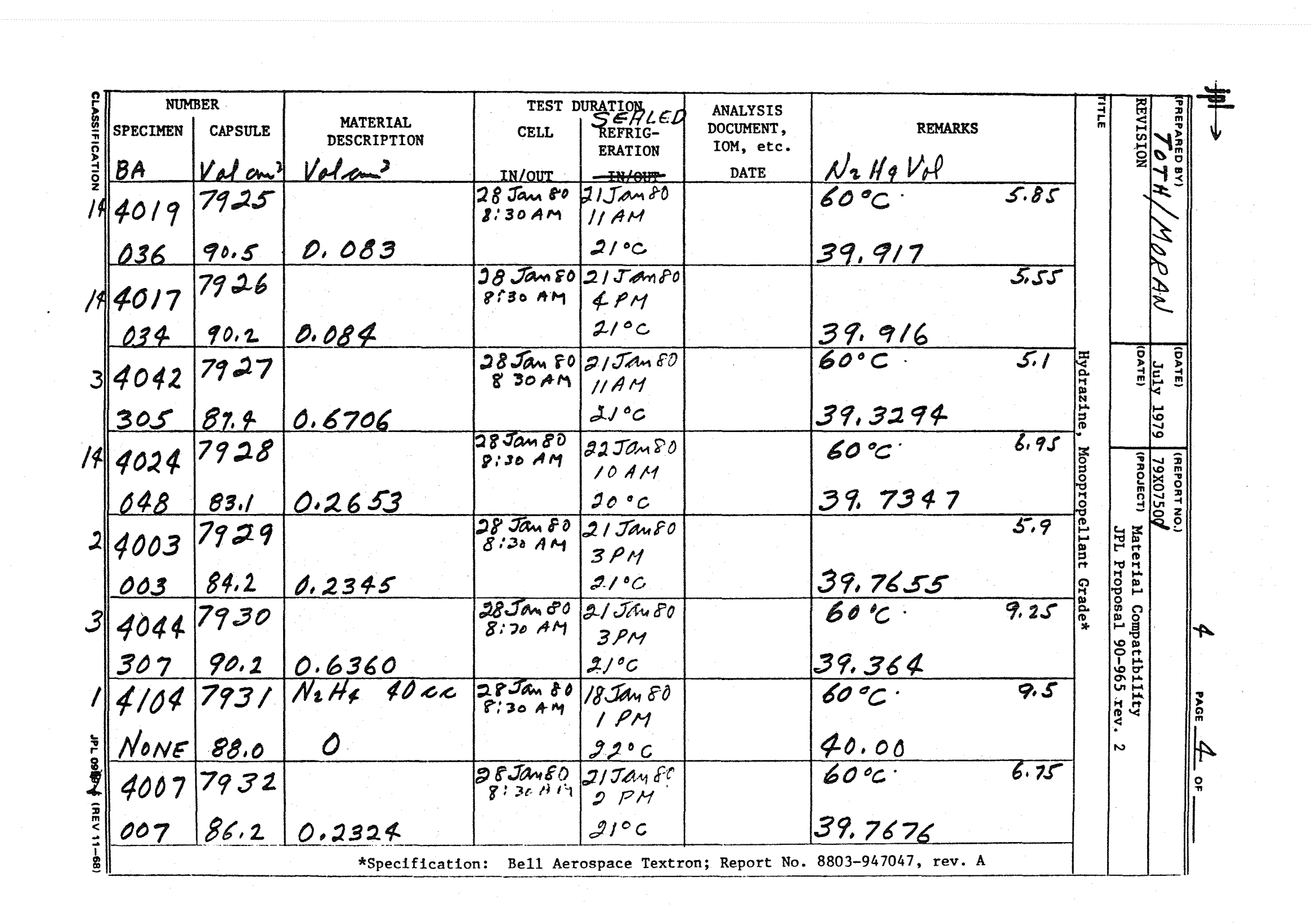




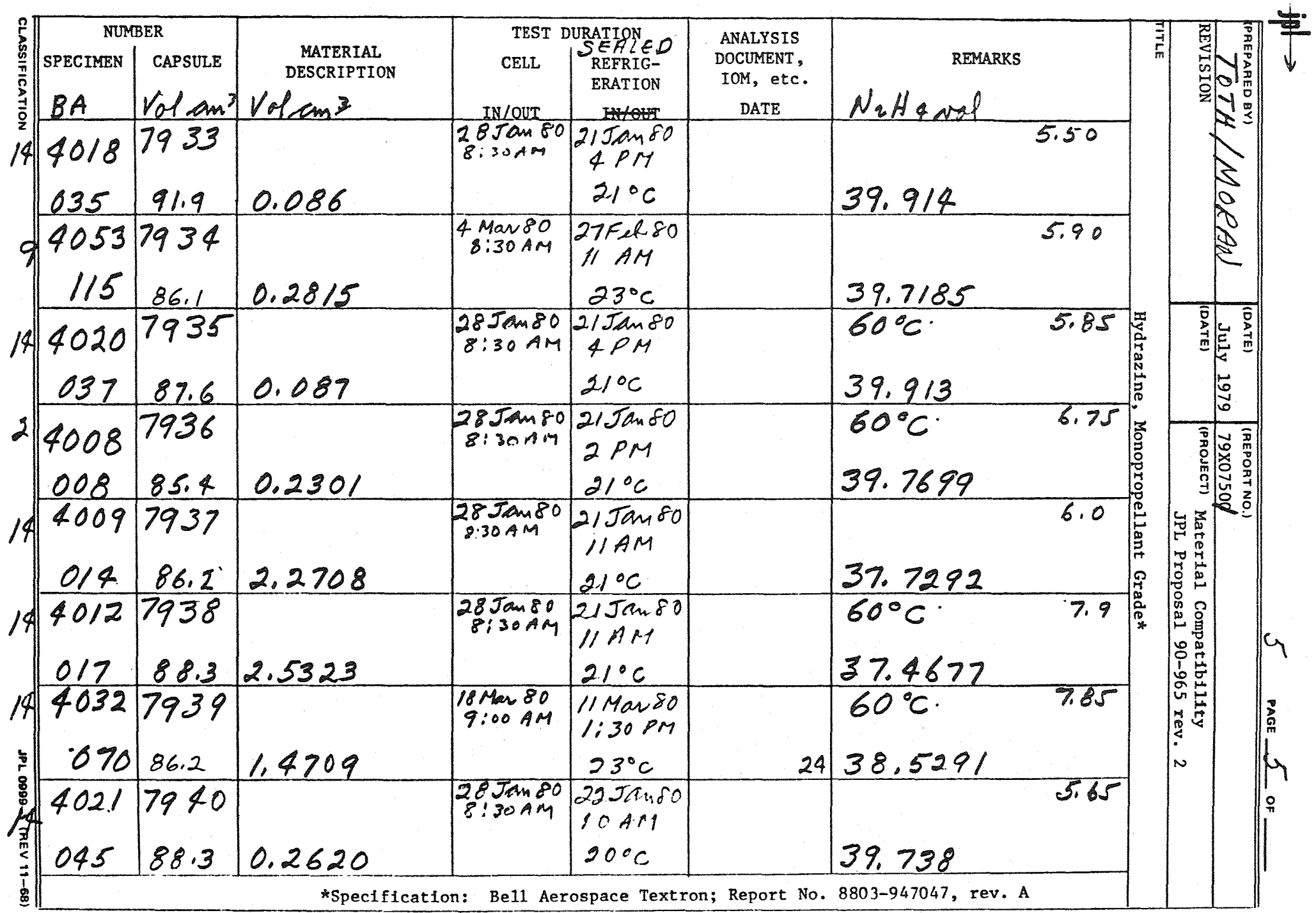




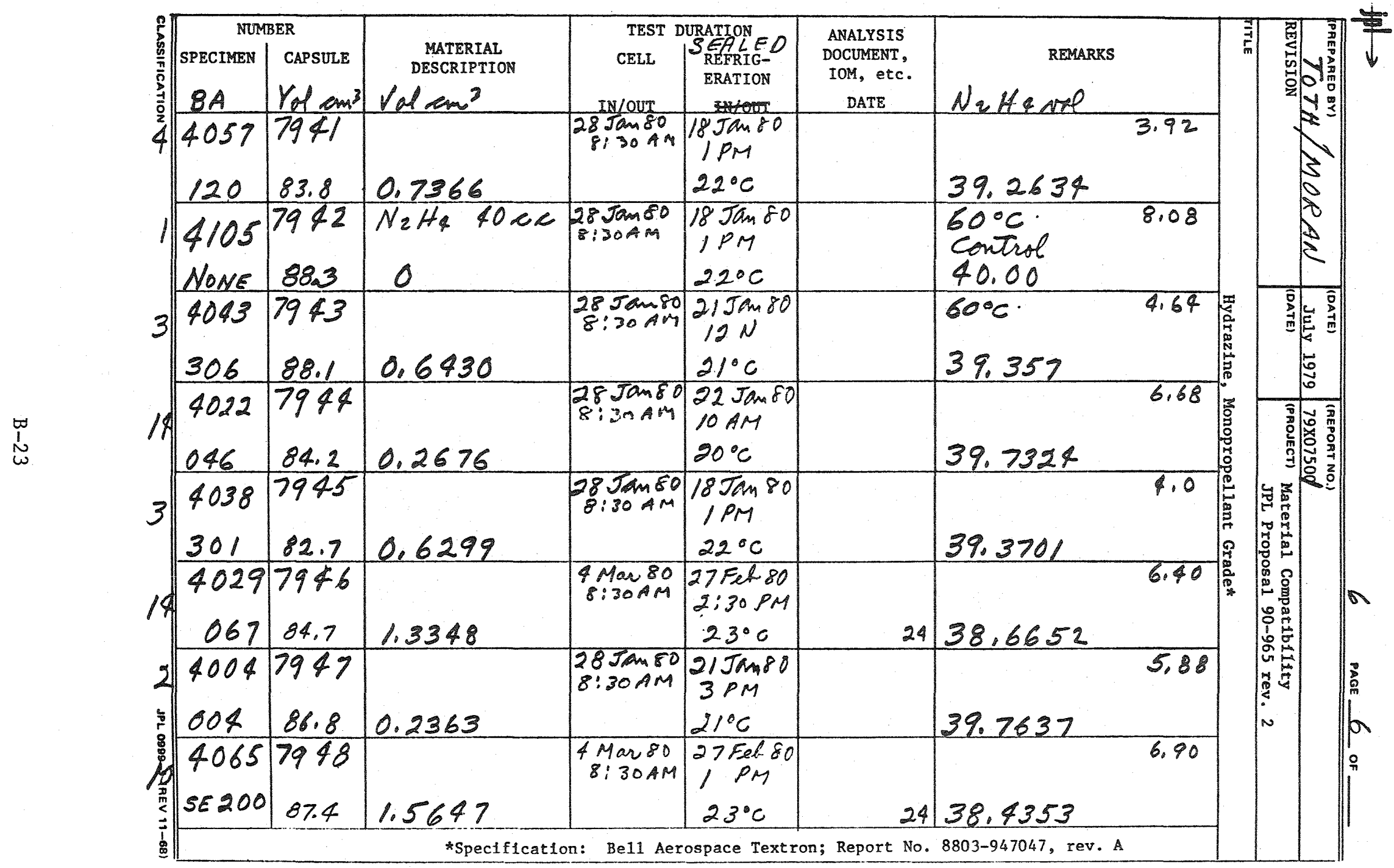




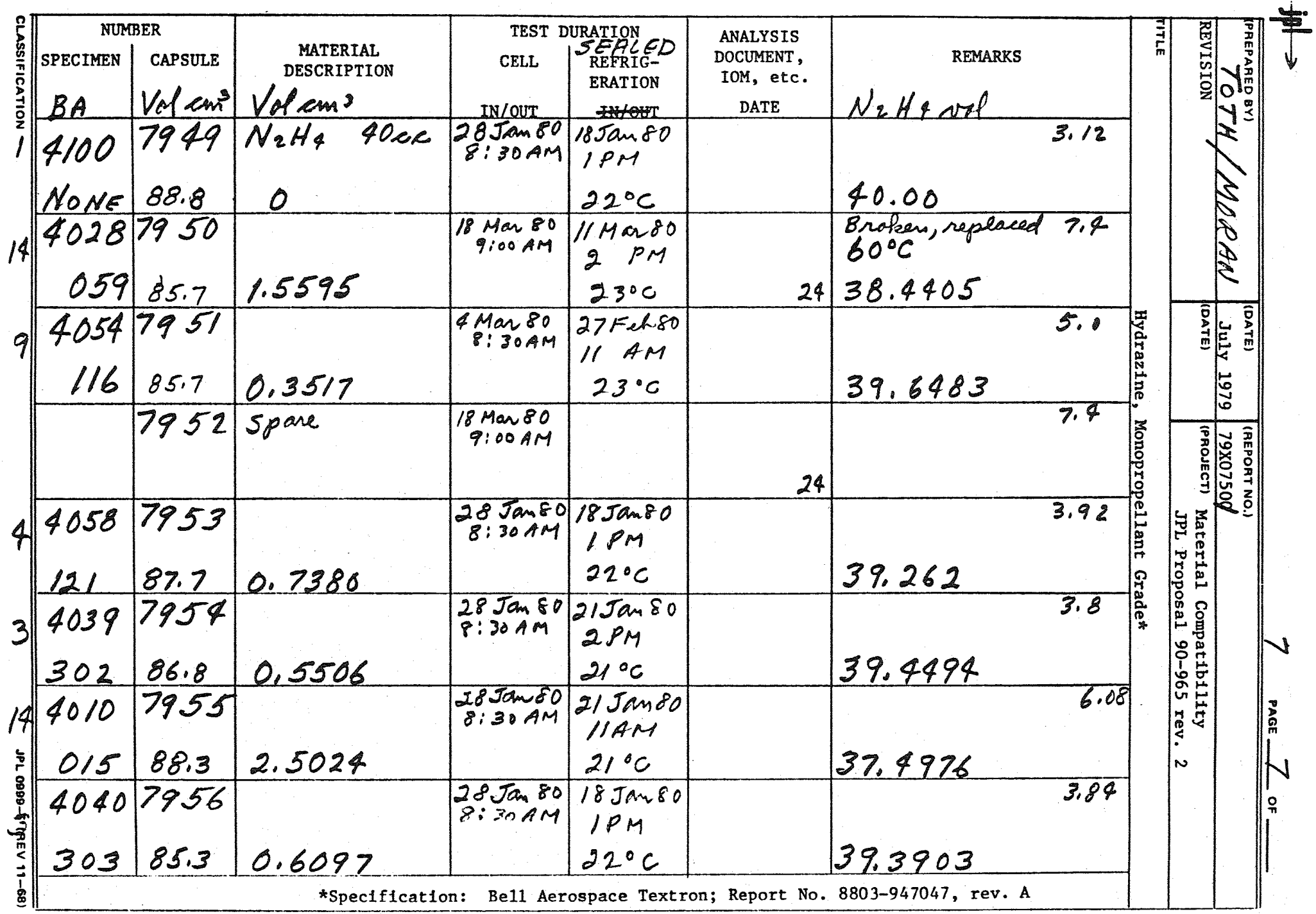




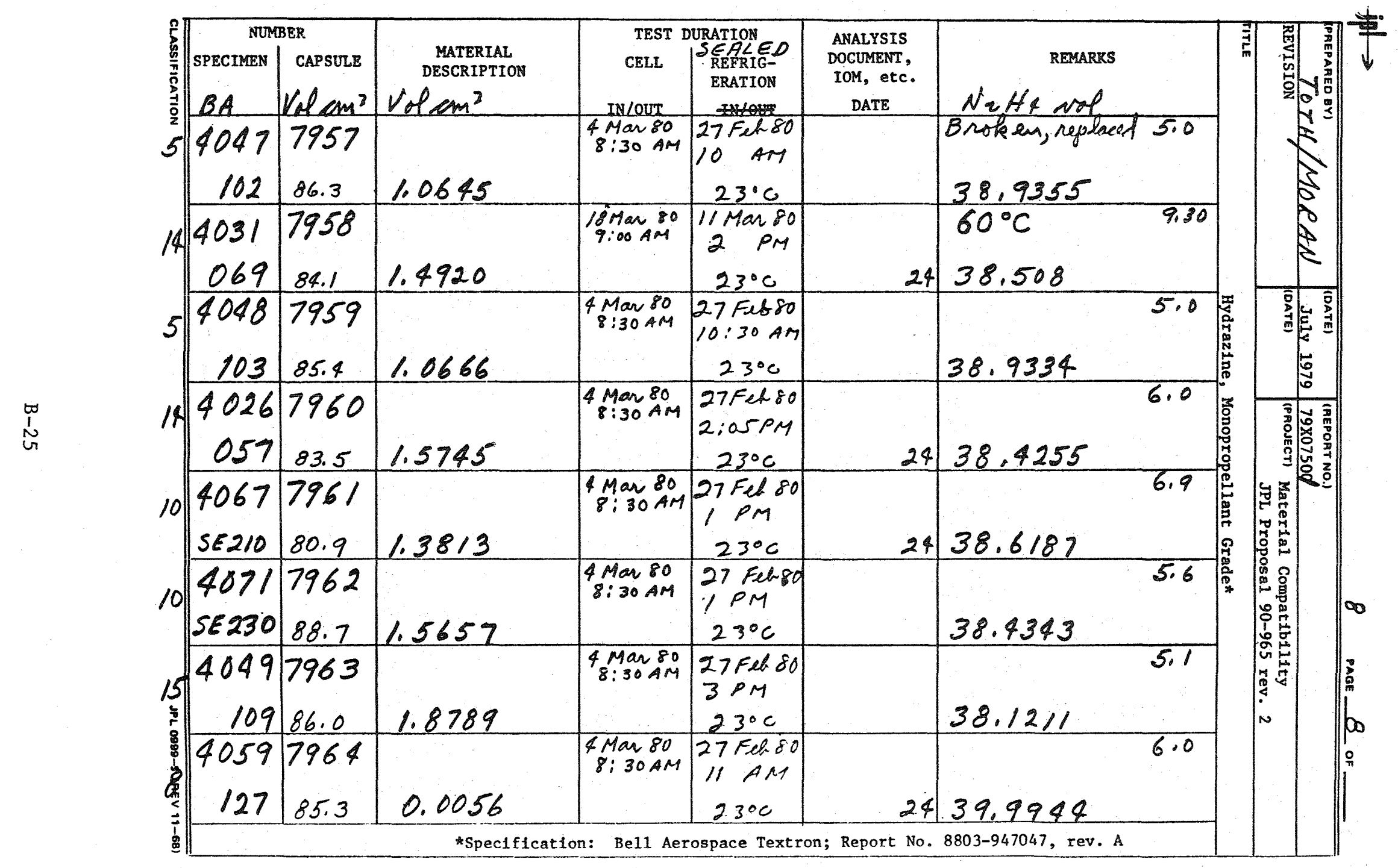




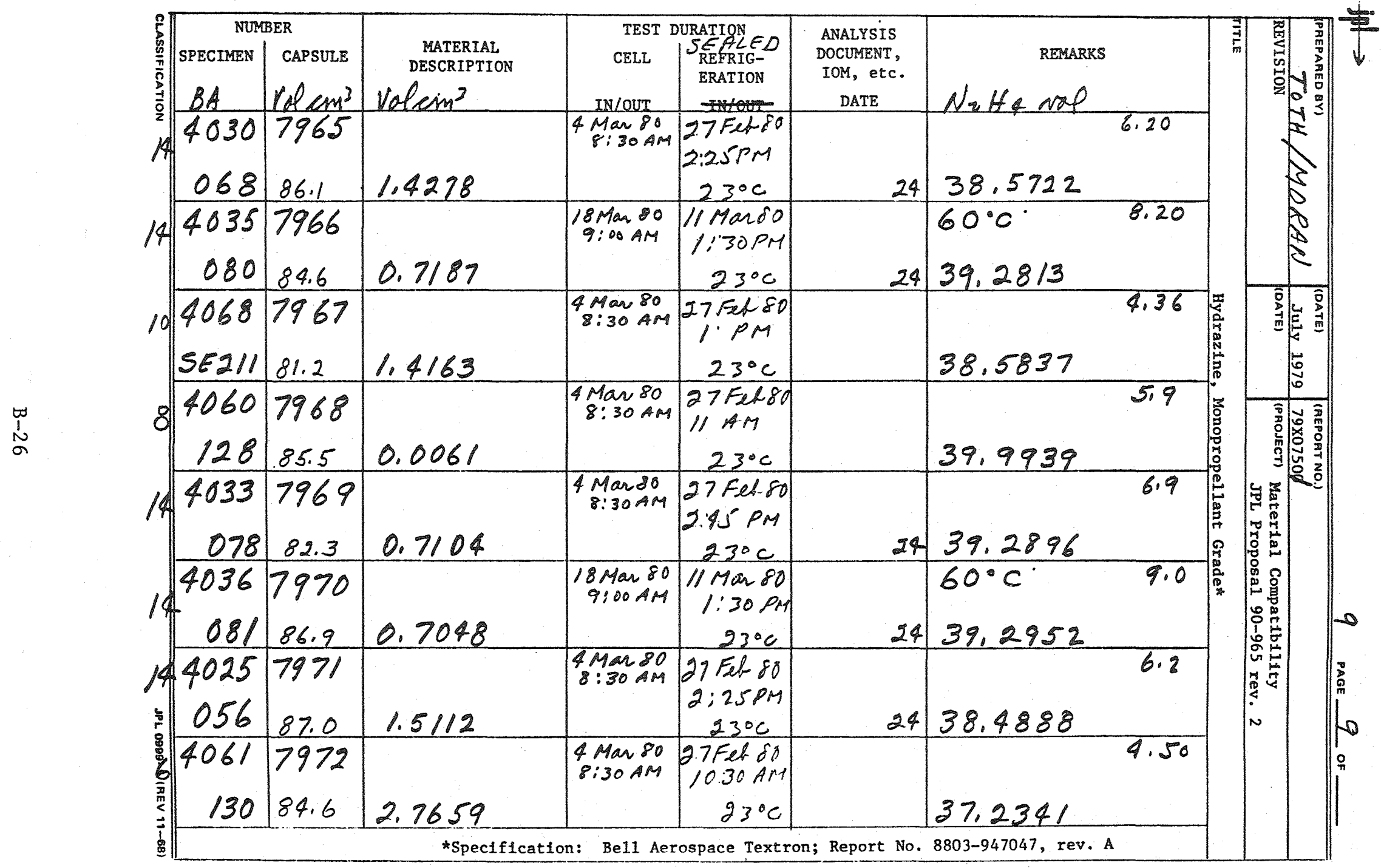




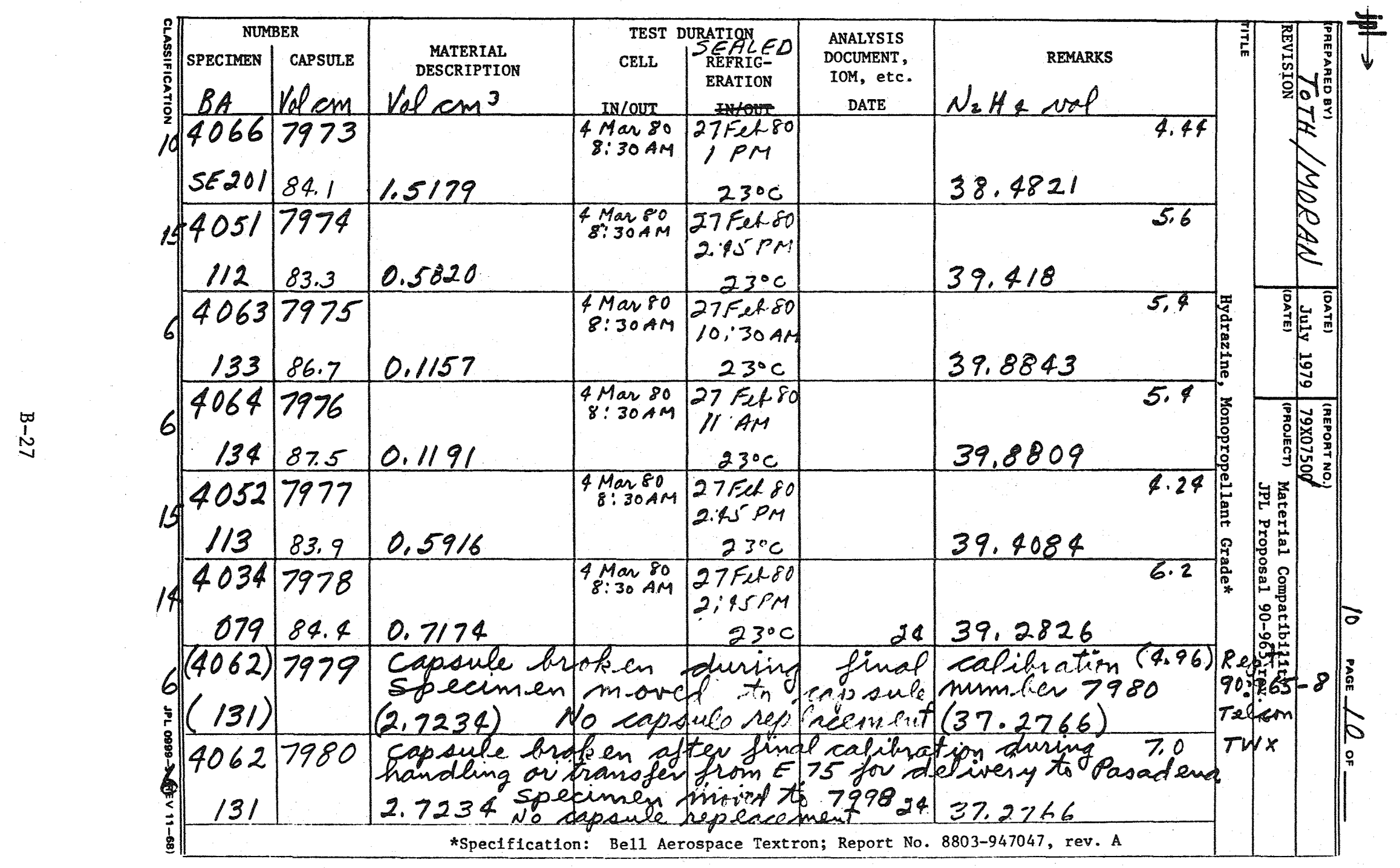




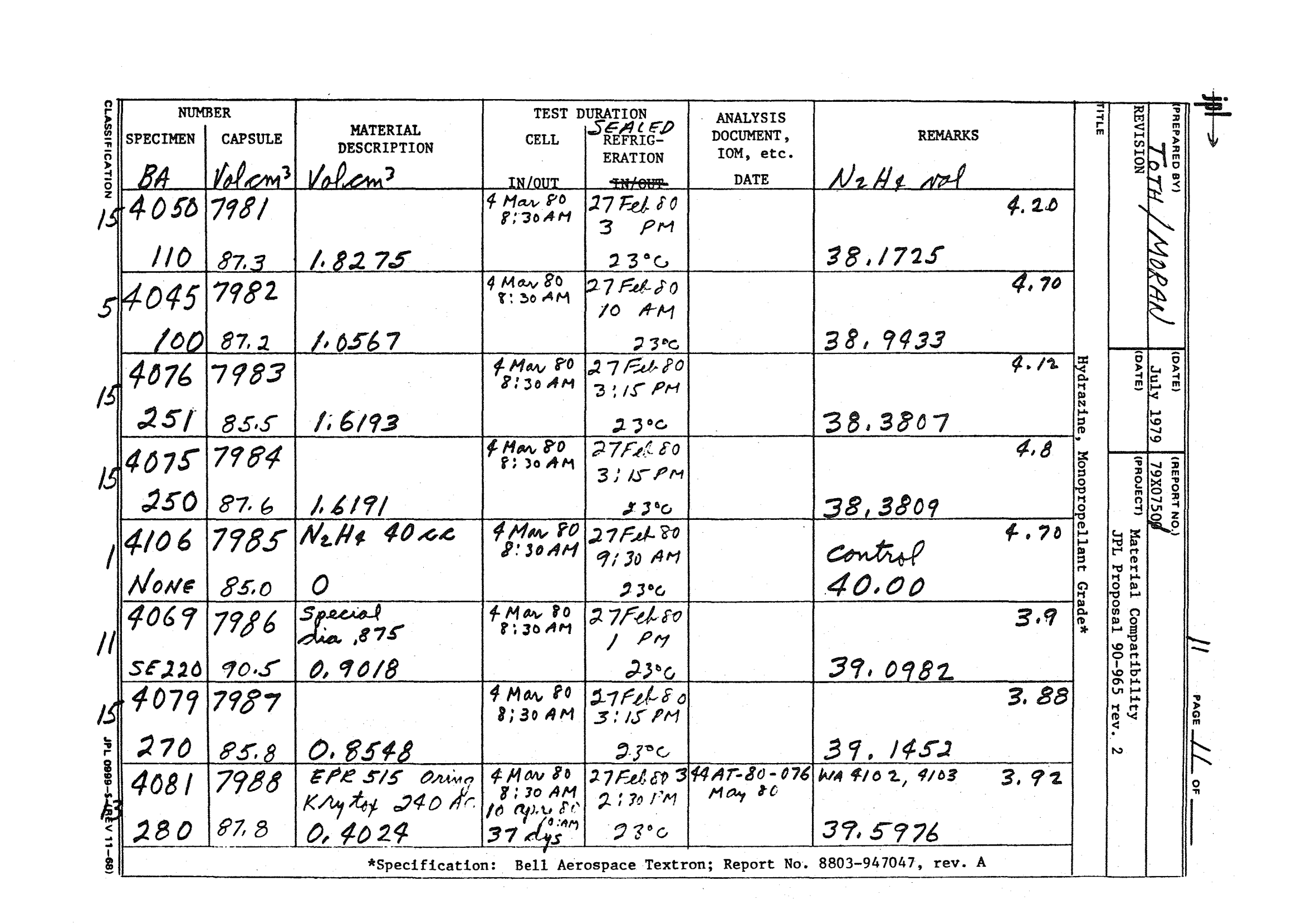




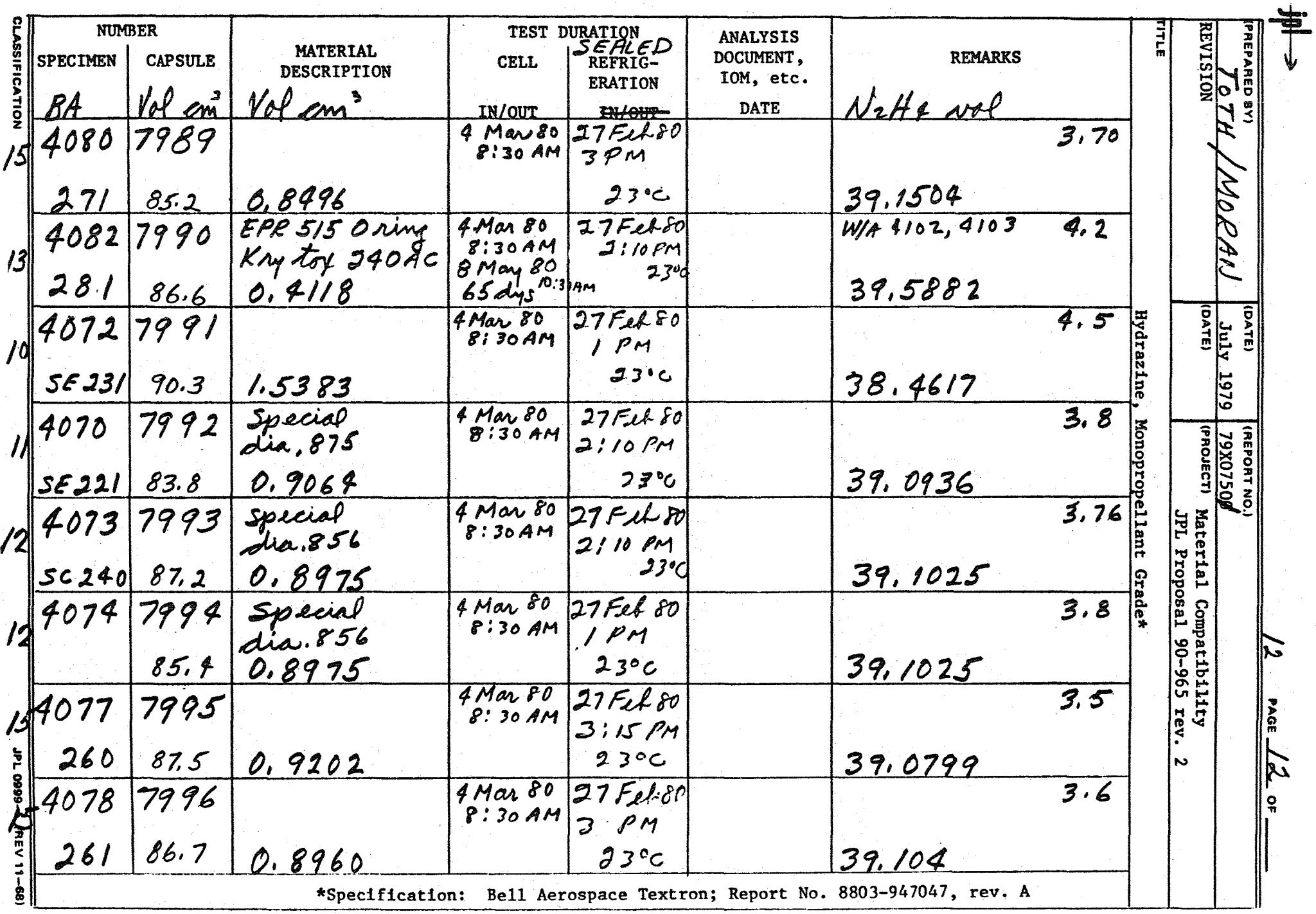




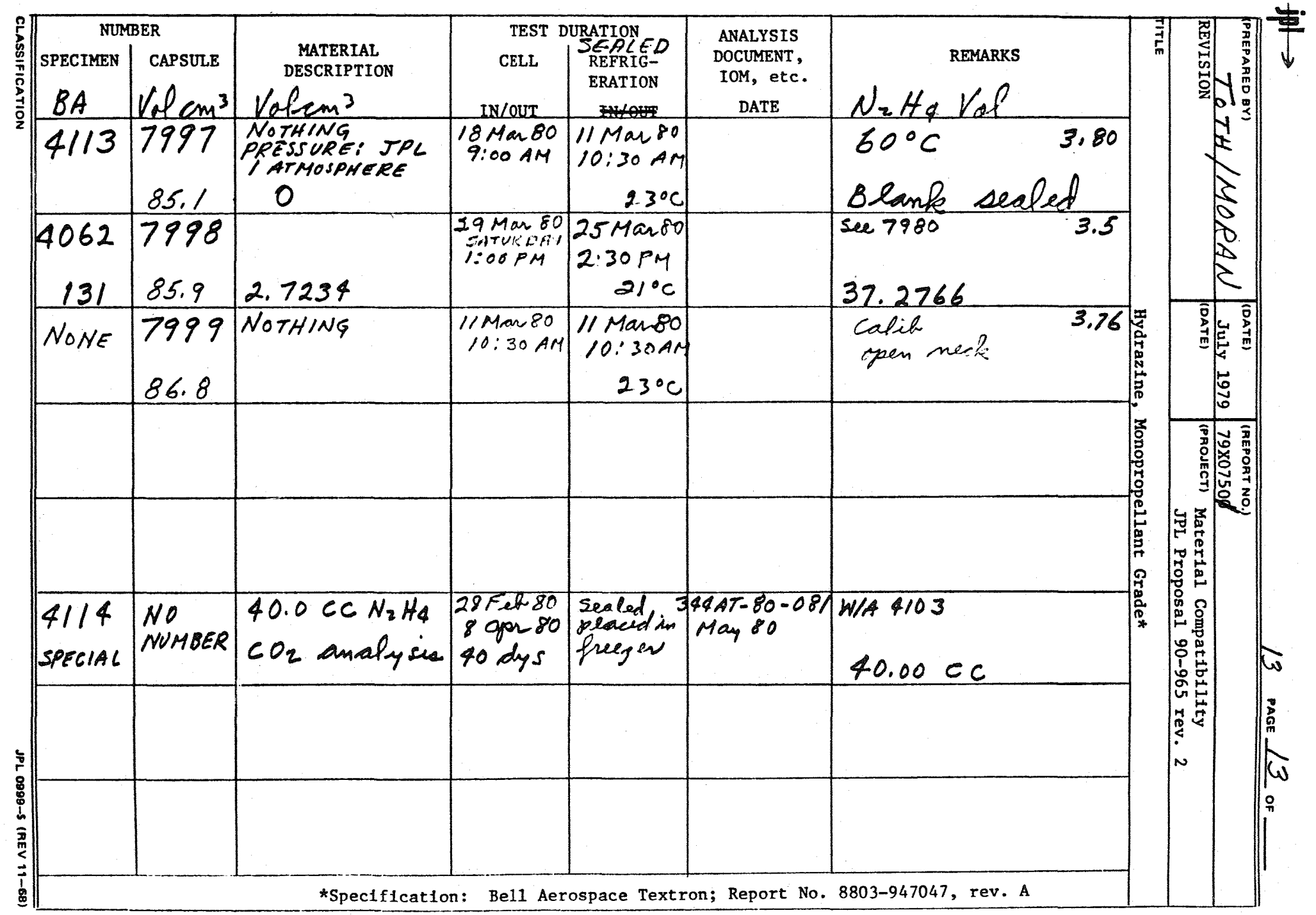




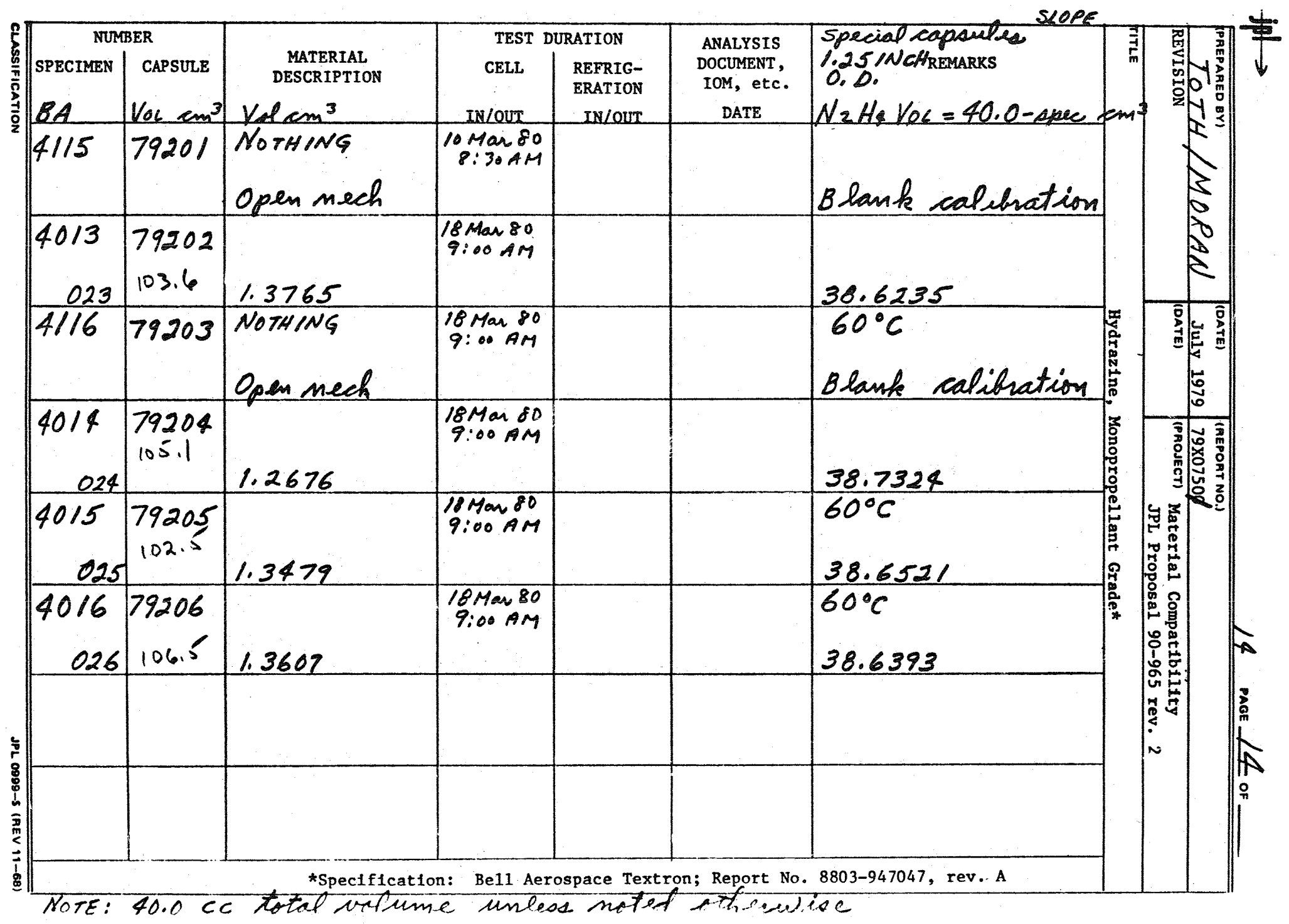




\section{APPENDIX C}

$\mathrm{CO}_{2}$ ANALYSIS

\section{A. DETERMINATION OF CARBON DIOXIDE ABSORBED BY HYDRAZINE}

The general laboratory test setup for $\mathrm{CO}_{2}$ analysis is shown schematically in Fig. C-1. The sulfamic acid solution is prepared by dissolving $150 \mathrm{~g}$ of reagent grade material in 1.0 liter of distilled water. To reduce the $\mathrm{CO}_{2}$ content of the sulfamic acid, high-purity helium, passed through Ascarite, is bubbled through the sulfamic acid solution via the glass frit, which provides a fine gas dispersion and efficient purging. The helium gas is passed through the sulfamic acid delivery tube for about 16 hours at $50-60 \mathrm{~cm}^{3} / \mathrm{min}$. The exit end of the helium gas from the sulfamic acid bottle is protected against air and $\mathrm{CO}_{2}$ with an Ascarite tube. This Ascarite tube is replaced with a new one after the helium purge. With the precautions outlined, the blank $\mathrm{CO}_{2}$ is under $2.0 \mathrm{ppm}$.

The apparatus is standardized by means of a $\mathrm{NaHCO}_{3}$ solution prepared by dissolving $0.381 \mathrm{~g}$ of dried $\mathrm{NaHCO}_{3}$ in 1.0 liter of distilled water. The solution is stored in glass, and air exposure is minimized. This solution provides $0.20 \mathrm{mg} \mathrm{CO} 2$ per milliliter. Its $\mathrm{CO}_{2}$ content is $200 \mathrm{ppm}$ by weight.

The column is 6.0 -mm-diam tubing, $3.66 \mathrm{~m}$ long (0.24-in.-diam, $12 \mathrm{ft}$ long), filled with 60 to 80 mesh F \& M Polypack No. 5. This packing gives good separation of $\mathrm{CO}_{2}$ at ambient temperature. The peaks are sharp, permitting direct reading of the heights and eliminating the need for peak area measurements. The column is bent into a number of $0.7-\mathrm{m}(2-\mathrm{ft})$ sections arranged close together and contained in a glass jacket. The filament-type thermal conductivity detector unit is kept at ambient temperature in a glass dewar to minimize temperature fluctuations. A $1.0-\mathrm{mV}$ recorder records the detector output. Helium flow is $60 \mathrm{~cm}^{3} / \mathrm{min}$.

The first step in the analysis is the determination of the blank: the $\mathrm{CO}_{2}$ picked up from the reagents and the system. The flow of the high-purity helium purge gas, after passage through Ascarite, is adjusted to $50 \mathrm{~cm} / \mathrm{min}$ by means of a flowmeter in the system. A 60-m. sulfamic acid solution is run. into the unit via the stopcock. The stirrer is adjusted to give vigorous constant stirring. Once set, the helium flow and stirring are kept fixed through the whole run.

After addition of the sulfamic acid, the helium gas is passed through the traps for 30 min to purge the system of air. The $\mathrm{CO}_{2}$ trap is then immersed in liquid nitrogen to the top level of the glass beads. The flow of helium is continued for $20 \mathrm{~min}$, after which time the stopcock on the $\mathrm{CO}_{2}$ trap is turned to isolate the loop on the trap.

The trap, immersed in liquid nitrogen, is transferred to the gas chromatograph sampling system. The stopcock on the $\mathrm{CO}_{2}$ trap is turned so as to evacuate the noncondensable gases in the trap and then turned to isolate the loop containing the frozen $\mathrm{CO}_{2}$. 

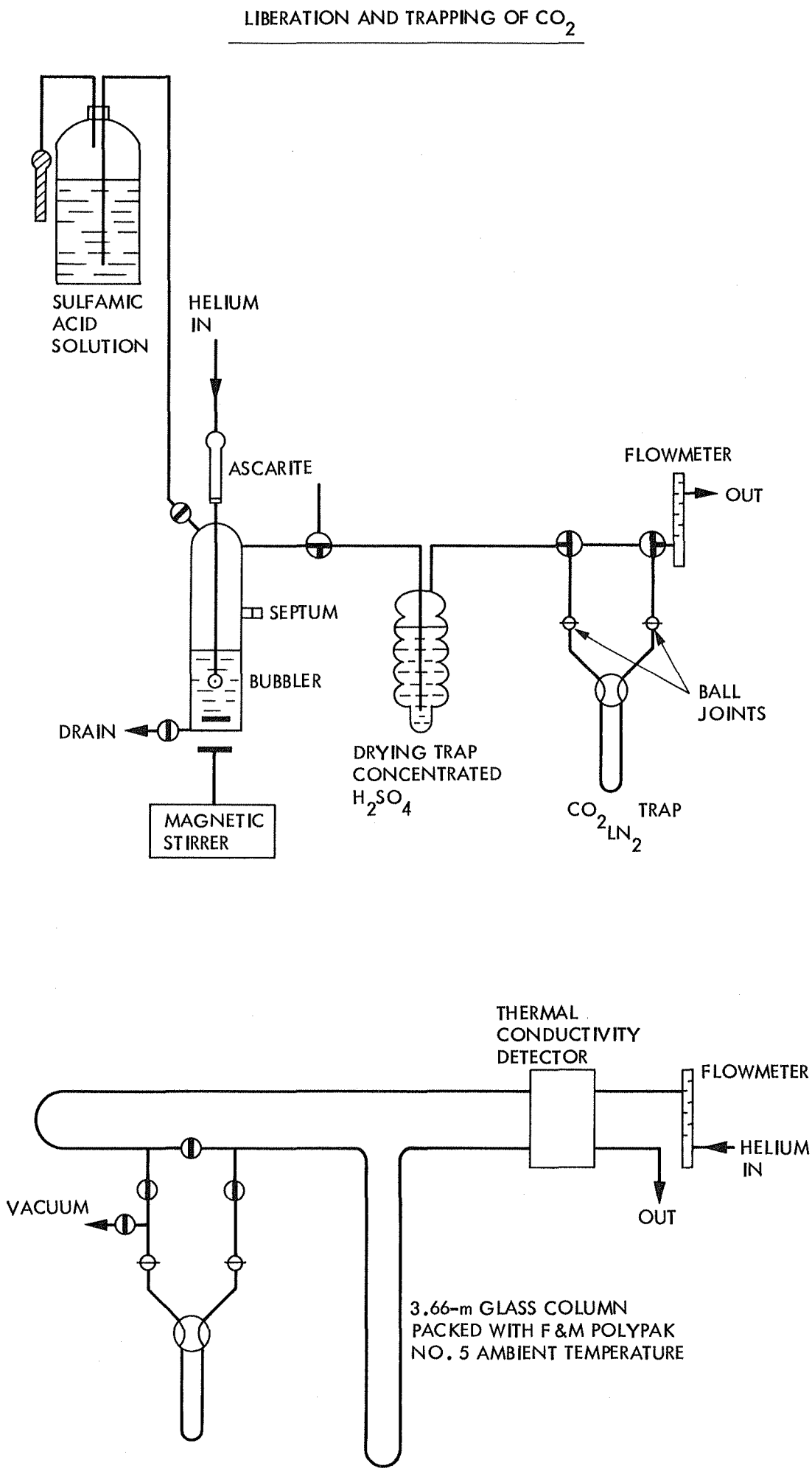

Figure $\mathrm{C}-1$. Test Procedures for $\mathrm{CO}_{2}$ Analysis 
The next step is to flow the helium gas through the branched leg of the sampling system. During this operation the liquid nitrogen is removed, and the $\mathrm{CO}_{2}$ trap thawed with warm water. After a few minutes, the stopcock is turned so as to flush the $\mathrm{CO}_{2}$ with helium into the chromatographic column for separation and assay. The blank run is repeated until consistent, low values are obtained.

The standardization run is made in the same manner as the blanks, except that after a 5-min preliminary purge with helium, $0.50 \mathrm{ml}$ of standard $\mathrm{NaHCO}_{3}$ solution is injected into the vigorously stirred sulfamic acid via the septum on the sulfamic acid unit. The released $\mathrm{CO}_{2}$ is frozen out during the 20-min duration in the $\mathrm{CO}_{2}$ trap immersed in liquid nitrogen. The trapped $\mathrm{CO}_{2}$

from the standard solution is transferred to the gas chromatographic sampling system. This yields a peak height for a standard of $100 \mathrm{ppm} \mathrm{CO}_{2}$.

The $\mathrm{CO}_{2}$ in the hydrazine is similarly determined. A $1.0-\mathrm{ml}$ sample is injected into the sulfamic acid solution via the septum, and the released $\mathrm{CO}_{2}$ is swept out of the solution for a period of $20 \mathrm{~min}$. The hydrazine injections should be made rapidly with a minimum exposure to air. The sulfamic acid solution is sufficient to neutralize $1.0 \mathrm{ml}$ of hydrazine and should therefore be discarded after each hydrazine analysis. If another sample is to be run, the sulfamic acid unit is refilled, and the blank and the standard determinations are made as before.

\section{B. CALCULATION FOR CARBON DIOXIDE CONTENT}

The formula for determining parts per million of carbon dioxide is

$$
\frac{\text { peak sample - peak blank }}{\text { peak standard - peak blank }} \times 100
$$

For hydrazine, where the density can be taken as 1.0 , a density correction term is not applied. The error due to this omission is about $1 \%$, well within the $\pm 10 \%$ precision for $\mathrm{CO}_{2}$ determination when the values are under $20 \mathrm{ppm}$.

\section{CONCLUSION}

The method described provides meaningful results for the determination of $\mathrm{CO}_{2}$ in hydrazine or its methyl-substituted derivatives. 
APPENDIX D

TEST COUPON PHOTOGRAPHS IN THE POSTTEST CONDITION

Figure D-1 shows test specimens from Program A, the secondary containment system; Figure D-2 shows test specimens from Program $B$, the primary containment system. 


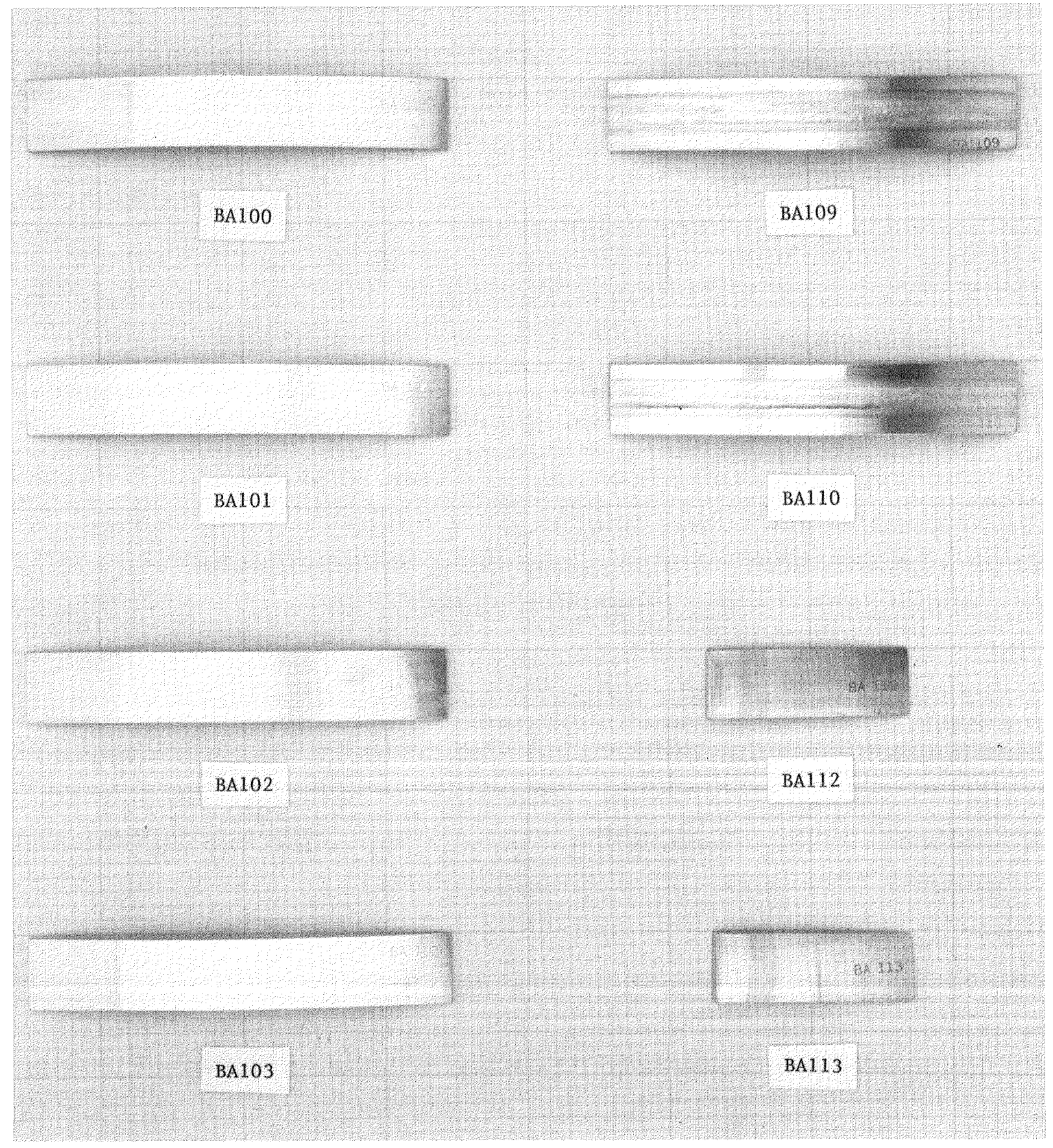

Figure D-1. Test Specimens, Hydrazine Decomposition Program "A" Secondary Containment System 


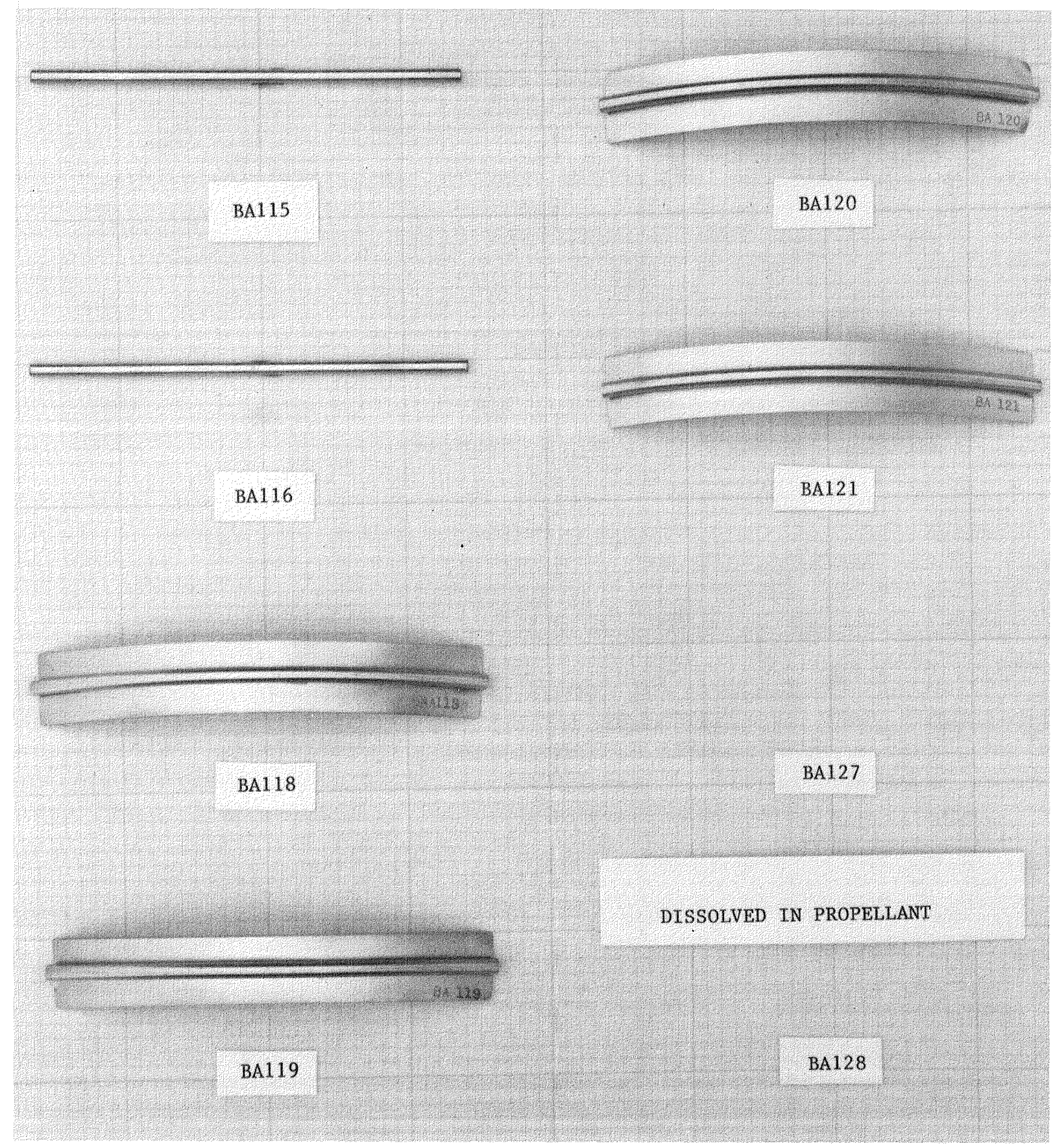

Figure D-1. Test Specimens, Hydrazine Decomposition Program "A" Secondary Containment System (Continued) 


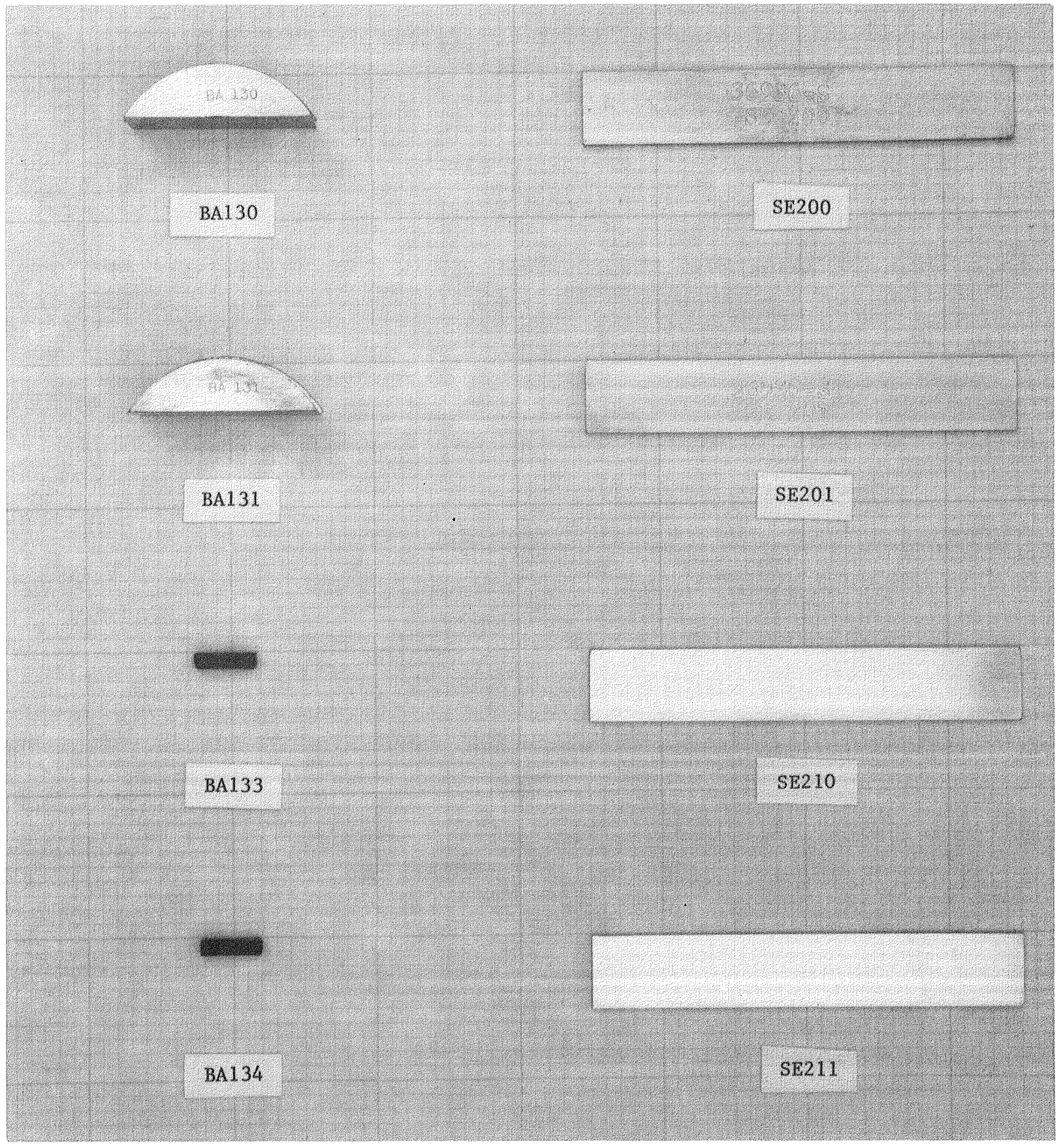

Figure D-1. Test Specimens, Hydrazine Decomposition Program "A" Secondary Containment System (Continued) 


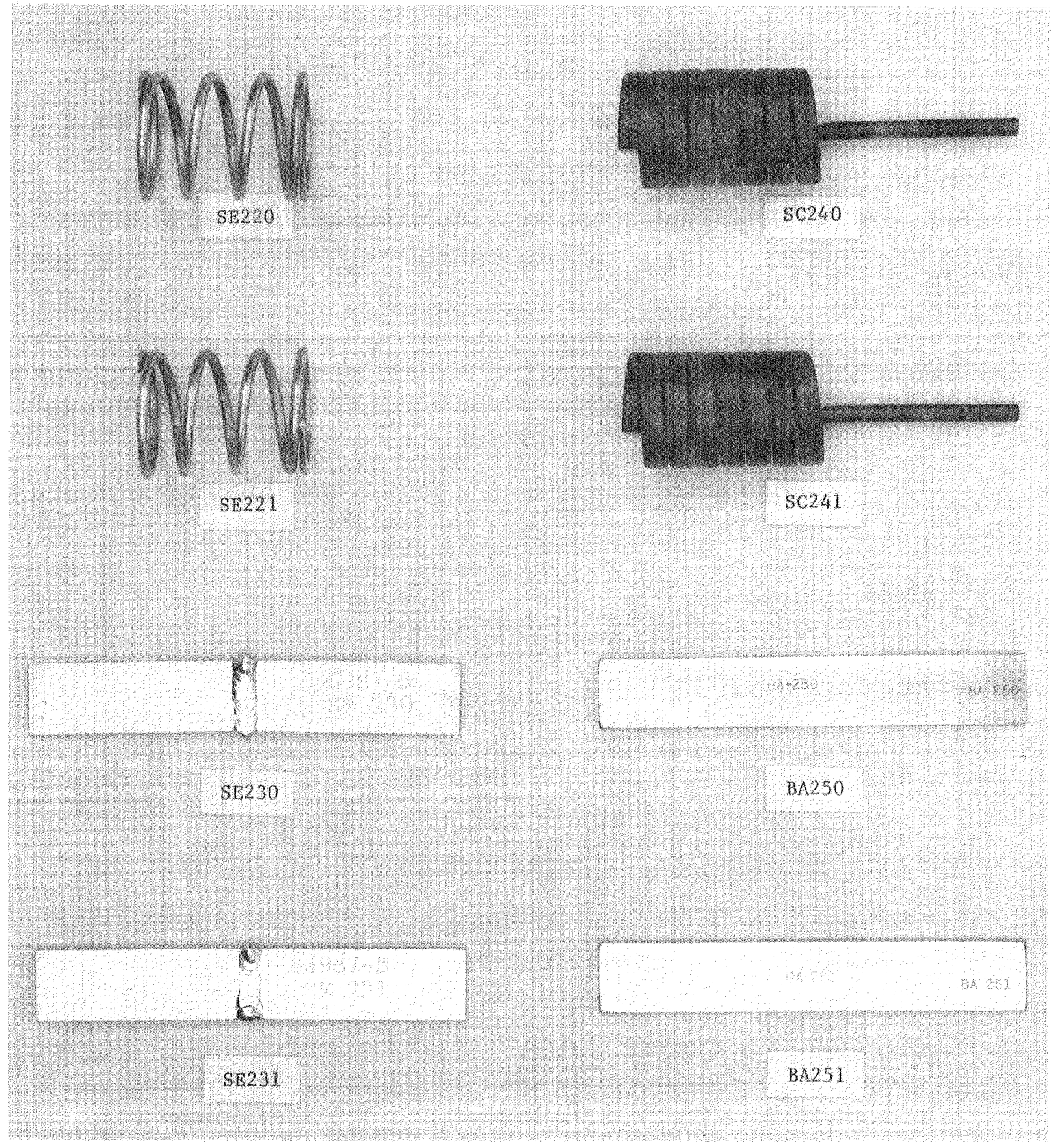

Figure D-1. Test Specimens, Hydrazine Decomposition Program "A" Secondary Containment System (Continued) 


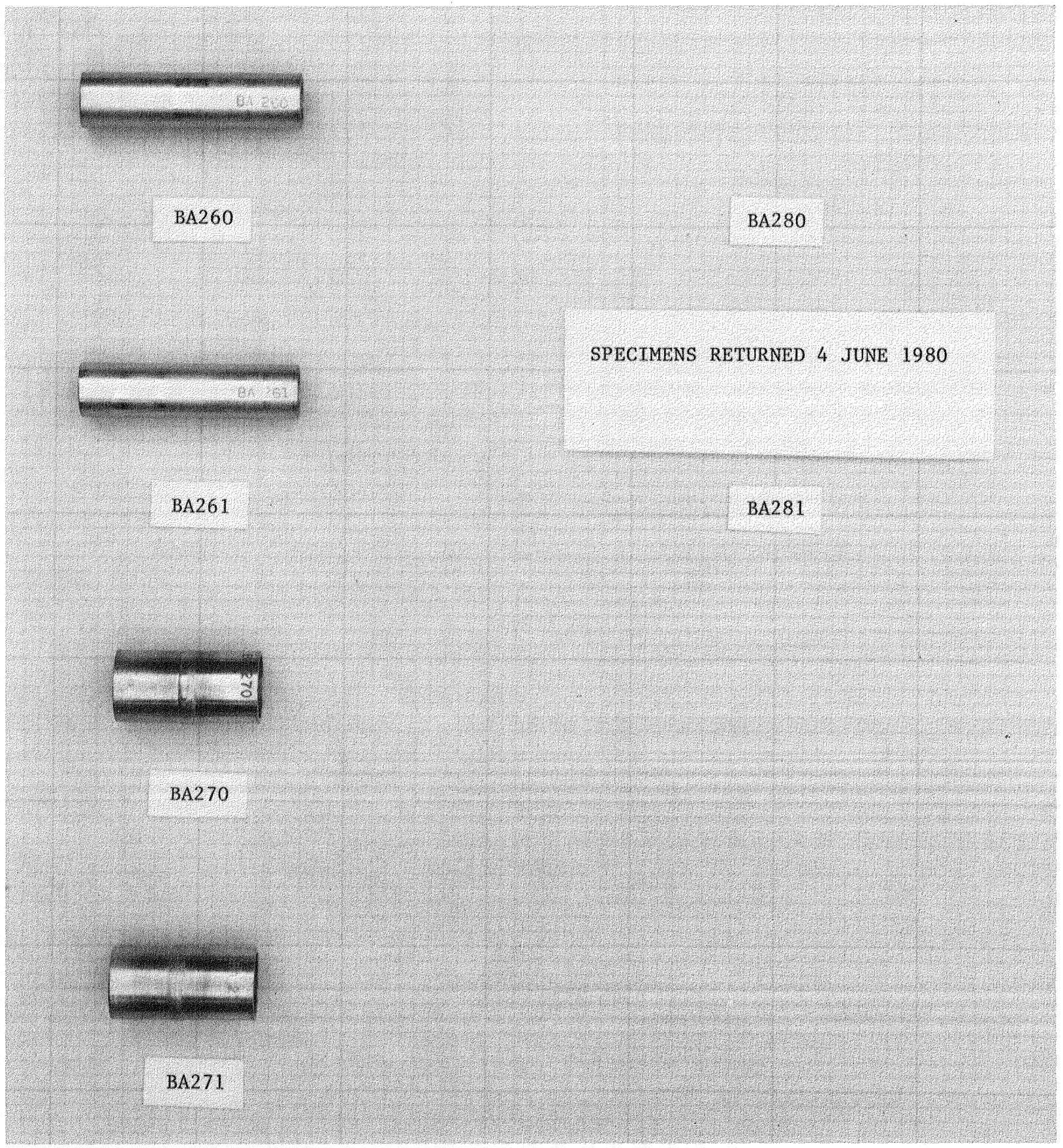

Figure D-1. Test Specimens, Hydrazine Decomposition Program "A" Secondary Containment System (Concluded) 


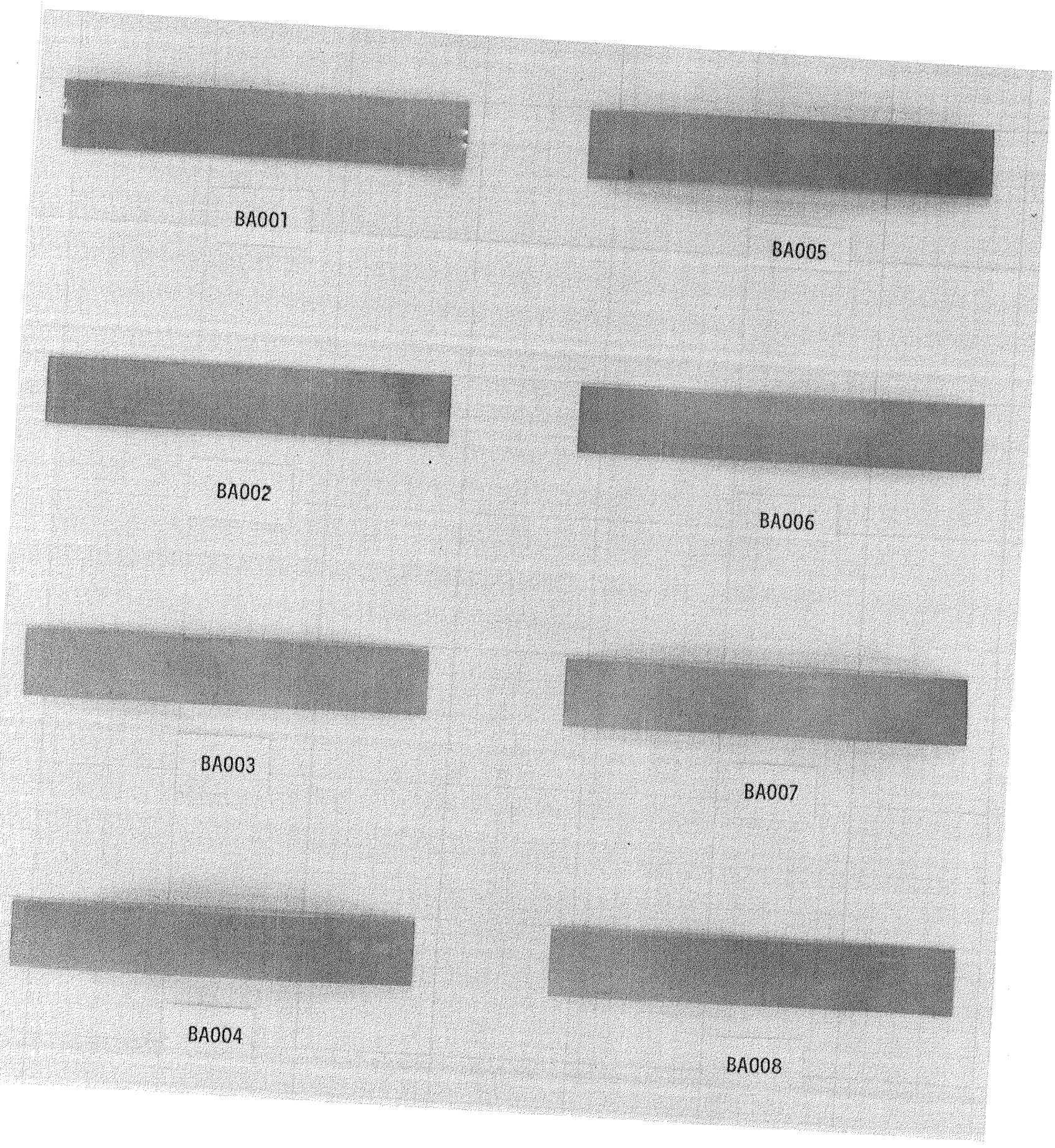

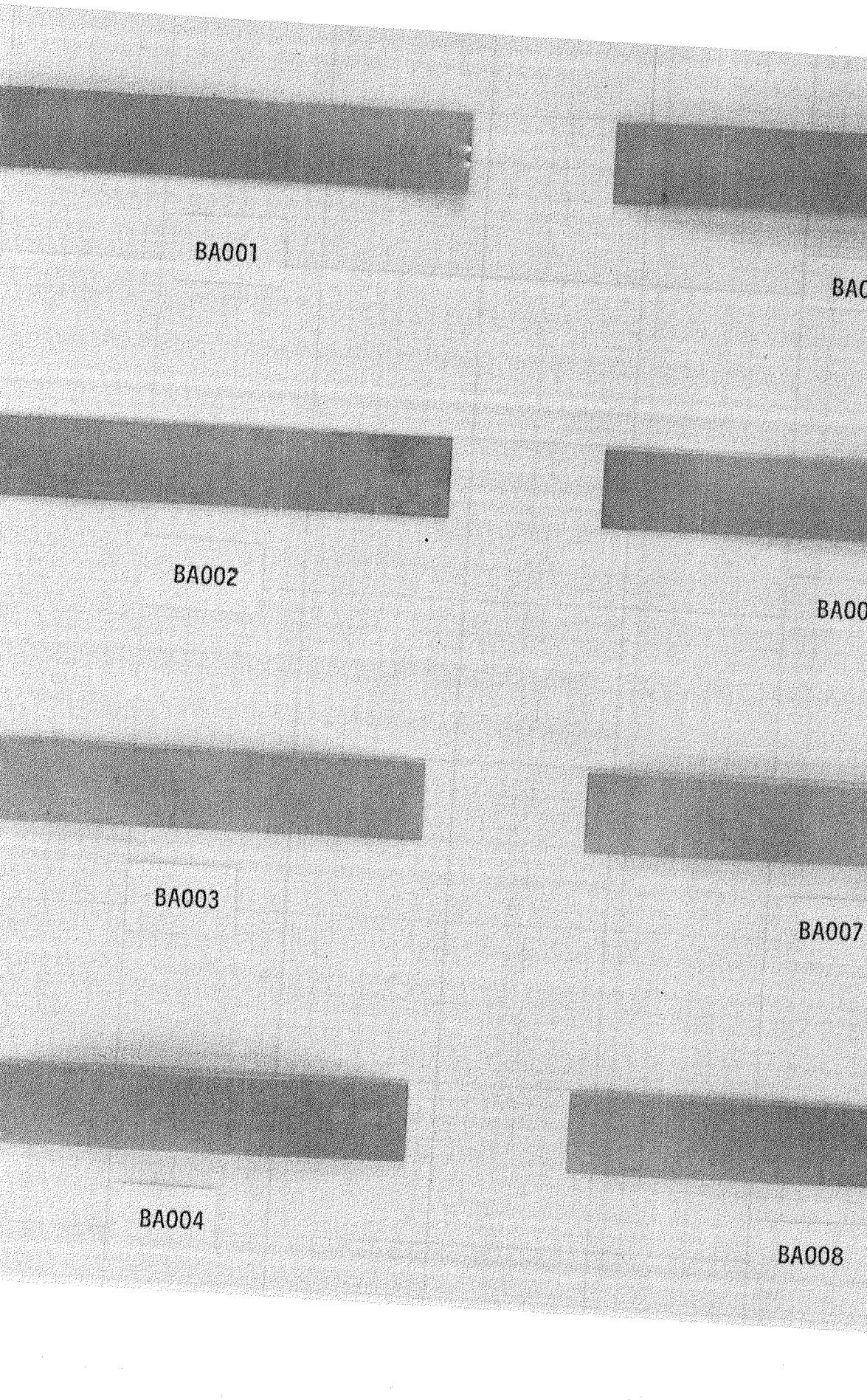

igure D-2. Test Specimens, Hydrazine Decomposition Program "B" -
Primary Containment System
\[ D-7 \]




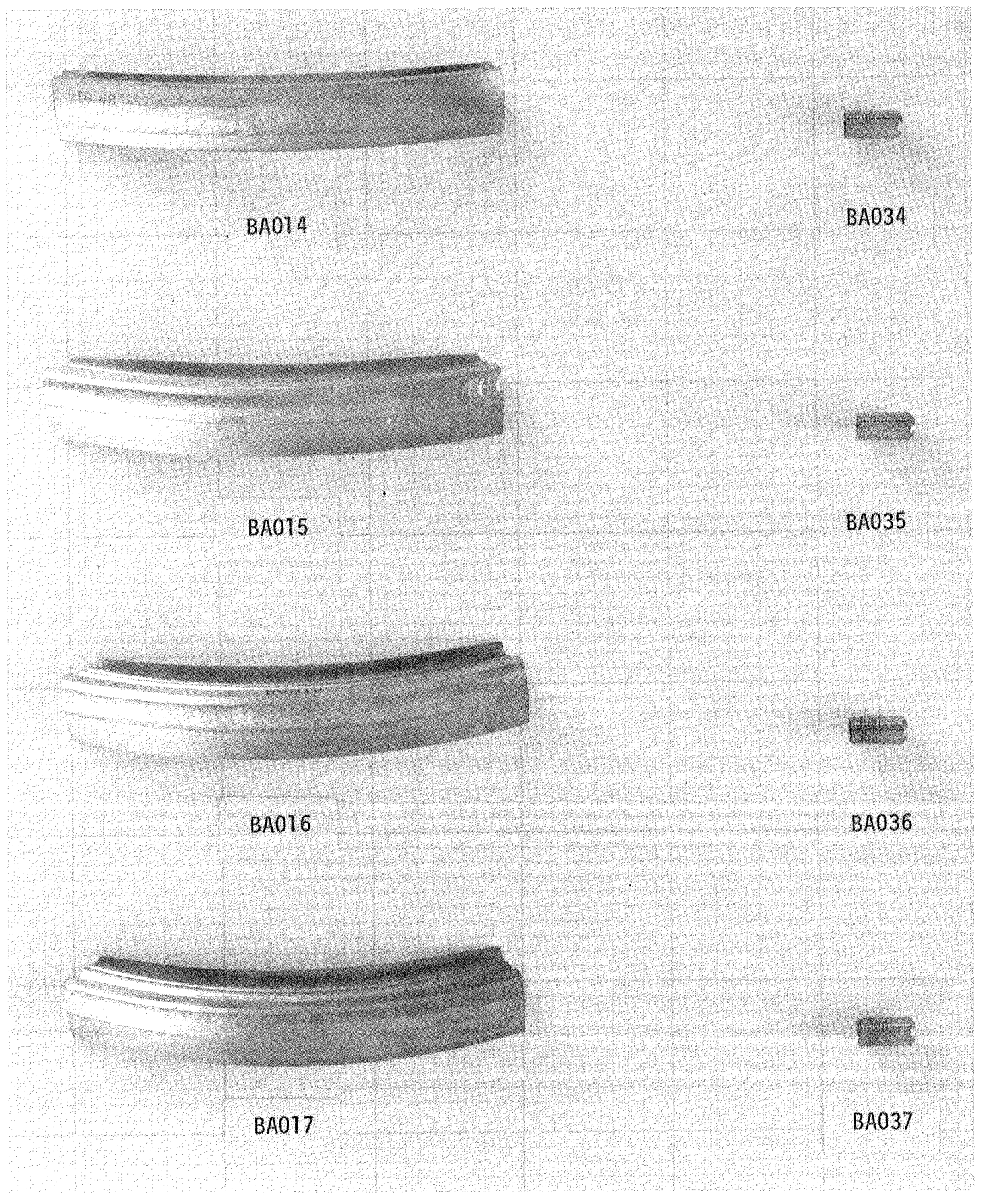

Figure D-2. Test Specimens, Hydrazine Decomposition Program "B" Primary Containment System (Continued) 


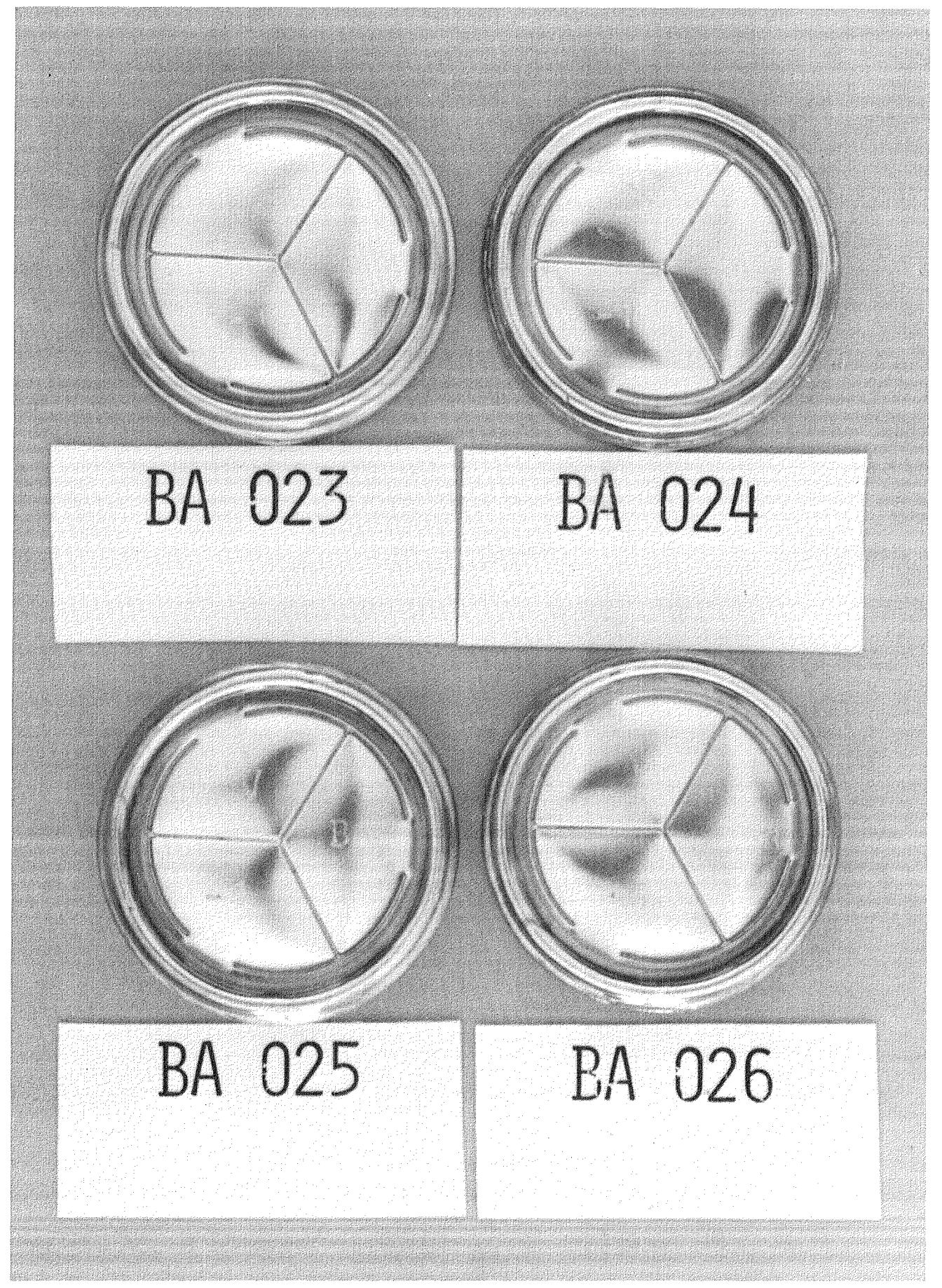

Figure D-2. Test Specimens, Hydrazine Decomposition Program "B" Primary Containment System (Continued) 


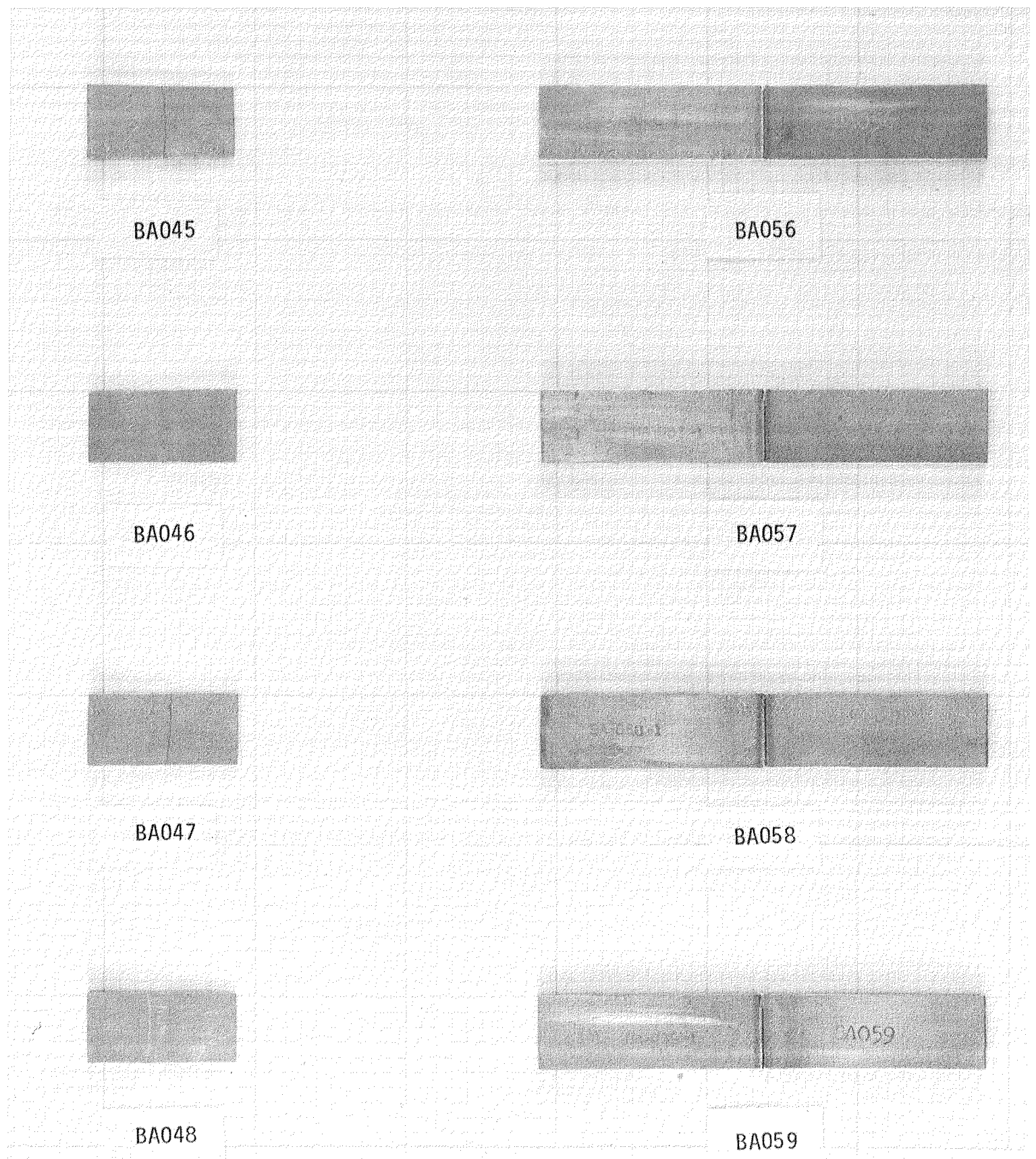

Figure D-2. Test Specimens, Hydrazine Decomposition Program "B" Primary Containment System (Continued) 


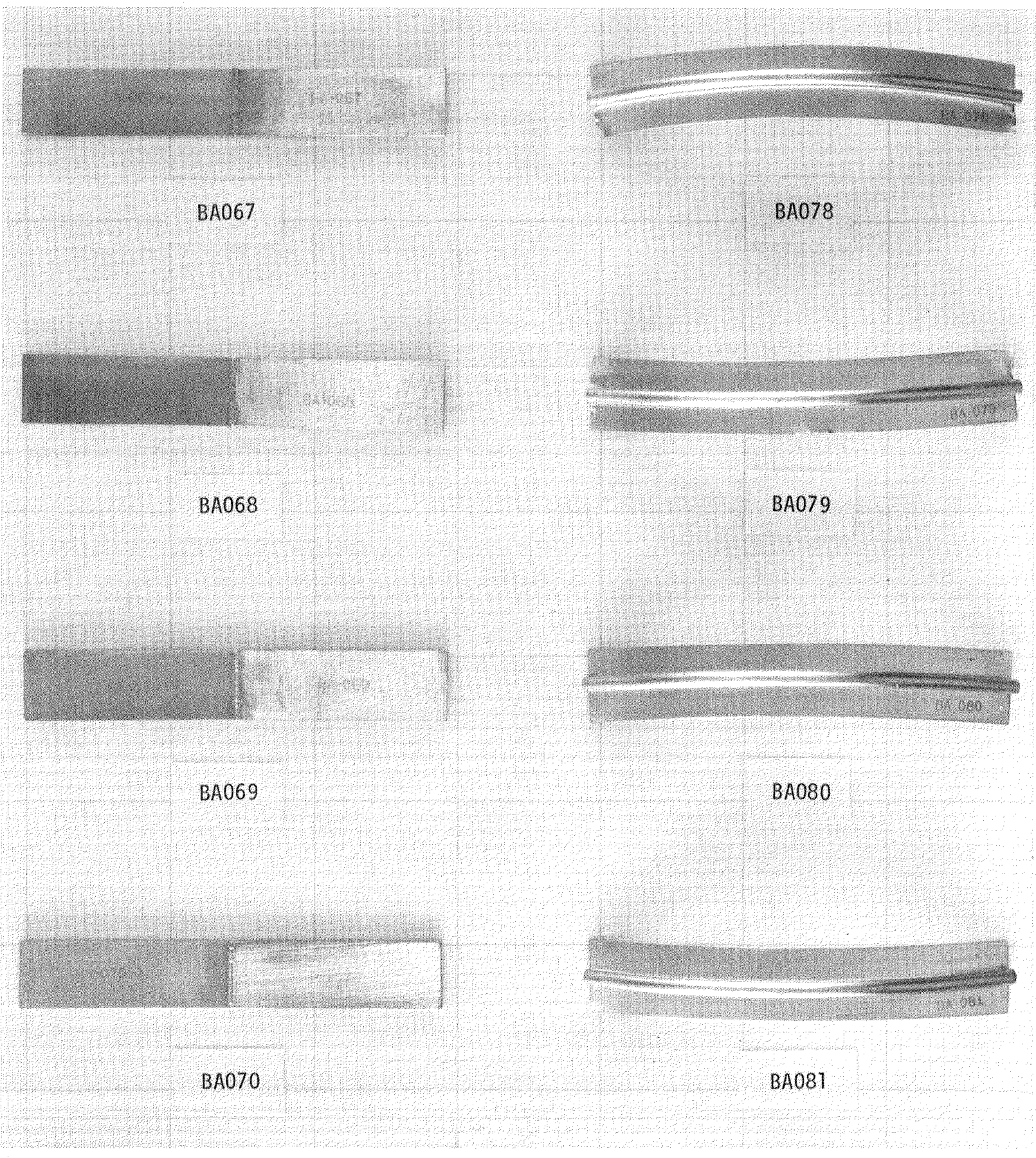

Figure D-2. Test Specimens, Hydrazine Decomposition Program "B" Primary Containment System (Continued) 


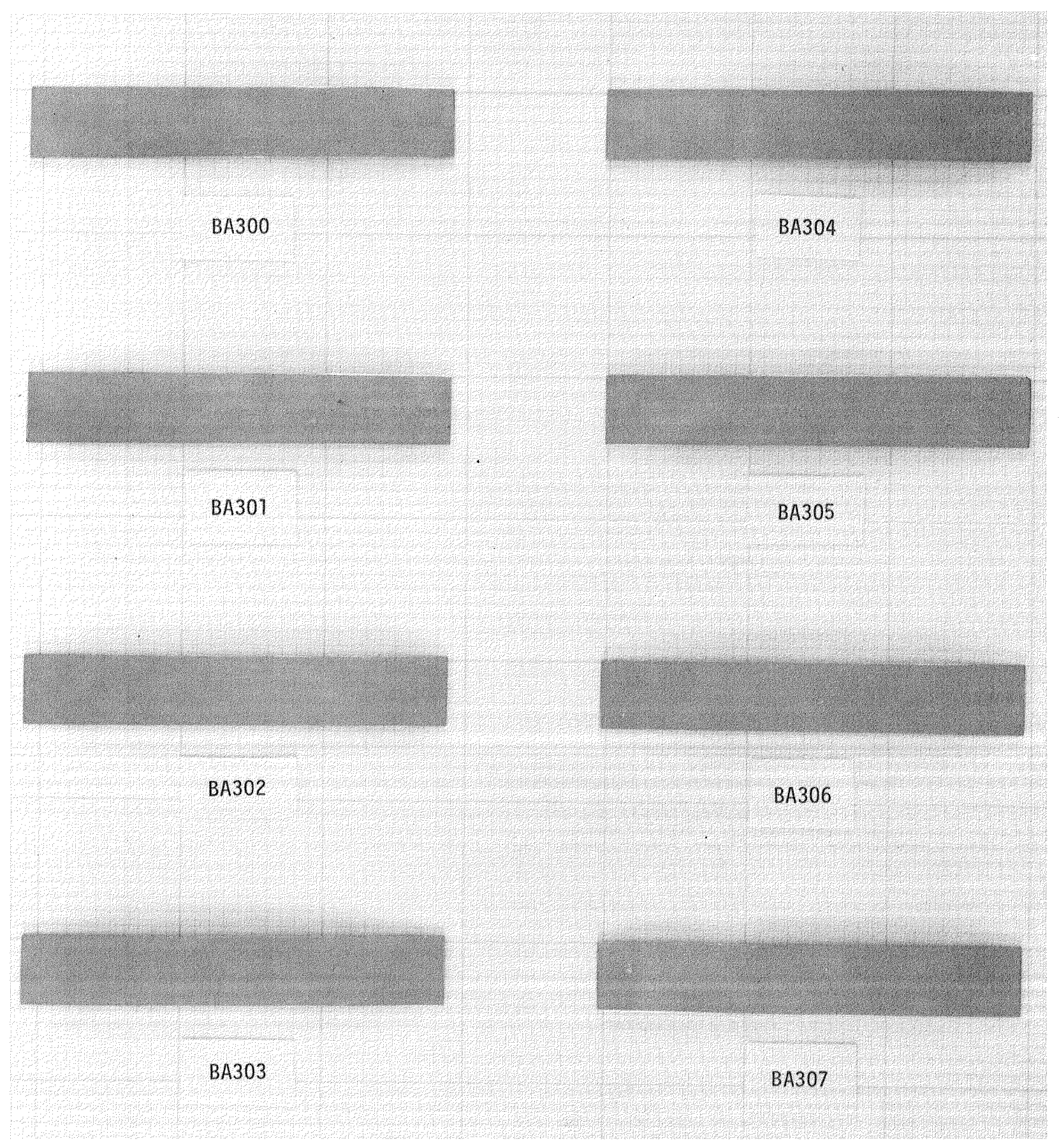

Figure D-2. Test Specimens, Hydrazine Decomposition Program "B" Primary Containment System (Concluded) 


\section{APPENDIX E}

347 CRES WELDS

\section{A. INTRODUCTION}

Some concern was expressed by the sponsor that the 347 CRES diaphragm in the burst disc assemblies (BA 023 to BA 026) might be subject to stress corrosion cracking in a hydrazine environment. All four specimens were removed from storage at 12.5 months rather than the scheduled 24 months. A cursory examination at JPL was inconclusive. However, a very thorough examination by BAT revealed that any crack formation in the diaphragms was due to the manufacturing and coining (crimping) process.

In the NASA long-term material compatibility test program, a few welded 347 CRES specimens were still in storage. Two were removed - one of which had been stored in the stressed configuration. These were thoroughly tested to determine the differences induced by storage while stressed versus storage while relaxed. Those results are not directly relatable to the $347 \mathrm{CRES}$ diaphragms, but it was believed that the information gained would be useful to this program.

\section{B. SAMPLES}

A11 samples were Type-347 CRES which had been heliarc welded. For al1 samples, the area analyzed was from the "top" surface immediately adjacent to the weld. The samples analyzed were those described below:

$$
\begin{aligned}
& \text { JPL } 0981 \text { - welded, no } \mathrm{N}_{2} \mathrm{H}_{4} \text { (control) } \\
& \text { JPL } 2005 \text { - welded, in } \mathrm{N}_{2} \mathrm{H}_{4}-4054 \text { days } \\
& \text { JPL } 1977 \text { - welded, stressed in } \mathrm{N}_{2} \mathrm{H}_{4}-4054 \text { days }
\end{aligned}
$$

For samples 2005 and 1977, the areas chosen had been at the liquid/gas interface during the testing. A dark discoloration of interest was particularly obvious in this area.

\section{XPS EXAMINATION}

Al1 three samples had been rinsed with distilled water upon removal from the hydrazine. Prior to analysis with XPS technique, the samples were further cleaned in an ultrasonic cleaner by serial rinses in trichloroethylene, acetone, and absolute ethanol. Samples were then blown dry with dry nitrogen gas.

The XPS spectrometer (modified HP5950A) averages over a region approximately $1 \mathrm{~mm} \times 5 \mathrm{~mm}$ in area and 50-100 $\AA$ in depth. Because of the exponential attenuation of the photoelectrons, the immediate atomic surface (approximately $30 \AA$ ) was weighted more heavily than the rest. 
Except for $\mathrm{Na}, \mathrm{Zn}$, and $\mathrm{N}$, all the observed elements are expected for 347 CRES. (The approximate theoretical composition of $347 \mathrm{CRES}$ is $0.08 \% \mathrm{C}, 2 \% \mathrm{Mn}$, $0.05 \% \mathrm{P}, 0.03 \% \mathrm{~S}, 1 \% \mathrm{Si}, 18 \% \mathrm{Cr}, 10 \% \mathrm{Ni}, 0.1 \% \mathrm{Ta}$, remaining $\% \mathrm{Fe}$.$) Oxygen is$ present in the form of various metal oxides and hydroxides as discussed below.

1. Chromium Region

JPL 0981. $\mathrm{Cr}_{2} \mathrm{O}_{3}, \mathrm{Cr}_{3}$, and some reduced $\mathrm{Cr}^{+3}$ species at lower binding energy ( $\mathrm{BE}$ ) than $\mathrm{CrO}_{3}$, but higher than chromium metal, were observed. chromium hydroxides may also be present.

JPL 2005 and JPL 1977. No differences were observed between these two samples. Spectra were consistent with $\mathrm{Cr}_{2} \mathrm{O}_{3}$ and chromium hydroxides. The atomic percent of $\mathrm{Cr}$ observed increased in the order $0981<2005 \cong 1977$.

2. Fe Region

The atomic percent of iron observed decreased in the order $0981>2005$ $\cong 1977$. For all three samples, effectively $\mathrm{Fe}_{2} \mathrm{O}_{3}$ and iron hydroxides were observed. There were some differences in the high $\mathrm{BE}$ side of the oxide peak. A small amount of $\mathrm{FeO}$ was observed on the control (0981) as well as the possibility of low-level FeO or iron sulfides.

3. Mn Region

The atomic percent of manganese observed decreased in the order 0981 $>2005 \cong 1977$. The spectra for all three samples may be assigned to $\mathrm{MnO}$ and nanganese hydroxides.

4. Zn Region

The atomic percent of zinc observed decreases in the order $0981>2005$

$\cong 1977$. Zn0 was present in al1 three samples.

5. Ni Region

The atomic percent of nickel observed was approximately the same for all three samples, with perhaps slightly more for 2005 as compared to 1977. The $\mathrm{Ni}$ was present as $\mathrm{Ni}_{2} \mathrm{O}_{3}$ and nickel hydroxides. The lower $\mathrm{BE}$ on 0981 was probably due to $\mathrm{Fe}_{2} \mathrm{O}_{3}$.

6. Carbon Region

Approximately the same amount of carbon was observed on a11 three samples. Primarily aliphatic carbon was present although substantial intensities in the $\mathrm{C}-0$ and $\mathrm{C}-\mathrm{N}$ regions were observed, showing some differences in detail between the samples. 


\section{Oxygen Region}

Approximately the same amount of oxygen was observed on all samples. The primary peak was due to metal oxides and hydroxides. The lower BE on 0981 was probably due to $\mathrm{Fe}_{2} \mathrm{O}_{3}$.

\section{Nitrogen Region}

The nitrogen intensity increases significantly in the order $0981<2005$ $\cong 1977$. The primary differences appear on the low binding energy side of 2005 and 1977, where a shoulder characteristic of reduced nitrogen species such as amines and ammonia transition metal complexes was observed. The high binding energy peak was consistent with a variety of species including protonated amines and amide polymers as well as hydrazine salts and nitrites.

\section{CHEMICAL ANALYSIS}

Chemical analysis of propellant and analysis of the decomposition gases indicated no significant differences between stressed and unstressed conditions (Table E-1). Both specimens were exposed to hydrazine for 4054 days.

Table E-1. Summary of Posttest Hydrazine Analysis

\begin{tabular}{lccc}
\hline & \multicolumn{2}{c}{ Prope1lant } \\
\cline { 2 - 3 } Specimen & $\begin{array}{c}\text { Decomposition } \\
(\text { wt\%/yr })\end{array}$ & $\begin{array}{c}\text { Dissolved Fe } \\
(\mathrm{mg})\end{array}$ & $\mathrm{cc} \times 10^{-\mathrm{N}_{2}} \cdot \mathrm{day}^{-1} \cdot \mathrm{cm}^{-2}$ \\
\hline JPL 1977, stressed & 0.174 & 0.21 & 1.48 \\
JPL 2003, unstressed & 0.154 & 0.21 & 1.15 \\
\hline
\end{tabular}

\section{E. SEM EXAMINATION OF SPECIMENS}

SEM photomicrographs of the surfaces of the specimens indicated that some pitting has occurred at the liquid-vapor interface. As seen in the accompanying photographs, (Figures E-1 to E-4) the distribution of pit sizes varies between the stressed and unstressed specimens. These same samples were sectioned and etched. Photomicrographs of the cross sections revealed no intergranular or intragranular corrosion. The markings seen on the photographs are the result of over-etching.

\section{F. CONCLUSIONS}

1. The pattern of surface corrosion was similar for each of the specimen examined.

2. No intergranular or intragranular corrosion was observed in stressed specimen. 
3. Fe and Mn dissolved more readily than does $\mathrm{Cr}$, leaving a corroded surface rich in chromium.

4. The XPS examination indicated no difference in the chemical nature of stressed and unstressed specimens.

5. Only minor differences were observed in metal content or decomposition of propellant between stressed and unstressed configurations. 


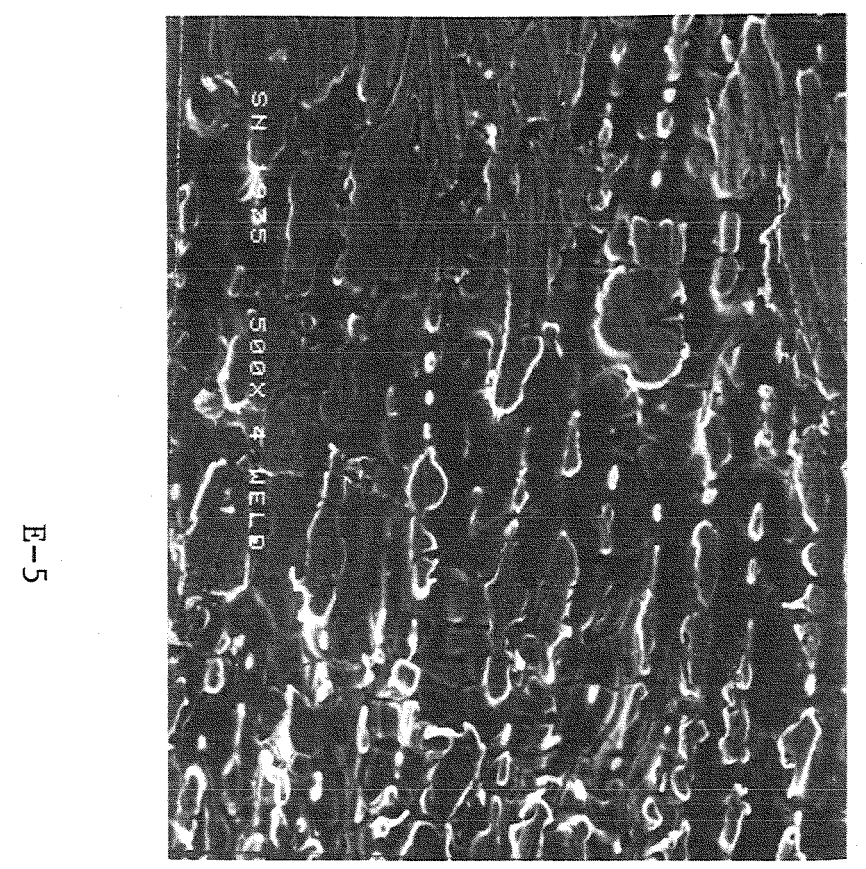

STRESSED WELD

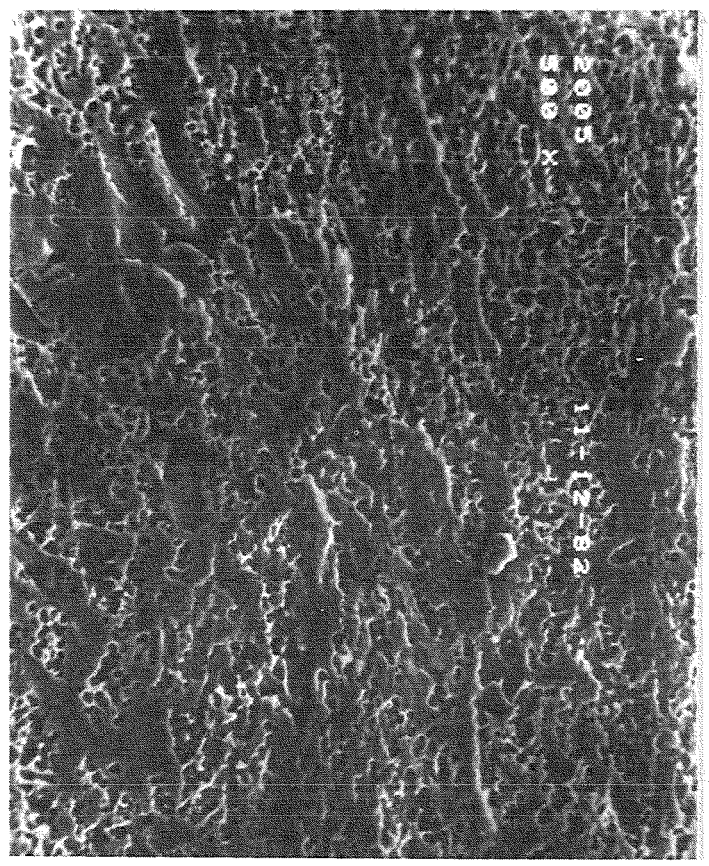

UNSTRESSED WELD

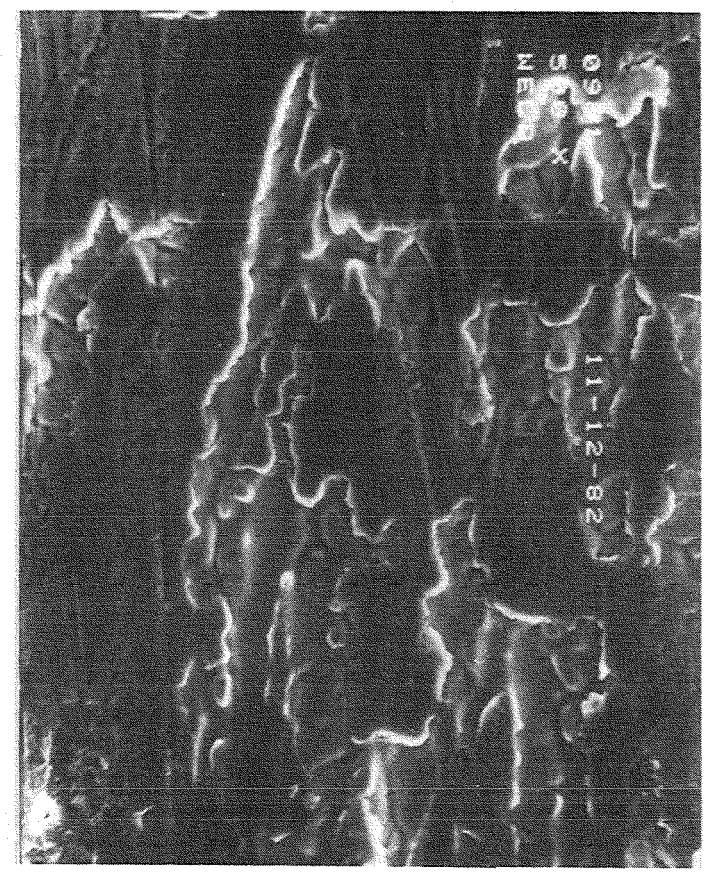

CONTROL WELD

Figure E-1. CRES 347 Weld Specimens, Surface Features at Weld 


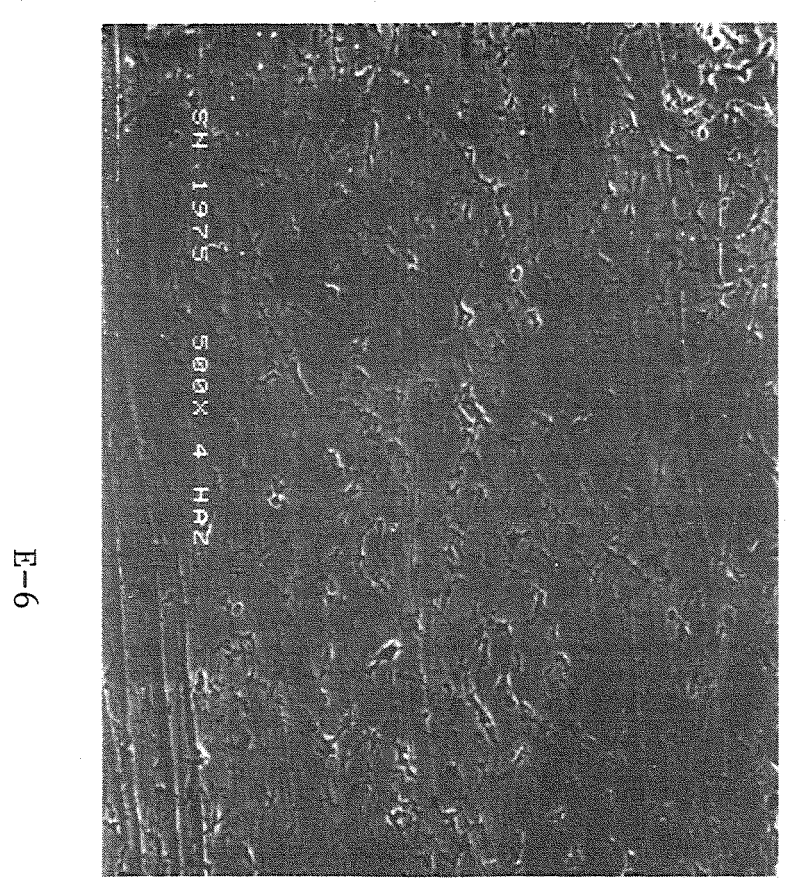

STRESSED HAZ

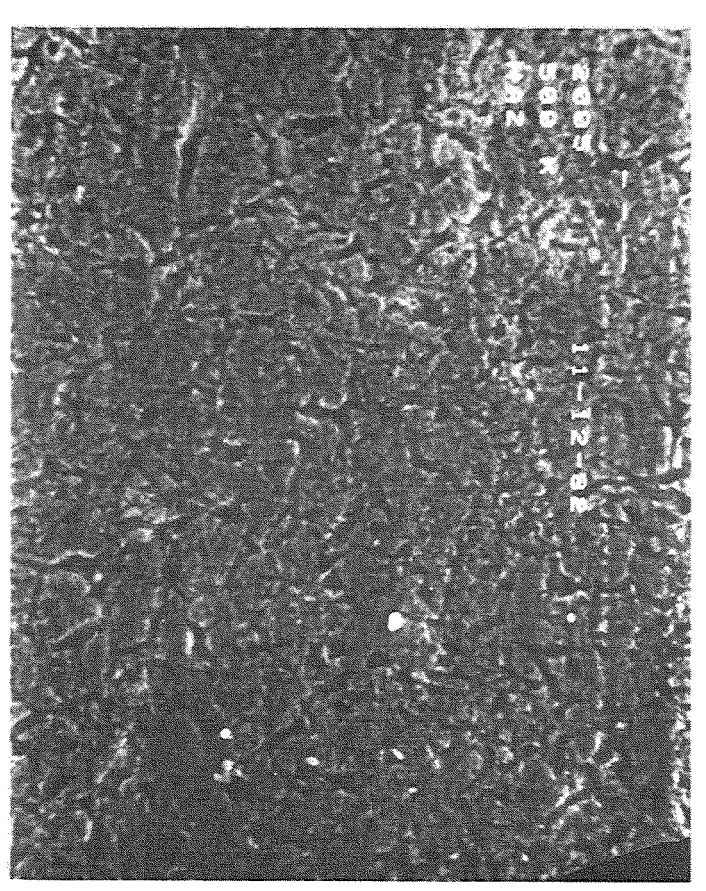

UNSTRESSED HAZ

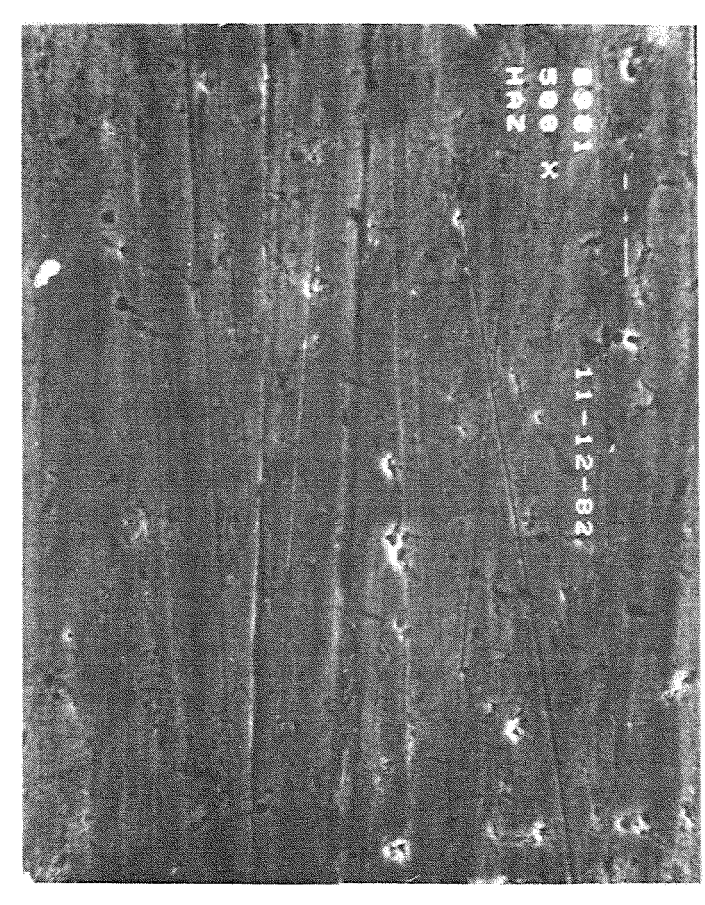

CONTROL HAZ

Figure E-2. CRES 347 Weld Specimens, Surface Features at Heat-Affected Zone 


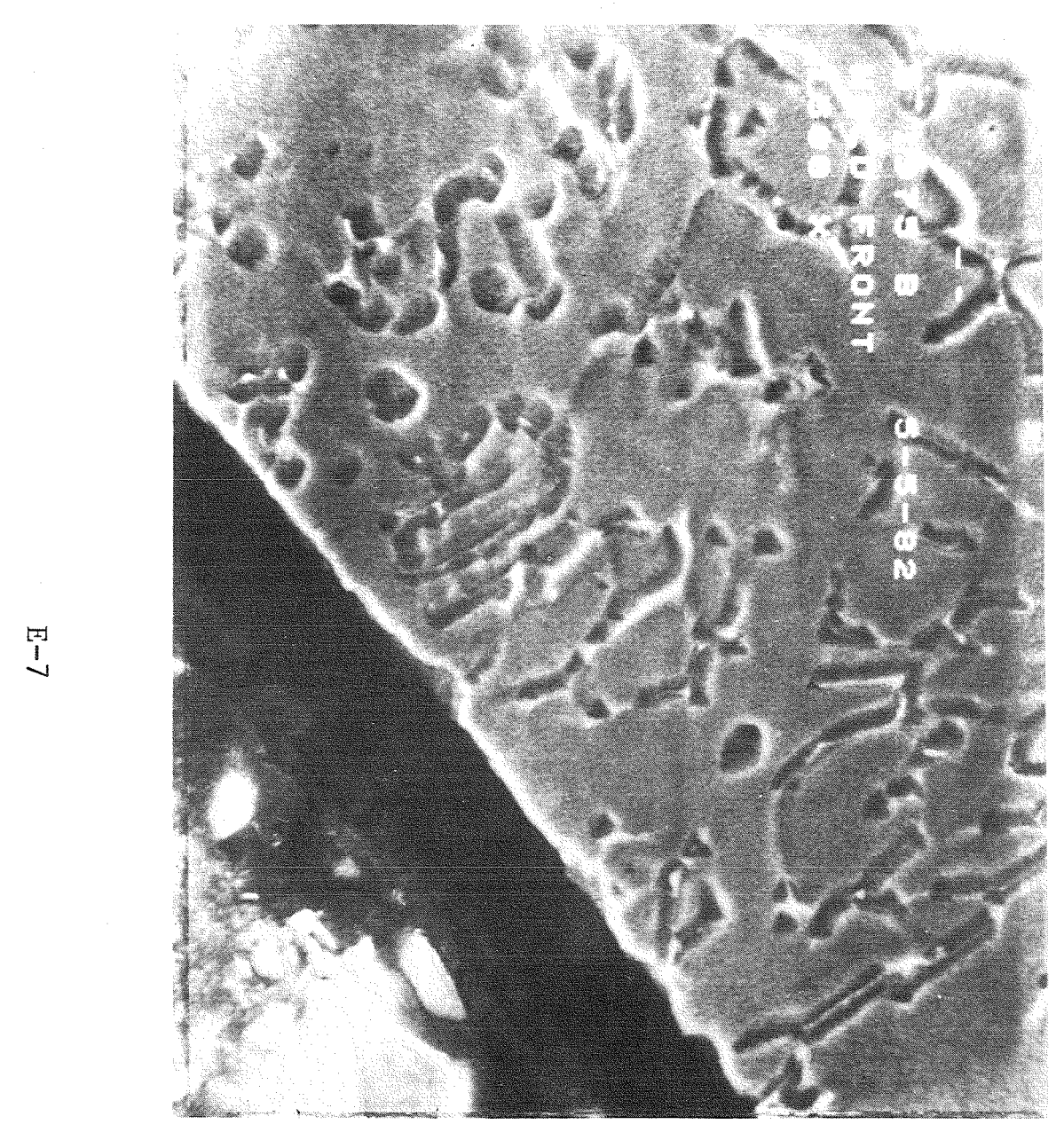

STRESSED WELD-TENSION

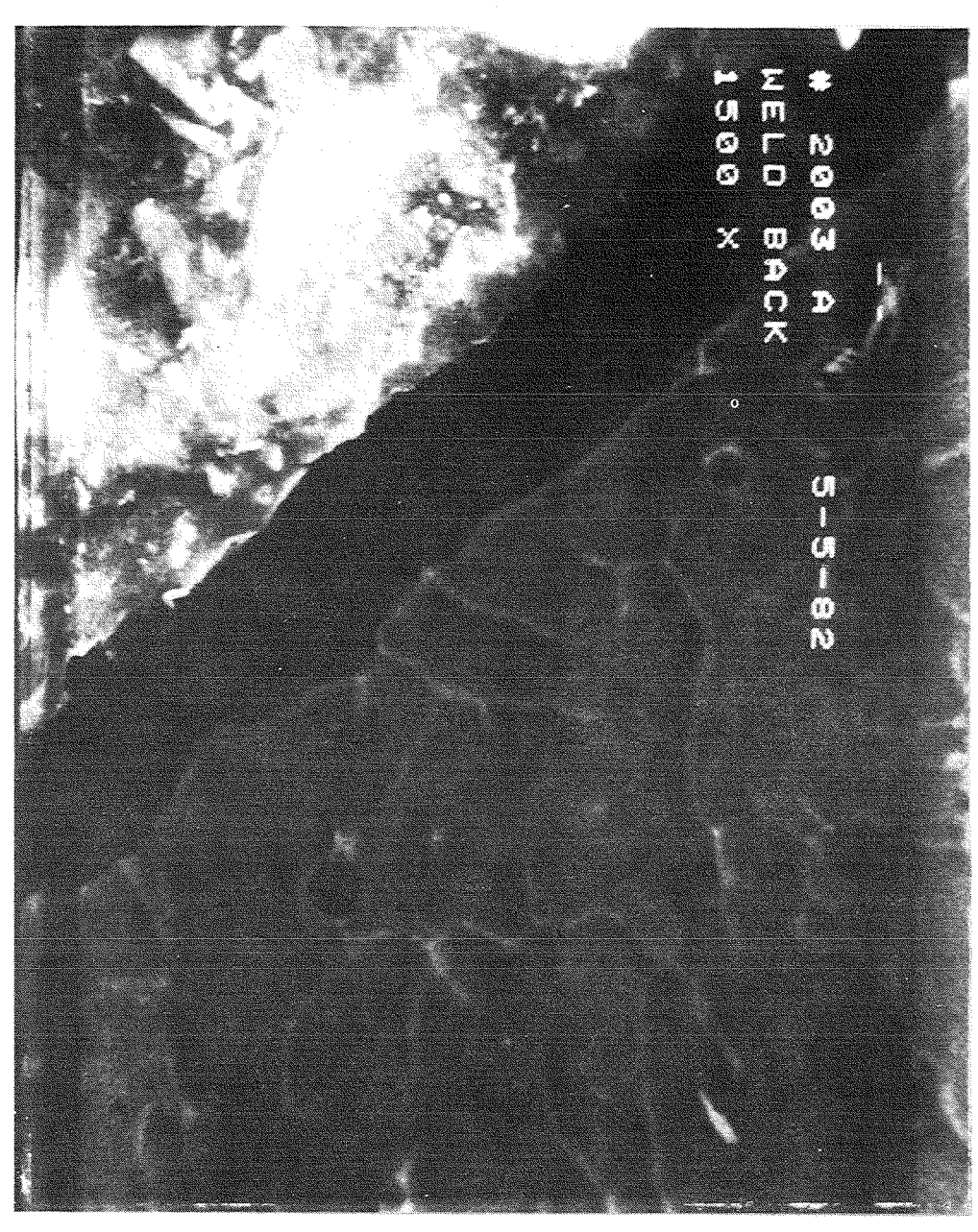

UNSTRESSED WELD

Figure E-3. CRES 347 Weld Specimens, Cross Sections at Weld 


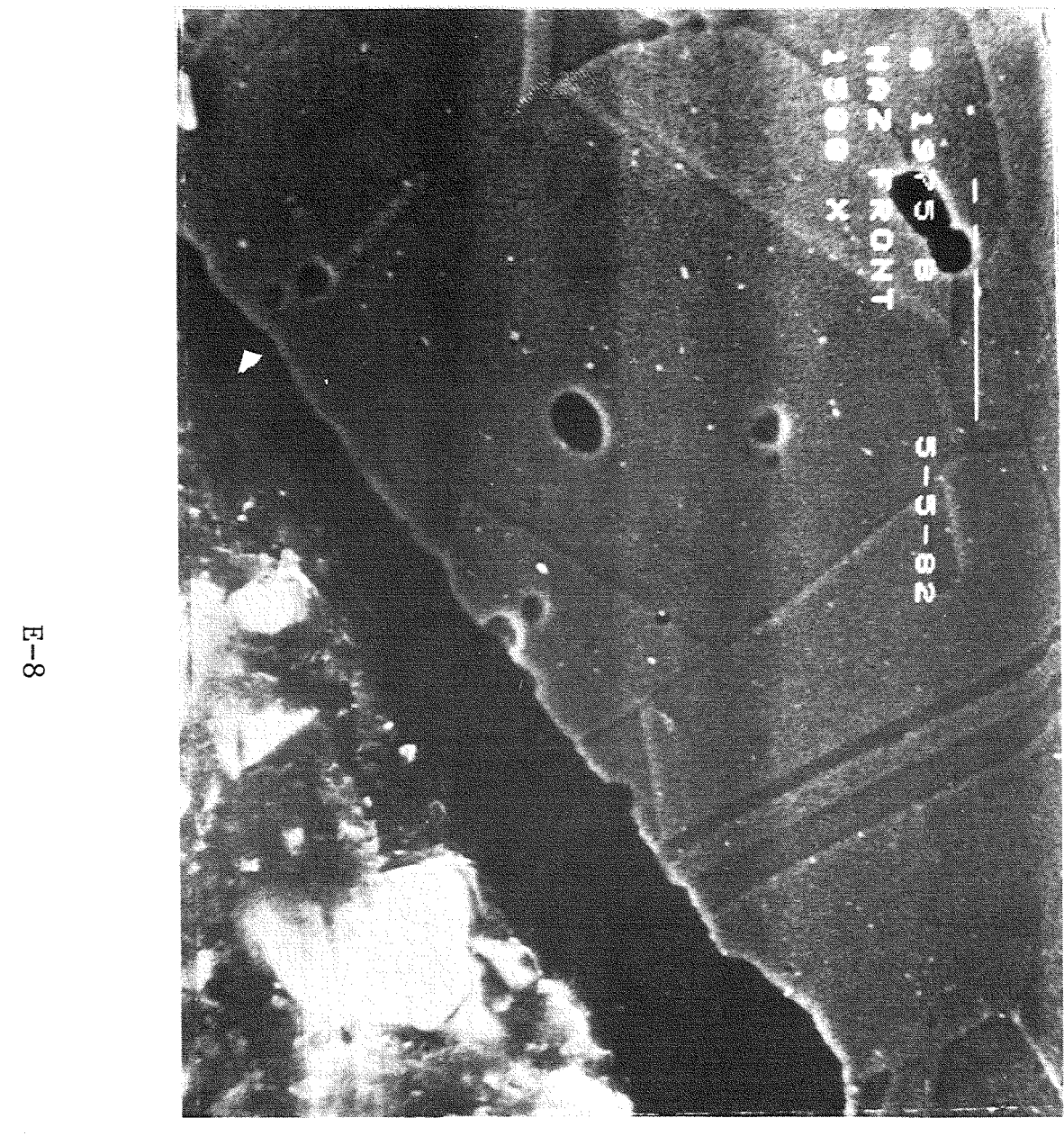

STRESSED HAZ-TENSION

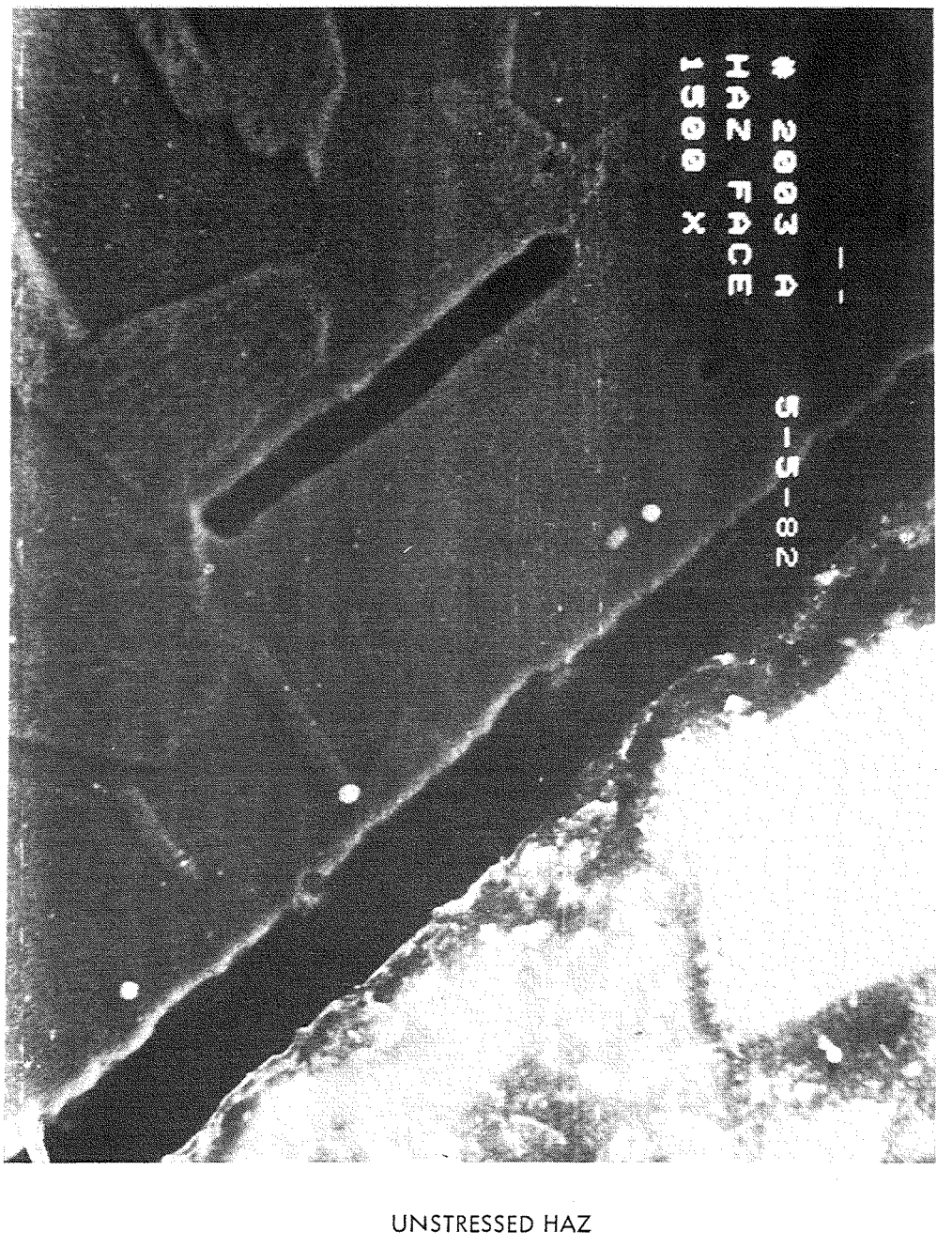

Figure E-4. CRES 347 Weld Specimens, Cross Sections at Heat-Affected Zone 
End of Document 